\title{
DIE ZUSAMMENSETZUNG DER VORAUER HANDSCHRIFT.
}

Die Vorauer hs. XI., uber deren bedeutung keine worte zu verlieren sind, ist durch ihren entdecker Joseph Diemer in 3 teilen veröffentlicht worden:

1. Die Kaiserchronik nach der ältesten handschrift des stiftes Vorau. Wien, 1849.

2. Deutsche gedichte des XI. und XII. jhs. aufgefunden zu Vorau. Wien, 1849.

3. Geschichte Josephs in Aegypten nach der Vorauer handschrift. Sitzungsberichte der philos.-histor. classe der kais. akademie bd. 47, jahrgang 1864. Wien, 1864.

Alle 3 teile sind diplomatisch genaue abdricke. Eine beschreibung der hs. lieferte Diemer in den 'dt. gedichten' Einl. s. I-VI. Daraus ist hervorzuheben, dass die ganze hs. von 135 blättern mit je 2 spalten auf einer seite, bis auf 4 blătter und $21 / 2$ spalten (die spalte hat 46 zeilen) von einem und demselben schreiber geschrieben sind.

Bei der abgrenzung der einzelnen dichtungen, die naturlich nicht mit uberschriften versehen sind, war Diemer ausser handschriftlichen grunden, seinem literarischen gefuble gefolgt, und von seiten der fachgenossen hatte er darin keinen widerspruch zu erfabren.

Dass der schreiber der hs. sich in der schreibung an die ihm vorliegenden hss. gehalten hat, hatte er wol bemerkt (Einl. s. IV), aber die differenzen nicht systematisch verfolgt, sie jedenfalls nicht als kriterium fur die zusammensetzung der hs. verwendet; es lag das nicht in seiner absicht.

Mullenhoff liess sich hieruber in den 'Denkmålern' s. 438, nachdem er zum 'Marienlob' und zur ersten 'Sammelhand- 
schrift' einige bemerkungen tiber die orthographie gemacht, folgendermassen vernehmen: 'Da jedoch diese eigenheiten (der schreibung) sich auch in andern teilen der sammlung (der Vorauer hs.) finden, wo sonst eine andre orthographie vorherrscht, so lässt sich durchaus nicht bestimmen, wie viel davon der vorlage oder erst dem abschreiber angehört. Daher und um auch nicht zu einer falschen vorstellung von dem dialect des sttickes (Marienlob) zu verleiten, schien es angemessener, die grammatisch richtigere bezeichnung der doppellaute herzustellen.' Also auch er hat sich nicht näher mit der schreibung der hs. beschäftigt: denn lässt sich kein princip in derselben finden, so darf man nicht von 'sammelhandschriften' reden; stellt man diese aber auf, so muss man ganz genau sagen können, welche eigenbeiten der ganzen hs. gemein sind, und andrerseits, welche es nicht sind und eben allein zur trennung berechtigen. Es wird sich übrigens später herausstellen, dass weder er noch Scherer darauf geachtet hat, dass einige blätter von 2 andern schreibern herruhren, obwol Diemer nicht nur in der Einleitung s. IV f., sondern auch unter dem text darauf aufmerksam gemacht hat.

Scherer seinerseits bemerkte in den 'Denkmälern' s. 414 in den anm. zu 'Summa theologiae': 'Das vorliegende gedicht bildete augenscheinlich mit den 3 folgenden, von denen jedoch die 3 Junglinge und Judith als eines tuberliefert sind, die zweite der Vorauer einverleibte handschrift. - Alle 4 weist ihre orthographie nach dem mittleren Deutschland; doch deutet eine anzahl von mundartlichen abweichungen auf verschiedene, noch nicht näher zu bestimmende gegenden.' - 'Davon wird einiges, gewiss nicht alles zufällig sein.' Ob diese ansichten berechtigt sind, wird sich zeigen. Jedenfalls hat sich auch Scherer mit der orthographie nicht näher befasst.

In den 'Quellen und forschungen' VII ist er der sache auch nicht nachgegangen; die orthographischen bemerkungen s. $78 \mathrm{f}$. und $89 \mathrm{f}$. sind bei ihrem sehr sporadischen auftreten und ihrer nur teilweisen richtigkeit eher dazu angetan, irrige ansichten luber die gesammten orthographischen verhältnisse der hs. aufkommen zu lassen.

So ist die schreibung der Vorauer hs. noch eine ungelöste frage, und doch ist ihre beantwortung eine unabweisliche vor- 
bedingung, wenn die zusammensetzung der hs. und die abgrenzung der einzelnen gedichte auf sicherer basis beurteilt werden soll.

Drängt sich überhaupt gegenwärtig die erkenntnis auf, dass der wert der schreibung altdeutscher hss. unterschätzt wurde, 1. in folge der jagd nach reimen, 2. unter dem streben nach der mhd. gemeinsprache, 3. durch das zu sichre gefuhl der conjecturalkritik; werden therhaupt specialuntersuchungen uber die schreibung einzelner hss. sich als nötig erweisen, so ist gerade bei der Vorauer hs. eine solche untersuchung erforderlich, weil in ihr die wichtigsten denkmale der vorklassischen mhd. periode erhalten sind, und sie kann in hohem grade lohnend werden, wenn es gelingt, den anteil des schreibers an den verschiedenen producten, die er uberliefert, im einzelnen festzustellen.

Die frage präcisiert sich demnach: Lässt sich entscheiden, wie viele vorlagen in die Vorauer hs. aufgegangen sind? oder mit andern worten, welche schreibungen und formen gehen durch die ganze hs., welche lassen sich auf einzelne teile beschränken? Fallen die nach den verschiedenen erscheinungen gewonnenen einschnittspunkte zusammen?

Ich behandle daher zunächst:

\section{Durch die ganze Vorauer hs. gehende}

A. Schreibungen:

1. Der unterschiedslose wechsel von $z$ und $z$, von kurzem und geschwänztem $z$ (Diemer, Ged. einl. III),

2. Der wechsel von $v$ - und $f$ - im anlaut der wörter.

3. Langes $f$ im anlaut, $s$ im auslaut der silbe, woneben $\int$ tritt; immer steht $\int$ in der verbindung $s p, s t, s c$ in jeder stellung.

4. Bunter wechsel zwischen $s c$ und sch; vereinzelt steht sh. Dazu wechsel mit $s$ - beim verbum suln, vereinzelt $s$ - beim subst. sulde (entweder analogie nach dem proklitischen verbum oder lautges. < scldi, wie sclúm > slum > sulum; vgl. Fierlinger, Kuhns zs. XXVII, 190) und gesach neben gescach (vgl. Diemer, Anm. zu dt. ged. 5,5), was wol nur vermischung zweier verba ist. 
5. Zweifelhaft kann man sein, ob nicht dem schreiber eu für iu zum teil zukommt, obwol in $D, J, M$ (benennung der complexe 8. u.) eu nie zu belegen ist. Sicherlich war es in $A, B, E, F, G$ schon in der vorlage. Aber ganz sporadisches auftreten von $e u$ in andern teilen, wie in $H$ und $L$ macht es wahrscheinlich, dass $e u$ dem schreiber adäquat war.

\section{B. Formen.}

1. Immer skef (zu skef - skif vgl. MSD2 458) und helfe, nur einmal in der Kaiserchronik hilfe 178, 20 neben sonstigem helfe.

2. lussam, assim. < lustsam (lusterregend), nur in dieser form.

3. Neben began, das aus formellen grtunden natürlich im reim weitaus uberwiegt, begunde, nur $1 \mathrm{mal}$ bigondi, Dt. ged. $108,10$.

4. Die lautges. form des prät. muose, nur 185,4 und 216, 18 muste im 'Alexander' neben 2 muse 190, 14 und $210,22$.

5. Die wortform wissage (prophet), ein beweis, dass die volksetym. anlehnung von ahd. wîzzago an wîs und sagen schon ganz durchgedrungen war.

Zunächst lässt sich nicht entscheiden, ob diese ubereinstimmungen eigentumlicbkeiten und absichtliche änderungen des schreibers sind, oder ob sie durch die vorlagen bedingt waren. Vielleicht wird durch die folgenden zusammenstellungen das letztere wahrscheinlich.

II. Lassen sich auf grund der andern schreibungen und formen einzelne complexe abgrenzen?

Es frägt sich hierbei, ob die einzelnen erscheinungen oder die complexe zum höheren einteilungsprincip genommen werden sollen? Im falle der verneinung der gestellten frage kommt naturlich nur das erste in betracht; da ich jedoch dieselbe bejahen muss, sind die complexe vorzuziehen, weil so verwantes nicht auseinandergerissen wird und in innigere verbindung mit den gefolgerten literarischen schlussen gebracht werden kann.

Die lubersicht über das orthographisch und grammatisch entsprechende der einzelnen teile werde ich dadurch erleich- 
tern, dass alle analogen erscheinungen unter den durchgehenden nummern $1-29$ besprochen werden. Ist unter der betreffenden nummer im einzelnen fall nichts zu erwähnen, so wird sie übergangen. Daran reihen sich jeweils unter nummer 30 'varia', d. h. erscheinungen an, die in andern teilen keine entsprechung haben, jedoch als charakteristica der einzelnen vorlagen wichtig sind. Es ist klar, dass unter 1-29 einzelnes auftritt, das für sich betrachtet nicht als kriterium gelten darf, welches jedoch in verbindung mit den andern punkten einen relativ wechselnden wert bekommt. Zur bequemeren orientierung wird am schluss eine vergleichende tabelle beigegeben, welche die resultate zusammenfasst.

Von der in der hs. vorliegenden reihenfolge der complexe durfte nicht abgewichen werden, indem dieselbe als für die gegenseitige abgrenzung von der grōssten wichtigkeit, auch bei der darstellung hervortreten muss.

So macht den anfang:

\section{A. DIE RAISERCHRONIR.}

Die orthographischen verhältnisse derselben sind nicht die günstigsten, indem sich der complex $A$ mehr durch seineu wechsel in der schreibung als durch constante regelmässigkeit gegen den zweiten complex $B$ abgrenzt.

Vielleicht hat dieser umstand von einer orthographischen untersuchung der hs. abgeschreckt, zumal auch hier ubersehen worden scheint, dass blatt 1 und 8 , das erste und letzte der ersten lage (Diemer s. $1,1-9,9$ und 55,5-62,18) von einem schreiber aus dem ende des 12. jh. nachgetragen sind, was pergament und schrift beweisen, während der urschreiber in die mitte des 12. jh. zu setzen ist. Wenigstens finde ich es nirgends erwähnt, ausser natürlich bei Diemer, Einl. IV und Dt. ged., einl. V. Die eigentumlichkeiten des jüngern scbreibers werden unten mit blatt 89 und 96, die gleichfalls von ihm herribren, besprochen werden, indem dort die frage praktischen wert hat. Dass Diemers aus paläograph. gründen abgegebnes urteil richtig ist, wird durch die auftretenden differenzen glänzend bestätigt. Seite $1,1-9,9$ und $55,5-62,18$ kommen also bei der folgenden darstellung der Kaiserchronik nicht in betracht. Nie schreibung der rubrikentitel ist im anschluss an 
die in den kritischen ausgaben mhd. gedichte herrschende schreibweise geschehen. Seite und zeile in Diemers ausgabe ist durch blosse zahlen angegeben.

1. ei. In buntem wechsel stehen $e i$ und ai. Zahlenverhältnisse aufzustellen hătte hier keinen wert, indem eben wie in einigen andern erscheinungen dieser bunte wechsel das charakteristicum von A ist. Selten ist ai. Dazu kommen einige $a$ und $e$, die ihres parallelismus wegen wol nur als schreibfehler aufzufassen sind, indem der zweite component vergessen wurde. Anders bediv (beide), das aber nicht ausschliessllich auftritt (vgl. Weinhold, Mhd. gr. § 63), und zwenzic 325,$18 ; 418,10 ; 488,24 ; 492,4 ; 498,4$ (zwanzech 203,3), welches letztere als reduction des diphthongen vor mehrfacher consonanz genommen und mit elf < eilf, entweder < einde weder verglichen werden kann. Auf ähnliche weise ist ja die nhd. form zwanzig < zwainzig zu erklären.

2. ou. Die gewöhnliche schreibung ist $\stackrel{D}{o}$ (welches häufig auch den laut $u o$, bisweilen $u$ vertritt: uorste = vurste 13,21; 520,$14 ; 524,3$; erzornde 190,14); daneben ou, ov selten au: chauflute 114, 10.

3. $i u$. Weitaus therwiegt $i u$, iv. Daneben $u$ und $e u, e v$, welche letzteren jedoch als wirkliche diphthonge aufufassen sind und mit der späteren monophthongierung nichts gemein haben. Gleichsam einen compromiss in der schreibung zwischen iu und eu stellen ziweiv (wozu) 81, 29 und under deiv 200,17 dar.

4. ie. Im wechsel stehen ie und $i$, numerisch etwa gleich, ohne dass es möglich wäre, irgend ein gesetz dafür zu finden; so auch im praeter. der reduplic. verben. Erwähnt sei nur, dass der vollkername 'Griechen' immer in der form crichen erscheint; ob das uberwiegen der formen flihen, zihen, sichen, liht, niht damit in verbindung zu bringen ist und mit Notkers gebrauch (Beitr. II, 131) verglichen werden kann, sei dahingestellt.

5. a herrscht an unbetonter stelle fast ausnahmslos. Beisp. für zerstreutes $i$ sind: michelin 26,22; ainigiz 30,24. Neben $e z$, die der entstehung nach weniger betonte form, tritt häufig $i z$. 
6. Umlaut. Bei umlautsfähigem $d$ stehen nebeneinander $a, a$, und selten $a e$. Ueber kurzes $a$ vor umlanthemmenden consonanten (vgl. Paul, Mhd. gr. ${ }^{2} \S 40$, anm. 1) ist zu bemerken, dass die verbindung -alt- häufiger als -elt-; umgekehrt -ehthăufiger als -aht- ist. Ausnahmslos tritt die form trehtin auf, wie ja tuberhaupt das gesetz für $h t$ schon im ahd. durchbrochen ist. Das zu grunde liegende trahtin, welches in andern vorlagen begegnen wird, darf nicht mit Weinhold, Mhd. gr. § 21 aus trohtin erklärt werden, sondern ist als eine andre ablautslautsstufe des got. draúhts (<druhtis) und des ags. umgelauteten dryhten $\mathrm{zu}$ fassen. Das wort bietet ubrigens schwierigkeiten. Oft ist geschriehen aht mit ligatur.

7. Contraction. age, ege, ai, ei wechseln. Genau genommen kann man eigentlich nur von einem wechsel zwischen age und ege reden, indem sich nur für die wandlung von ege $>e i$ ein lautgesetz aufstellen lässt. Das contractionsproduct steht auf ganz gleicher stufe mit altem ei (vgl. die heutigen dialecte). Wenn gerade hier bei sonstigem schwanken die schreibung ai bevorzugt wird, erklärt sich das als anlehnung an die nicht-umgelauteten formen mit age (vgl. Paul, Mhd. gr. ${ }^{2}$ $\S 86$ ). Beisp.: Magenze 13,2; megenze 463,5; als vermischung maingenze 479,32; magede 55, 23; magede 273,13; maide 57, 20; als compromiss maigede 287, 14; tegedinge 321, 18; teidinge 9,32; getregede 319,$9 ;$ treistu 81,29. Allein steht legete 45, 30 etc.; dagegen herrscht lit < ligit. Hänfig ist git < gibit; kut $<$ quidit 10,29; chut 16,19. Ganz gewöhnlich sind die contrahierten formen von lâzen; als 3. sg. präs. laeter 114, 16; uerlat 116,5; lat 142,10.

8. Gruppe -or-. Von der dem bairischen dialect eignen wandlung dieser gruppe zu -ar- (vgl. Weinhold, Mhd. gr. \& 21; Bair. gr. §6), die als parallele zu ou $>a u$ gefasst werden kann bei der vocalischen natur des $r$, sind folgende spuren da: wart 68,$12 ; 130,2: 147,31 ; 211,21$ etc. (im ganzen 8 fälle); warden (= geworden) 122,31;155,19; uerwarfen (part.) 149, 2; gewarfen 164, 15.

9. Synkope ist im inlaut wenig eingetreten. Durchgehend ist bilede, helede, selede, hemede; ambeht, dienest, mennisce; lebete, lobete, swebete; hinat, dessen bedeutung ubrigens schon abgeschwächt ist, wie 375,22 : hinat bi dirre naht be- 
weist. (Auf dieser abschwächung mag die vermischung mit heut beruhen, wie wir jetzt eigentlich unlogisch heut nacht sagen statt heint nacht.) An synkopierungen treten auf: immer bette, praet. < betote, trotz kurze der wurzelsilbe, indem wol die gleichheit des stammauslauts und des cons. der endung die ausstossung begünstigt hat. Ofters mante < manete 36,28 ; habte neben habete s. unter $24 ;$ wiste $<$ niseste 32,$25 ; 43,3$; wirsten 159, 8; lemtig 114, 17 neben lebentic 156, 25; aim < ainem 9,$32 ; 29,14 ;$ uan < uanen 159, 25.

10. Abschwächung der nebenvocale. Im partic. der schw. verba erhaltung von -ot; weniger häufig im praet. -ote. Die endung des superlativ ist als -ist gewahrt; -ost in uorderost 416,7; im compar. uerror 385,3. Durchgehend ist die form manode. Neben nieman tritt niemen 252,$32 ; 253,7$. Im dat. der pron. und st. adj. flex. herrscht die endung -me.

11. Svarabhakti ist sehr selten; eigentlich lässt sich nur die neigung, $z w$ - in zew- zu wandeln, feststellen. Es sind im ganzen 17 fälle, welche die zahlwörter 2, 12, 20 liefern. Ferner seien erwähnt: kenehte 144, 4 als sporadische erscheinung und der schon im ahd. stattfindenden einschiebung entsprechend durich 15,8 ; uerswalich 268,6 ; beualich $352,2$.

12. Accente. Der circumflex steht sehr ungleichmässig. Meistens ist circumflectiert die partikel $\hat{e}$, offenbar, um dem kleinen wort- und schriftkörper eine stlutze zu geben. Sonst kommen auf 100 seiten bei Diemer, also etwa 3200 verse circa 30 circumflexe, auf $\hat{a}, \hat{e}, \hat{\imath}, \hat{a}$, bisweilen auf $\hat{\imath}=i e$ und $\hat{a}=u o$. Vielleicht ist auf chôm 205, 24 gewicht zu legen, weil im ags. côm auch länge eingetreten ist (vgl. Sievers, Ags. gr. $\S 390)$. Falsch stehen die circumflexe sehr selten; beisp. sûs 470,32. Einfacher strich, accut steht sehr vereinzelt: áb 205,15; dáne 210,32 ; wálbliut 217,14 ; din 234,17 ; häufiger nur in den interjectionen ówol, ówe, ówi.

13. Dentale. a) Im anlaut erscheint mhd. $d$ - als $t$ - in 44 fällen, so dass auf c. 400 verse éin fall kommt, und zwar verteilen sie sich in folgender weise: nach auslaut. $-n$ : 12 fälle, nach $-s: 8$, nach $-z: 6$, nach $-t: 6$, nach $-c h: 5$, nach $-l: 3$, nach vocal: 2 , nach $-m: 1$, am anfang des verses: 1 . Abgesehen von den fällen nach $-n$, deren zahl weniger von bedeutung ist, indem dieser auslaut bei weitem numerisch überwiegt, lassen 
sich die fälle nach $s, z, t, c h$, als spuren des Notkerschen kanons auffassen, worin 14 a bestärken wird. Nicht mitgerechnet ist tutisk, das weitaus häufiger ist als dutisk, weil ja uberhaupt bei der entwicklung dieses wortes besondere verhältnisse gewirkt $z u$ haben scheinen. Als eine folge des wechsels von $d$ - mit $t$ - sind wol die verschwindenden schreibungen dail 278,17; dier 315,32 ; divre 319,9 aufzufassen.

b) Die verbindung $d w$ - und $t w-$. In betracht kommen dwingen, dwahen, dwerch (urgerm, $p w-$ ) und twellen, twalm, twâle (urgerm. $d w$-). Diese beiden gruppen sind nicht mehr getrennt: die letztere erscheint immer mit $t w$-, die erstere ver-

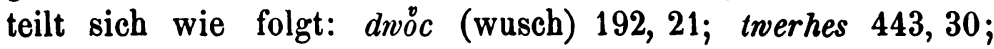
das wort dwingen mit $11 d w$ - und $30 \mathrm{tw}$-. Der wechsel findet an- wie inlautend, d. b. auch in den compositen von dwingen statt, und lassen sich die anlautenden fälle mit dem auslaut des vorhergehenden wortes in keine beziehung bringen.

c) Die gruppe - nt -. Weitaus uberwiegt die erweichung -nd-, welche sich bekanntlich vom ahd. zum mhd. vollzieht; daneben steht $-n t$, welches in den präter. sante, wante, kante, rante, brante, wo $-n t-<n d t$, nnt entwickelt ist, bevorzugt wird. Jedensfalls unrichtig ist die ansicht Rödigers, welcher gelegentlich einer besprechung des 'Trierer Silvester' (Haupts Zs. XXII, 180) äussert: 'solde, wolde, uirgulde etc., kunde (konnte), wânde, dagegen durchweg sante, bekante, brante, also $t$ nach -an-'. Der grund der nichterweichung ist nicht in der natur des vorhergehenden vocals, sondern in der verschiedenen entstehung der gruppe -nt- zu suchen, indem eben in diesen fällen ndt oder nnt zu grunde liegt, deren nächste weiterentwicklung ntt gewesen sein wird. Darauf fuhrt auch das wort 'winter'; got. vintrus wird durch das $r$ in *winttrus verschärft, und in folge dessen hat das wort auch in solchen altdeutschen hss., wo sonst $n t>n d$ erweicht ist, die schreibung wintar oder winter. Also ist ältere gemination auch hier die ursache. Das ursprüngliche verhältnis zeigt z. b. branten : ze scanden 483, 29; brante : lande 484,17; besanten : lande 516, 27.

d) -lt- ist nicht erweicht; ausnahmsweise in driualde 18, 22. Der wechsel von solte, solde und wolte, wolde gehört nicht hierher: s. unter 20.

14. Labiale. a) anlaut. $b$-. Es wechselt $p$ - und $b$ - im 
gesammtverhältnis von $4: 3$. Für den wechsel nach dem verschiedenen auslaut des vorhergehenden wortes lässt sich folgendes verhältnis von $p: b$ aufstellen:

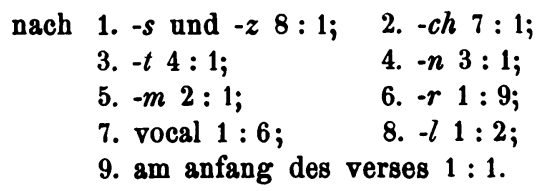

Das 1., 2., 3., 4., 5. und 6. -verhältnis stimmt mit dem Notkerschen kanon, so dass dieser hier in einer allerdings nicht ganz consequenten durchfuhrung vorliegen würde, wozu 13 a zu vergleichen ist. Das gesetz wurde ja noch in späterer zeit beobachtet, was die hss. von Wolframs werken beweisen.

Merkwtirdig ist, dass 'daz, buoch' (die quelle), bäbes, biscolf (aber die form s. 28 b), der stammname baieren niemals mit $p$ auftreten; als ungemein häufig in der Kaiserchronik, gleichsam alle als geheiligte eigennamen, scheinen sie ausserhalb der regel zu stehen. Oder es mutet einen ähnlich an, wenn man in einem reglement fur rechtschreibung liest, es seien die endungen -iren, -irung nicht mit ie zu schreiben, dagegen regieren und Regierung. Gleichfalls hat die unbetonte vorsatzpartikel $b e$ - immer $b$-. Ueber die natur des wechsels s. Paul, Beitr. VII, 126. Im wortauslaut steht $-p$.

b) $f<$ urgerm. $p$ erscheint immer als $f$, bisweilen als $f f$, nie als $v$ oder $u$, im gegensatz zu andern complexen der hs.

c) Die gruppe $w u$-. Beliebt, aber nicht constant ist die schreibung $w$-, indem mit $u$-lauten gespart wird, wie z. b. schon in den Otfridhss. Beisp.: listwrchore 174,22; underwnden 186,26; wnderlicher 201,13; uberwnden 231, 15.

d) Die gruppen $d w-, t w-, s w-, z w$ - erscheinen taberwiegend in dieser schreibung (beztiglich zen-, vgl. 11), weitaus seltner ist $d v$ - etc.

15. Gutturale. a) $k$. Am anlaut der silbe wechseln $c h$ und $k$-, ersteres uberwiegt. Ueber die ungefähr im bairischen dialect sich vollziehende wandlung von $c h>k$ vgl. Paul, Beitr. VI, 556. Gemination aus urgerm. $k j, k r$ erscheint als $k, k k, c h$ : so dike 10,30 ; dikke 136,30 ; diche 214,21 ; rekke 136, 29; akker 
336,17 ; naket $295,21(<k v)$. Gemination aus urgerm. gg als $k$ : luken 106, 5; brucke : ruke 364, 7.

b) g. Im auslaut des wortes waltet bunter wechsel zwischen $-c$ und $-c h$; vereinzelt ist $-k$ in den sik koften 491,20. Im auslaut der silbe im wortinnern steht $c$ : burcgraben 162,3; burcgraue 236,19; uracten 309,9 ; geuocte 437,1. Dass das verhältnis berc, berzes das ursprïngliche sei, wonach dann durch ausgleichung doppelformen entstanden, bespricht Paul, Beitr. VII, 132. Im wortanlaut erscheint selten $k$ - oder $c$-; ich bemerkte nur: ain kokelare 64,18 und der carte 210,18, welcho nicht als spuren des Notkerschen kanons gelten können.

c) Die gruppen qua-, que-, qui- sind immer zu ko-, ku-, bezigglich cho-, chu- verschmolzen. Als beispiel diene: chom 13,9; rekomen 38,16; kot (sprach) 407, 14; kôle (quâle) 196, 25; kochsilber 114, 25 (mit volksetym. anlehnung an kochen?); êkonen 118, 32; kurne 55, 3; erkuket 276, 8; chut 275, 25.

16. Assimilationserscheinungen sind selten. Zunăchst ist zu vergleichen $13 \mathrm{a}$ und $14 \mathrm{a}$, da der Notkersche kanon von haus auch doch eine assim. ist. Dann wäre zu nennen lemtiges 114, $17<$ lebentiges; tampome 12, 7; gimmir 208, 1; 422, 14 etc.; ahzec 303,18 < ahtzec. Ueber das hăufige lussam s. I B 2.

17. Metathesis. In betracht kommt nur der wechsel der vorsatzpartikel er- mit re- Ueber die lautliche bedeutung kann man schwanken; wahrscheinlich ist re- nur als ausdruck von sonant. $r$ zu verstehen. Ich fand: re- im ganzen 297 fălle; davon:

$$
\begin{aligned}
& \text { nach }-v o c .: 140 ;-n: 48 ;-r: 46 ;-l: 21 ;-t: 10 ; \\
&-s,-z: 6 ;-c h: 3 ; \text { am anfang des verses: } 23 .
\end{aligned}
$$

Das gesammtrerhältnis von er- zu re- ist etwa $12: 11$; nach -r $1: 8$; nach vocal $1: 6$; nach $-n 1: 5$; nach -t $8: 1$; nach -ch $7: 1$; nach $-s,-z 6: 1$. Demnach ist klar, dass nach vocal, $-r,-n$ re-, nach $-c h,-s,-z,-t$ aber er- weitaus bevorzugt ist. Dazu stimmt Weinhold, Mhd. gr. § 146. Es treten in gegensatz vocale und liquiden einerseits, tenues und spiranten andrerseits, so dass diese erscheinung wol dem Notkerschen kanon zur seite gestellt werden kann. Auch in der heidelberger hs. der Kaiserchronik findet sich der wechsel nach Diemer, Dt. ged. anm. 8. 17. Als analogon wäre anzufuhren, dass im provenzal. 
an stelle des gewöhnlichen -re der wurzelbetonten infinitive, welqhes wie im afr. $=r$ steht, nach zischlauten -er erscheint. Vgl. Bartsch, Chrestom. provenç. ${ }^{4}$ s. 437.

18. Grammatischer wechsel. An formen ohne ausgleichung sind zu nennen: geleren 33,16 ; leeren 276,16 ; genaren 216, 12 (6 mal); praes. heuen 301,$10 ; 383,26$; aber hop 491, 7 etc. mit ausgleichung. Umgekehrt ist in werfen (in bewegung sein) immer ausgeglichen zu gunsten von $f, v$ : iruen 37,3 ; woruen 252,22 ; erworuen 212,24 ; reworuen 414,10 , was besonders bairisch sein soll. In sagen (= sahen) 29,7 liegt mischung des wechsels von $h-w$ mit $h-g$, wie im ags., vor (vgl. Sievers, Ags. gr. § 391). Dass auch im schwachen verbum ursprünglich grammatischer wechsel bestand, beweist flêhen, das nur in 4 fällen mit $-h$-, in 22 aber mit $-g$ - erscheint.

19. Verbum sîn. Häufig ist wir birn, ir birt. Der imperat lautet wis, weset.

20. wellen. 2. sg. präs. du wil 166,$15 ;$ wildu 68,$22 ; 166,17$ etc. Im präter. bunter wechsel zwischen wolde und wolte, ebenso zwischen solde und solte. Dass der fall für sich zu stellen ist, beweist die erhaltung der gruppe -lt-: s. $13 \mathrm{~d}$. Das verhältnis der beiden formen ist noch nicht endgültig dargelegt.

21. mugen. Weitaus luberwiegt megen und mahte; nur ganz sporadisch ist mugen und mohte. Das verhältnis ist 20:1.

22. Das prät. von wizzen tritt auf in der lautges. form wesse, daneben häufiger weste.

23. wurchen. Das praeter. lautet worhte, das partic. geworht. Die andre ablautsstufe warhte, gewarht ist nicht zu belegen. Umgekehrt ist nebenbei bemerkt das verbum holen nur in der stufe halen vertreten $(116,1 ; 168,3 ; 226,34 ; 235,4$; $236,31 ; 307,29 ; 331,12 ; 407,222 ; 444,16)$.

24. haben. Als präterita fungieren habete, habte, hele, hiete, die erste form am häufigsten, hette nur 478, 15.

25. stân, gân. Die $\hat{a}$-formen tuberwiegen bei weitem im reim, was begreiflich ist; im innern des verses concurrieren die $\hat{e}$-formen. Der imperativ lautet genc.

26. Flexion. a) pronomen. Als acc. pl. m. des pers. pron. tritt neben $s i$ die form $s i v$, offenbar aus dem neutr. verallgemeinert, und zunächst für verschiedene geschlechter: vgl. 
mhd. beidiv, nhd. zwei, wo die neutrale form den sieg davontrug. Die verteilung ist sehr verschieden; besonders vielo beispiele stehen auf s. 150-200. Vgl. Judith jun. (E 26).

b) 2. sg. pl. präs. und prät. Die endung ist im sg. -st. Interessant für die entwicklung derselben sind schreibungen wie: muisestu 166,6; wores tu 283, 20 als die beiden phasen assimilation und verschmelzung, worauf falsche abtrennung erfolgte unter dem einfluss der prät. präs. anst, kanst, tarst, weist, muost. Die $2 \mathrm{pl}$. mit der endung -ent liegt vor in wellent 11,31 .

c) Präteritum. In der st. flexion ist zu nennen scrai 330,27 ; screi 375,$31 ; 407,30$ (die beiden letzten im reim: ei), welche formen ja neben scrê fungieren (Weinhold, Mhd. gr. $\S 337$ ). Starkes präter. mit dem -e der sw. flexion erscheint in stunte 166, 25 und raite 170,28; es ist kein zufall, dass der stammauslaut beidemal $-t$ ist, wodurch vermischung mit der endung te nahe lag ( $\mathrm{ggl}$. nhd. wurde). branhten 296,9 ist kaum als junge analogie nach den präs. formen mit erhaltenem $-n$ - zu betrachten. Ueber muose s. I B 6; uber wesse II A 22.

27. Zahlwörter. Zu erwähnen ist: 2. fem. zui 110,12; 3. n. m. drie 296, 5; driestunt 438, 29; uumfe 477, 22; 7. die gewöhnliche form ist siben; nur 186,19 suben. Bevorzugt ist suben vom jungeren schreiber, worlber unten näheres. Man hat darin wol einfluss des labials zu sehen und mag fromede 53,5 und emfromeden 507, 26 vergleichen. Andre belege siehe Diemer, Gen. und Exod. II, 217. 11. ainlef; 20. zenainzec; 5 mal zwenzec, wozu vgl. 1; 80. ahzec vgl. 16; 100. zehenzec, daneben hundert; dies steht aber nur fur mehrere hundert, was Kluge, Etym. wörterbuch s. 142 als das ursprüngliche betrachtet und mit recht als stutze fur das frühere duodecimalsystem des altgerm. anfuhrt, indem fur 100 kein selbständiges wort existierte.

28. Einzelne wörter. a) fiur erscheint immer (33 mal) mit $i u$, $i v$, im gegensatz zu andern complexen. Ueber die sonderstellung des wortes s. Müllenhoff, Haupts zs. XVIII, 136. Jedenfalls ist die form fuir die ursprüngliche, was schon ags. $f \hat{r} r$ beweist, indem einem fiur in diesem dialect nur * feór entsprechen könnte. 
b) biscof. Das wort kommt, für sich oder in der composition erze-, $46 \mathrm{mal}$ vor und immer in der form biscolf. Andre belege s. Diemer, Gen. u. exod. II, 93 und Dt. ged. anm. s. 51, wo bemerkt ist: 'scheint dialekt. form besonders in Oesterreich.' Dazu stimmt z. b. ein spätrer beleg aus dem 14. jh. in der Klosterneuburger hs. nr. 1226, vgl. Germania VIII, 105, wo die form stets pischolf lautet. Lexer, Mhd. wb. citiert die ansicht von Grimm, wonach ahd. bischouf zu bischolf ubergegangen wäre. Eher wäre das umgekehrte anzunehmen, unter einfluss romanischer lautentwicklung. Jedenfalls haben, wie Weinhold, Bair. gr. § 159, Mhd. gr. § 193 äussert, die häufigen eigennamen auf -olf $<-$ wolf, mit welchen das wort seiner natur nach leicht in verbindung kam, eingewirkt. Ich glaube, dass das altfranz. nevuld < nepótem, welches z. b. im Rolandslied offters vorkommt, in ăhnlicher weise als anlehnung an die eigennamen auf -old zu erklären ist, mit welchen auch dieses wort oft in zusammenstellung kam. Die form neovild ist durch die assonanzen gesichert: vgl. Chanson de Roland, ed. Gautier, Edit. Class. ${ }^{12}$ p. 530.

c) lichname erscheint immer in dieser form (16 mal), im gegensatz zu andern complexen.

d) diemüete ist interessant wegen seiner vielfältigen gestalt: diemute 317,25 ; devmuite 347,24 ; dîmuite 410,3 ; deomit 417,6 ; terimote 462,9 ; vgl. uber die entwicklung des wortes B $28 \mathrm{~d}$.

29. Varia. a) Aphäresedes $j$ - ist als kriterium wenig zu brauchen, weil die in betracht kommenden fälle zu selten widerkehren. In der Kaiserchronik ist zu nennen: enehalb 12,10 ; iamer 30,$31 ; 196,18$; iameren 350,19 ; amer 421, 22; ameren 484, 16.

b) Das wort atem tritt nur einmal, 120,7, in dieser gestalt auf, sonst immer als ahtme (7 mal); ob dieser form gewicht beizulegen - unorgan. $h$ ist sonst selten - und ein zusammenhang mit got. ahma, den Kluge, Etym. wb. s.12 leugnet, herzustellen ist, kann ich nicht entscheiden. Die wörterbulcher citieren die form ahtme nicht.

c) Das adverb. betalle 358, 17 und 362, 27 und bitalle 377, 24 sei seines zweifelhaften ursprungs halber erwähnt: vgl. Weinhold, Mhd. gr. § 149. 
d) Die form salter ist 2 mal, 196, 2 und 277, $15 \mathrm{zu}$ belegen, mit vereinfachung der anlautenden doppelconsonanz wie in salme und sitich.

e) Einmal stran (strom) : ran 231, 25, was als bairisch und ostfränkisch gilt. Jedoch ist hierauf kaum viel gewicht zu legen, weil das verhältnis der ahd. mhd. doppelformen stroum, strâm, strâm unklar ist: s. Kluge, Etym. wb.

f) Ungemein häufig ist in der Kaiserchronik das wort urvar, und zwar immer in der bedeutung 'ufer'. Kluge bemerkt zu diesem wort: 'aus mhd. uover; dem ahd. fehlend' (Etym. wb. s. 352). Sollte nicht eine vermischung der beiden worte möglich sein? Bei uvularer aussprache des $r$ kommt sich ihr klang sehr nahe.

g) Ueber of, boven s. schluss von $L$.

Dass die Kaiserchronik aus den verschiedensten elementen zusammengesetzt ist, mag man nun sagen componiert oder compiliert, wird man ebensowenig leugnen können als es verfehlt ist, aus ihrer gestalt ursprünglich selbständiges loslösen zu wollen. Ueber die einheit hat gehandelt Debo, Graz 1877. Was den verfasser betrifft, haben Giesebrecht und andre vermutet, dass er ein Regensburger geistlicher sei; die entscheidenden beweise fur den bairischen ursprung stellte zum ersten mal zusammen $H$. Welzhofer, Untersuch. ub. d. Kaiserchronik 1874; vgl. Scherer, Haupts zs. XVIII, 298. In der schreibung weisen nach Baiern in unserer hs. nr. 1. 8. 15a. 19. 26 a. 28 b. 29 e.

Ueber das ursprungliche ende åusserte sich der 'Grundriss' von Koberstein-Bartseh's 1872, I, 156: '1147, nach andern schon 1137 abgeschlossen.' Giesebrecht gab sein urteil in der Gesch. d. dt. Kaiserzeit IV, 399 dahin ab: 'Die melrfach ausgesprochene vermutung, dass das buch ursprïnglich mit Lothars tode geendigt, die regierung Konrads später hinzugesetzt sei, hat keinen zureichenden grund, und vieles spricht dagegen ...' Scherer a. a. 0. 8. 299 war andrer meinung: er sah in den versen nach dem tode Lothars ein schlusswort und kam zur ansicht, dass die Kaiserchronik demnach einen kunstlerischen abschluss besitze, 'nur allerdings hundert verse vor dem ende 
der haupthandschriften'. Er zog die verse 526, 22-33 noch zum urspringlichen werk und setzte demnach die abfassungszeit ins jahr 1141, wo die gemahlin Lotbars, Richenza, starb. Ich glaube nun der schon von andern vorgetragnen ansicht, dass das werk mit 526, 21, also mit dem jahre 1137 abschloss, eine stutze, wenn nicht entscheidende bestätigung geben zu können. Es treten nämlich nach den versen:

swer daz liet uernomen habe.

der sol ain pats $\tilde{r} \tilde{r}$ singen.

dem almæhtigen got ze minnen.

des chaiser Lutheres sele.

er was wol des riches herre. (Diemer, s. 526, 17-21)

eigentümlichkeiten in der schreibung und in den formen auf, die sich im ganzen vorhergehenden teil nicht belegen lassen. Nämlich: 1. unetymolog. ie $=\hat{\imath}, i, e$ : ziet 527, 12; uertrieben 528,1; hiemele 528,3; entriennen 528,16; uielf (Welf) $529,2$.

2. Neigung $\mathrm{zu} i$ für unbetontes a: bildwngen 526,30; uirliezen 528,15 .

3. $\operatorname{sad}(=$ sat $) 529,2$.

4. Unorgan. $h$ - im anlaut: hêre 526, 25. 526, 32. heren 527, 13; hêre 527, 21; sonst: rath 529, 22; Lůlhewige 529, 29.

5. Eigentumliche accente: diéu érde wol iér 526, 23. Sodann: uuôrhte 526, 26; netvêlte 530,6 mit unberechtigtem circumflex, wie sonst fast nie: vgl. nr. 12.

6. Die form uirsten 528,20 ; sonst steht immer uursten oder uorsten, so $13,21.520,14.524,3$. Vielleicht liegt ubrigens hier umlautsbezeichnung vor: vgl. MS D. ${ }^{2}$ anm. s. 407.

7. Die form lenger 530,6; sonst steht immer im comparativ langer: so $230,26.251,13.317,9$. 331,31. 441,27. 443, 17. 461, 8. 470,30. 483,32. Dass in lenger keine eigentlumlichkeit des Vorauers schreibers zu suchen ist, beweist auch der umstand, dass in der ganzen hs. sonst nur die form langer zu belegen ist.

8. Die form liuzel 528, 30. 529, 19. 529, 23, während vorher nur luzel zu belegen ist; so luzzeln 199, 27; luzel 202, 18. 211,6. 217,6. 227, 2; luzzelen 515, 23.

Ist dadurch bewiesen, dass die verse $526,22-530,6$ in 
der vorlage der Vorauer hs. erst später hinzugefügt wurden, so ist darin involviert, dass die Vorauer hs. wegen der treue ihrer widergabe der in der vorlage vorhandenen differenz, wozu die folgenden beobachtungen stimmen werden, das böchste vertrauen verdient. Dass die Vorauer die älteste hs. der Kaiscrchronik ist, steht längst fest. - Hinfällig wäre dann auch die ansicht, welche Welzhofer äusserte, dass in der uberlieferten form der Kaiserchronik eine bearbeitung einer ălteren gestalt durch den fortsetzer von Lothar bis Konrad vorlăge (vgl. Scherer, a. a. 0. s. 301, wo die ansicht citiert ist). Ebenso unhaltbar ist dann die vermutung Edward Schröders (Zs. f. dt. d. XXVII), wonach der pfaffe Konrat, der verfasser des Rolandsliedes, die Kaiserchronik umgearbeitet und das stuck von Lothar II. bis Konrad III. hinzugefugt habe. Denn läge eine bearbeitung vor, so kōnnte zwischen dem hauptteil und dem fraglichen schlussteil keine sprachliche differenz bestehen. - Es hat demnach die älteste form der Kaiserchronik mit 526, 21, mit dem jahre 1137 abgeschlossen.

\section{B. BÜCHER MOSES}

(= Diemer, Dt. ged. s. $3,1-85,3$ und Wiener sitzungsberichte 47 , s. 636-687).

Der titel tut einstweilen nichts zur sache: ich wähle nur, um eine gesammtbezeichnung des complexes zu haben, die von Diemer gebrauchte uberschrift. Eine sonderstellung nimmt der sog. 'Joseph in Aegypten' bl. 78 b, z. 39 - bl. 87 d, z. 24 ein, welchen Diemer, Dt. ged. 8. 32 (vgl. einl. XL) wegen der ziemlichen ubereinstimmung mit der Wiener bs. der Genesis (Fundgruben II, 52, 37-82, 21 und Massmann, Deut. ged. s. 278, v. 3454 - s. 310, v. 6063) unveröffentlicht liess, bis er im jahre 1864 a. a. o. denselben nachlieferte. Dass der 'Joseph' aus der Wiener bearbeitung in die Vorauer aufgenommen wurde, ist jetzt allgemein gebilligt: vgl. Vogt, Beitr. II, $209 \mathrm{ff}$. und Scherer, Quell. und forsch. I, 57. VII, 45. XII, 56. Durch die folgenden orthographischen zusammenstellungen wird sich ergeben, dass die stücke Diemer s. $3,1-31,30(=\alpha)$, der Joseph $(=\beta)$, Diemer s. $32,1-85,3(=\gamma)$ sich in derselben vorlage befanden, und dass der Joseph in seiner orthographie eine mischung zwischen derjenigen der Wiener hs. und derjenigen 
der Vorauer hs., wie sie in $\alpha$ und $\gamma$ vorliegt, darstellt. Ich behandle also wider die einzelnen erscheinungen und unter jeder getrennt die stlucke $\alpha, \beta, \gamma$. W. ist $=$ der Wiener hs., welche ich nach dem zuverlässigeren abdruck der Fundgruben, nicht nach Massmann citiere (s. Beitr. II, 317). Im Joseph der Vorauer hs. $(\beta)$ bedeuten die einfachen zahlen die verse, indem Diemer durchgezählt hat (vers 1-1324). Zu bemerken ist noch, dass blatt 89 der hs. (= Diemer s. 39, 12 bis $45,22)$ und blatt 96 (= Diemer $83,28-90,10)$, d. h. das erste und das letzte blatt der 12. lage, wie das erste und letzte der ersten lage (s. oben bei der Kaiserchronik) von einem jüngern schreiber aus dem ende des XII. jh. erneuert wurden (vgl. Diemer, s. 39 und 83, Einl. s. V). Diese stellen mussen naturlich bei der folgenden betrachtung unberïcksichtigt bleiben. Die nicht unbedeutenden eigentümlichkeiten bezügl. änderungen des jüngern schreibers werden zusammen unter $\mathrm{C}$ besprechung finden, wo eine zusammenfassung derselben notwendige vorbedingung der kritik ist.

$$
\begin{aligned}
& \text { 1. ei. a) } 90 \text { ei, } 15 \text { ai, } 1 \text { aei; } \\
& \text { B) } 117 e i, 16 a i \text {; - W. ei; } \\
& \text { y) } 106 e i, 9 a i \text {. }
\end{aligned}
$$

Das starke uberwiegen der schreibung $e v$ in $\alpha$ erklärt sich erstens daraus, dass dort der artikel dev viel häufiger vorkommt als in $\beta$ und $\gamma$, und in diesem wort, wol mit der unbetontheit zusammenhängend, ev bevorzugt wird; zweitens aus der erwägung, dass bei vorhandenem schwanken in der vorlage auch beim getreusten schreiber das procentverhältnis der mischung sich etwas ändern konnte. - Hervorzuheben sind in $\beta$ : livf : tivf 59; liub 340; livf 594.597; liup 1214; 1233; $\gamma$ : livgen 48,29 ; livfen 52, 22 ohne brechung des iv; daneben tifev $\beta 1059$ und libev $\gamma$ 71,27. Es liegen hier reste von dem im oberdeutschen ursprünglichen zustand vor, welchen Braune Beitr. IV, 557 nachgewiesen hat, wonach iu durchgängig vor labial und guttural gewahrt blieb. - Umlaut von $\hat{u}$ in $i u$, der ja 
schon bei Notker vereinzelt zu belegen ist, zeigt $\gamma$ heuten (häuten) 37,25 und hivten $81,10$.

4. ie erscheint in $\alpha$ ) mit grosser consequenz als $i$; nur 7 ie und $7 e i$, welche letzteren als verwechslung bei dem mangel des dem schreiber gewöhnlichen ie anzusehen sind.

B) Auch als $i$; nur $11 i e$; - dagegen W. immer ie.

r) Desgleichen als $i$; $6 \mathrm{ie,} 1 \mathrm{ei}$.

Entsprechend in $\alpha, \beta, \gamma$ tifel.

5. ə. $\alpha$ ) immer $e$, mit ausnahme der vorsatzpartikeln ir-, vir-, int-.

B) Ebenso.

W. int-, aber ver- und vir-, er- und ir-.

$\gamma$ ) Wio in $\alpha$. Dazu bizeichenlich 81, 23 und bizeichenunge 82,10 als nur scheinbare ausnahme, da die betonung bizeichen etc. anzunehmen ist (vgl. Lexer, Mhd. wb).

6. Umlaut. $\alpha$ ) $\hat{a}$, aht, alt immer ohne umlaut.

B) Desgleichen; nur 1 gewelte 124. - W. aht, aber elt.

$\gamma$ ) Wie in $\alpha$.

Eine ausnahmestellung von der gruppe aht macht wider, wie in der Kaiserchronik, trehtin, welches nur in dieser form zu belegen ist. $\mathrm{Ob}$ man sailde $\beta 928$ als umlautsandeutung oder als verschrieben ansehen will aus alterem sálide, wird zweifelhaft sein. Ueber umlaut von $a$ s. $3 \boldsymbol{\gamma}$.

7. Contraction. $\alpha$ ) age, ege, ai, ei;

$$
\begin{aligned}
& \beta) \text { age, ege; - W. ebenso; } \\
& \gamma) \text { age, ege, ai, ei; }
\end{aligned}
$$

In $\alpha, \beta, \gamma$ latt; in $\beta$ quît 1062, chut 1160; in $\beta$ und $\gamma$ gitt. In $\beta$ verdient erwähnung gesam : getan 341 , in W. gesan, wo der sinn yesagen feststellt.

8. Gruppe or $=$. Uebergang in -ar-feblt.

9. Synkope ist im inlaut selten; beispiele: $\alpha$ ) bilede $28,13 ; \beta)$ ambahte 127 ; faizel $181 ; \gamma$ ) wisesten 53,27 ; feizt 64,6 ; helede : selede 77,15 ; satte (sättigte) 78, 23 vergleicht sich dem bette der Kaiserchronik (stamm auf dental). Im auslaut uon, uone; ane, uile.

10. Abschwächung der nebenvocale. Immer erhalten ist die endung des sw. prät. -ote. Als archaische formen treten auf: a) nacchot 8,10 ; 
B) suntone 1111; minnone 1050 (gen. plur.).

) Herro 67, 9; meror $82,20$.

Der superlativ auf -iste, der dat. der pronom. und der st. adj. flex. auf -me auslautend.

11. Svarabhakti ist selten. In allen 3 teilen ist nur zesewen oft $\mathrm{zu}$ belegen; in $\alpha$ ) und $\gamma$ ) suel und suer (säule, sauer) 12,4 . 47, 10. 47, 26. 65,9. 78, 27. 81, 11.

12. Accente. Als längenbezeichnung fungieren wie in der Kaiserchronik circumflexe, aber häufiger auftretend als dort, auch auf $\hat{\imath}=i e, \hat{a}=u o$. Selten steht der accent unberechtigt wie in frêch 74,2. So dürfte der schreibung $\hat{a} z$ $8,3(\alpha)$ wert beizulegeu sein, als beweis, dass auch im mhd. die reduplicierte form erhalten ist, was zum got. frêt $<$ fru-êt (Lucas 15,30) und zum ags. êt, frêet (vgl. Sievers, Ags. gr. §391) stimmt.

13. Dentale. a) Mhd. $d$ - erfordert wenig bemerkungen. Es erscheint als $t$ - in den stellungen: $\alpha$ ) wistu 7, 15; mit ter 3,14 ; hast tu 25, 22;

B) $d a z$ tu 288, welche als assimilation oder in bezug auf 14 a als spuren eines kanons zu fassen sind. - Auffällig ist in $\beta$ ) gedovbet; dovbet 161 an stelle von $t$ -

b) $d w-t w$. Im gegensatz zur Kaiserchronik ist $d v-<$ urgerm. $b v$ - und $t v$ - $<$ urgerm. $d v$ - streng auseinandergehalten in $\alpha, \beta$ und $\gamma$. Ebenso in W. $\alpha$ ) dvinge 7,16 ; gedvanc $22,13-$ uirtvelel 13,27; tvalte 24, 27. 26, 27.

$\beta)$ gedvange $132 ;$ gedvanc 431 ; dwrigen 582 ; dvric 598; dvinget 1181 - tvalme 312 ; tvalte 382 .

r) dwanc 38,4; dvere 39, 11 (got. pvairhs); dvingen 61, 30 .

c) - nt-. Es besteht ein wechsel zwischen -nt- und der erweichung -nd-im verhältnis von: $\alpha) 4: 7 ; \beta) 40: 26$; $\gamma$ ) $11: 23$. In $\beta$ ist also -nt- bevorzugt, wozu stimmt, dass $\mathrm{W}$. nur - nthat. Beiläufig bemerkt hat die Exodus der Wiener hs. im gegensatz zur Genesis die schreibung -nd-, so dass sich die von Vogt, Beitr. II aus andern argumenten nachgewiesene zweiheit der verfasser durch die orthographie bestätigen lässt. In sante etc., wo $n t<n d t$ oder $n n t$ entstanden, uberwiegt wie in der Kaiserchronik immer $n t$ gegenuber $n d: \alpha) 5: 3$; $\beta$ ) $12: 1$; y) $7: 1$. Ueber die erklärung s. A 13 c. 
d) $-l t$ - ist durchgängig. Ueber wolde - wolte, solde solte s. 20.

14. Labiale. a) $b$. Im anlaut wechselt $b$ - und $p$-je nach dem auslaut des vorhergehenden wortes in folgender weise:

\begin{tabular}{|c|c|c|c|c|c|c|}
\hline & \multicolumn{2}{|c|}{$\alpha$} & \multicolumn{2}{|c|}{$\beta$} & \multicolumn{2}{|c|}{$\gamma$} \\
\hline nach auslaut. & b- & p- & b- & p- & b- & p- \\
\hline -vocal & 19 & 7 & 43 & 24 & 36 & 2 \\
\hline$-\mathbf{n}$ & 11 & 4 & 17 & 8 & 24 & 4 \\
\hline$-\mathbf{r}$ & 9 & 3 & 19 & 7 & 10 & 2 \\
\hline -ch & - & 3 & 1 & 10 & - & $\mathbf{5}$ \\
\hline$-t$ & - & 6 & 3 & 11 & 3 & 10 \\
\hline$-3,-8$ & 2 & 8 & 4 & 16 & 1 & \\
\hline
\end{tabular}

Diese verhältnisse weisen deutlich auf den Notkerschen kanon, der aber, wie immer in spätrer zeit, nicht consequent durchgeführt ist. - Das unbetonte präfix be- hat nur diese schreibung, so dass in dem alleinstehenden pivilde 67,14 in vocal und consonant des präfixes ein beweis futr dessen betontheit liegt, die beim nominalen compositum auch zu erwarten ist.

b) $f<$ urgerm. $p$ ist nur in $\beta$ teilweise durch - $u$ - vertreten. Die fälle sind: slafen 158; slaues 301 (W. slaffes 59, 45); hulfe 888; heluen 907 (W. helfen 74, 18); slauest 1043 (W. slaffest 77, 28).

c) Die gruppe wu- ist stets vollständig ausgeschrieben.

d) $d w-, t w-, s w_{-}, z w_{-}$ist gewöhnlich durch $d v-, t v-, s v-$, $z v$ - widergegeben; allein stehen in $\beta$ dwrigen 582 und in $\gamma$ dwanc 38,4 .

15. Gutturale. a) Einfaches $k$ wechselt als $c h, k, c$ in dieser fallenden abstufung. Gemination $<k k$ tritt als $c k$ und cch auf: $\alpha$ ) nacchot 8,11 ; nacchet 14, 2; acker 22, 5; stricken : dicke 22,6 .

B) lachchen (lacken) 176; hekket (sticht) 145; secchen (säcken) 566.

\%) dicche : bocche 57,12; gebahchen 78, 24 (vgl. uber dies wort Paul, Beitr. IX); bedecchet : smekket 83, 16. - Urgerm. gg liegt vor als $k k$ in $\alpha$ ) gehukke : mukken 38,$20 ; \beta$ ) likken 571; r) rukke $74,3$.

b) Mhd. $g$ ist im wortanlaut 2 mal als $k$ - zu belegen: $\beta$ ) is kovme (wahrmehnung) 25; $\gamma$ ) den krimmigen 73, 24. - Im Belträge sur gesohichte der deutsohen sprache. XI. 
silbenauslaut im innern steht $c$, im wortauslaut wechselt $-c$ und -ch. - Charakteristisch ist die verschmelzung ink- < intg-, immer in der form ink-, nur einmal inc- in $\gamma$ ) inculten 51, 2. $\mathrm{Ob}$ sich damit in bezug bringen lässt, dass urgerm. $g g$, wie bemerkt immer die schreibung $k k$ hat?

c) Die verbindung qua-, que-, qui- ist in $\alpha$ ) immer verschmolzen (15 fälle).

B) $35 \mathrm{mal}$ verschmolzen, $6 \mathrm{mal}$ nicht.

r) $15 \mathrm{mal}$ verschmolzen, 1 mal nicht: quam 73,9.

16. Assimilationserscheinungen. $\mathrm{Zu}$ vergleichen ist 13 a. 14 a. Sonst ist zu nennen: $\alpha$ ) wouns 19,5 ; wous 20,21 (wuchs); $\beta$ ) franspuite < framspuote 122.

17. Metathesis. Die vorsilbe er-tritt ganz vereinzelt und fast nur nach auslaut. $-r$ als re- auf: $\alpha$ ) er reluste 8,1; er reslagen 10, 27; er reloste 16,4; ers retrac 21,11 ; er rechorn $28,27 ; \beta)$ er regazte 750 ; nimer rewintet $1278 ; \gamma$ ) gar relogen 35, 28. Gerade diese abstufung, das abnehmen, je grösser die entfernung rom complex A wird, spricht dafür, dass hier nur eine reminiscenz an die in der Kaiserchronik vor allem nach $-r$ massenweis vorkommenden $r e$ - vorliegt.

18. Grammatischer wechsel. Ausgleich zu gunsten von $f$ herrscht auch hier in $\alpha$ ) irworfen 30,$14 ; \beta) 27 ; \gamma$ ) irwurfen 55,3. In $\beta$ ist sonst hinzuweisen auf gewuige (zu gewahen) 284 ; gewugen 673 ; wurten 322 ; wurte 323 ; genaren 397 ; in $\gamma$ auf genare 51,24; flegeter 65,9 wegen erhaltung des wechsels.

19. Von sîn seien erwăhnt wir birn, ir birt; imper. wis, weset.

20. wellen. Im praet. wechselte wolle und wolde, ebenso wie solte und solde; uberwiegend ist entschieden $l t$, indem im gesammten folgendes verhălitnis vorliegt:

$\begin{array}{lccc} & \alpha & \beta & \gamma \\ \text { lt } & 18 & 29 & 27 \\ \text { ld } & 15 & 8 & 1\end{array}$

21. mugen zeigt einen wettstreit zwischen den formen mahte, megen und mohte, mugen:

$\begin{array}{cccc} & \alpha & \beta & \gamma \\ \text { erstere } & 4 & 20 & 14 \\ \text { letztere } & 2 & 21 & 12\end{array}$

W. hat nur mahte und megen. 
22. wizzen. Das präter. ist vertreten durch: $\alpha) 6$ wesse, 1 nisse.

B) 4 wesse, 1 wisse.

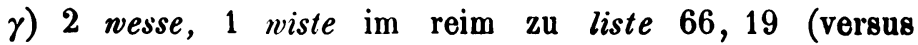
tyrannus).

23. wurken weist in allen 3 teilen nur die formen worhte, geworht auf.

24. haben ist im prät. auch hier mannigfaltig: $\alpha)$ hete; B) hete, habete, hate; $\gamma)$ hete, habete.

25. stân und gân. Das verhältnis der $\hat{a}$ - zu den $\hat{e}$-formen ist in $\alpha) 13: 26$; $\beta$ ) $3: 27 ; \gamma) 9: 25$. Also die $\hat{e}$-formen sind entschieden in der therzahl.

26. Flexion. a) In der pronom. flexion nimmt $\beta$ ) eine sonderstellung ein, indem 3 mal als n. pl. neutr. die form dei erscheint, welche nach der ansicht von prof. Paul ein alter dual ist: finf iare dei 735; dei kint 955. 957. Dazu stimmt, dass in W. statt div meist dei steht.

b) Die 2. sg. geht auf -st aus.

c) In bezug auf die gestalt des prăter. ist zu verweisen auf $d z$ unter nr. 12 und livf unter 3- Dazu kommt in $\gamma$ ) stunt : muit 60,23 und stiten : hùten 60,28 , worin man wol reste des ursprünglichen präteritums ohne verschleppung der prăsensnasalierung sehen kann. Diese formen begegnen nach Weinhold, Mhd. gr. $\$ 336$ sowol in Ripuarien als in Oberdeutschland.

d) Interessante formen sind erhalten in: $\alpha$ ) irwerigen : sverigen 19,25; weregen : generegen 30,5 ; svergende $20,25$.

$\beta)$ nerigen : werigen 74 ; irwerigen : sverigen 939.

$\gamma$ ) werigen : irnerigen 38, 26; herige 47,6. 52, 27.67,17. Vgl. uber diese formen Paul, Beitr. VII, 108.

27. Die zahlwörter weisen wenig bemerkenswertes auf: 2. fem. $\alpha$ ) und $\gamma$ ) zvô $24,10.57,27$. 5. $\alpha) 4 \mathrm{mal}$ feunf; $\beta) 6 \mathrm{mal}$ finf. - W. finf; $\gamma$ ) 3 mal finf. - Diesem unterschied in $\alpha$ ) und $\gamma$ ) ist bei dem häufigen wechsel der formen finf und frunf wol wenig wert beizumessen. Die labiale färbung des vocals hat sich offenbar entwickelt unter dem doppelten einfluss der vorausgehenden labialen spirans und des folgenden labialen nasals, indem die form ja urspringlich fimf lautet.

28. Sonstige einzelne wörter: a) fiur ist vertreten in 
a) durch 3 uevr; merkwürdige schreibungen sind die adj. uov̂rin 9,27; ưierinen 17,24, welche vielleicht mehr auf uuir deuten. In $\beta$ ) fehlt das wort, während in $\gamma$ ) widerum $8 \mathrm{mal}$ uevr, resp. uieur, $1 \mathrm{mal}$ als adj. fuerin 47,12 vorkommt. Ueber die entwicklung des wortes vgl. A 28 a.

b) biscof ist aus nale liegenden grunden des inhalts in diesem complex nicht zu belegen.

c) lichname nur in dieser gestalt in $\beta$ ) 89. 1077. 1085.

d) diemüete hat die formen: $\beta$ ) dimuit 146; demutlichen $658 ; \gamma$ ) dimuit 59, 18. 59,22; dimuteclichen 59, 20; devmüte 50, 8. 53,7. 71, 28. - Die entwicklung dieses wortes zur spät-mhd. und nhd. form dênut ist bekanntlich eine crux: woher kommt das $\hat{e}$ ? Im ahd. bestand wechsel zwischen diu- und die-; nur von der ersten form ist auszugehen, da die zweite immer nur dî- hätte ergeben kōnnen. Besprochen ist, dass wie in der Kaiserchronik, so in den buichern Moses iu als eu erscheint, und nichts hindert, darin eine lautliche entwicklung zu sehen, indem eu als wirklicher diphthong aufzufassen ist. Erst durch die dichtung der geistlichen bekam das wort seine eigentümliche bedeutung; in sudosten Deutschlands vor allem war diese in blite; im sudosten herrscht die schreibung devmuite und schon demite ( $\beta$ 658), so dass man versucht ist zu glauben, es habe dort eine assimilation des labialen vocals an den labialen nasal stattgefunden, und diese dialectisch entwickelte form sei durch die präponderanz einer epochemachenden literatur zu verbreitung und ansehen, endlich zum alleinigen gebrauch gekommen. Allerdings nur eine vermutung meinerseits, die aber bei dem schwierigen worte erlaubt sein wird.

29. Varia. a) A phärese des $j$-ist schwankend: $\alpha$ ) amerlichen 27, 20; iamerote 29,11; $\beta$ ) ennen 61. 306. 1210; amer 474. 595. 691 ; enes 979 ; ener 1071 ; ene 1205 , wozu W. stimmt; $\gamma$ ) enehalb 46, 19.

b) Die form wilch steht in $\beta$ ) 712 und $\gamma$ ) 62, 29; 63, 2; sie entspricht dem ahd. wielih, nebenform von welih, wobei ie nach nr. 4 auch hier als $i$ erscheint.

c) Das suffix -nusse zeigt $\alpha$ ) geuancnusse 16,$5 ; \gamma) 36,15$.

d) Die form uirnunste hat $\alpha$ ) 3,13 und 6,21; der wechsel mit der form vernumft ist vielleicht auf wechselnde accent- 
verhältnisse zurlickzufüren. uernunst ist wesentlich oberdeutsch: s. Weinhold, Mhd. gr. § 142 .

Durch die zusammenstellung dieser orthographischen und formellen eigentumlichkeiten ist evident, dass $\alpha$ ), $\beta$ ) und $\gamma$ ) zu derselben vorlage gehören, die sich sowol gegen $\mathrm{A}$, die Kaiserchronik, als gegen D (C kommt wenig in betracht: s. u.) scharf abgrenzt. Eine ganz erstaunliche consequenz weisen $\alpha$ ), $\beta$ ) und $\gamma$ ) auf in 1.2.4.5.14a.15 b. 18.21.23; a) und $\gamma$ ) in 6.7.11. $28 \mathrm{a} \cdot$ Eine differenz zeigt nur 27 (feunf - finf). Eine sonderstellung nimmt $\beta$ ) ein, indem es in 6.7. 13 c. 14 b. 26 a zum teil eine mischung $z$ wischen den in $\alpha$ ) und $y$ ) einerseits und den in W. andrerseits herrschenden eigentumlichkeiten darstellt. Nur für $\beta$ ) $14 \mathrm{~b}$ und $15 \mathrm{c}$ sind in W. keine parallelen. Es war also $\beta$ ) aus $W$. oder wegen $14 \mathrm{~b}$ und $15 \mathrm{c}$ aus einer mit dieser fast identischen hs. in die zweite vorlage des Vorauers schreibers aufgenommen worden.

Dass nun $\alpha$ ) und $\gamma$ ) inh altlich aus verschiedenen elementen bestehen, war längst bekannt, indem Diemer, Einl. 8. XL, nachdem er den titel 'Bücher Moses' fur das 'ganze gedicht' motiviert, die einzelnen abschnitte bezeichnete als schöpfung, sündenfall, geschichte Jacobs und Josephs, 'der geschichtliche teil der tubrigen bucher Moses in noch mehr verkurzter form und mit vielen beziehungen auf das neue testament, und insbesonders auf den messias und die hl. jungfrau.' - 'Wichtig ist die hymne auf die letztere.' - 'Hierauf kommt die geschichte Balaams etc.' Zunächst trennte nun Mullenhoff die 'Hymne auf Maria' los und nahm sie unter dem titel 'Marienlob' als selbständiges gedicht in die denkmäler auf (II nr. 40; vgl. die anm.). Sodann stellte Scherer als pendant zu seiner theorie von den 6 verfassern der Wiener Genesis (Quell. u. forsch. I) in Quell. u. forsch. II die ansicht auf, es zerfielen die 'Bucher Moses' in folgende einzelgedichte von verschiedenen verfassern, wovon wider einige die vorhergehenden gekannt und auf sie rücksicht genommen hätten: 1. Genesis von 2 oder 3 verfassern, worüber Scherer selbst nicht im klaren ist, - Diemer 8. 3-31; 2. Joseph in Aegypten = Wiener sitzungsberichte a. a. o.; 3 . Moses $=$ Diemer $32,1-69,6$; 
4. Marienlob $=69,6-72,8 ;$ 5. Balaam $=72,8-85,3$. Die grtunde Scherers fur diese trennung sind ziemlich allgemeiner natur und nirgends bestimmt formuliert; sie reducieren sich eigentlich auf die stoffliche verschiedenheit resp. zusammensetzung, auf welche schon Diemer a. a. o. hingewiesen hat, und die niemand bestreiten wird. Nur zur 'Genesis' Scherers ist s. 45 erwähnt: 'wahrscheinlich wird schon die metrik schärfere unterscheidungen an die hand geben', eine untersuchung ist jedoch nicht angestellt.

Die unhaltbarkeit der Schererschen theorie in bezug auf die Wiener Genesis, wo die grunde etwas reichlicher fliessen, hat Vogt in den Beitr. II auch nach der metrischen seite unzweideutig nachgewiesen. Auf grund der obigen orthographischen zusammenstellungen glaube ich nun behaupten zu können, dass auch die sog. 'Bucher Moses' als einheitliches gedicht aufzufassen und als ein ganzes gewollt sind. Ich argumentiere einfach folgendermassen: die fast totale ubereinstimmung der orthographie und der formen in $\alpha$ ) und $\gamma$ ) darf nicht als zufall gelten; sonst kann man alles als zufall erklären und literarische forschung uberhaupt unterlassen. Woher kommt also diese ubereinstimmung? Zunächst wird man sagen, sie sei von dem schreiber der vorlage $B$ hergestellt. Warum weicht aber dann $\beta$ ) von dem vorhergehenden $\alpha$ ) und dom folgenden $\gamma$ ), die gleich sind, ab? Nun, dann ist sie von dem sammler der einzelnen stlicke des complexes $B$ oder von dem letzten dichter hergestellt. Wie ist aber dann zu erklären, dass $\beta$ ), das dritte, resp. vierte stluck, nach Scherer, der aufgenommene Joseph, von den vorhergehenden stlucken $1-3$ und von den folgenden 5-7, die ubereinstimmen, in consequenter weise abweicht? Ein sammler oder der dichter des letzten stucks hat unmōglich einzelne teile in der schreibung total normalisiert, einen andern aber nicht. Damit kommt man nicht durch. Die ubereinstimmung von $\alpha$ ) und $\gamma$ ) kann nicht absichtlich hergestellt sein, sondern sie ist ursprunglich, und das ganze ist einheitlich concipiert. So erklären sich die vorliegenden verhăltnisse auf die einfachste art von der welt: ein geistlicher fand geschmack speciell am 'Joseph' der Wiener bearbeitung; er schrieb sich denselben ab, und es mischte sich unwillkürlich seine schreibweise mit der der Wiener hs.; er 
schickte dann selbständig eine kurze genesis voraus und liess nach dem Joseph diejenigen scenen aus dem II. und III. buch Moses folgen, die sich ihm besonders fur geschichtlich-epische darstellung zu eignen schienen, und man wird sagen müssen, dass diese auswahl nicht ohne geschick vollzogen ist. - Es handelt sich nun speciell um das 'Marienlob', welches wenigstens dem gewählten titel nach, lyrisch ist, und wenigstens nach Mullenhoffs auffassung aus funf strophen zu 24 zeilen besteht. Zunächst ist wol die stattliche anzahl von zeilen bedenklich; sodann wäre es ein leichtes, aus den gesammten buchern Moses bei ihrer meist paratactischen redeweise, wo man fast uberall aufhören kann, strophische form herauszuklauben, zumal wenn man sich die freiheit nimmt, in etwa je 100 versen eine lucke von 3 zeilen und umstellung anzunehmen, ohne dass der sinn irgend dazu zwingt, wie es Mullenhoff in der ersten 'strophe' tut. Was nun den lyrischen inhalt betrifft, so sagt selbst Scherer, Quell. u. forsch. XII, 68: 'Marienlob erhebt sich erst in der funften und letzten seiner langen strophen zu einigem lyrischen schwung.' Nun, einigen lyrischen schwung wird man doch selbst dem prosaischsten dichter bei diesem gegenstand zutrauen durfen, in einer zeit wo der Mariencultus immer gluhendere formen annahm, wo jeder, als ein kind seiner zeit, redete in einer sprache, die fur ihn dichtet und denkt. Aber, was weder Mullenhoff noch Scherer sagt, es ist auch anlass vorhanden, uber Maria zu sprechen, und es liegt eine sehr geschickte einleitung dazu vor. Scherer erwăhnt a. a. o. nicht, dass Josua - iosve 65,1 und 66,4 nach dem nicht ohne teilnahme geschilderten tod Mosis immer in der form iesus auftritt: 67, 18. 67, 24. 68, 4. 68, 9. 68, 29. Erst Rōdiger bemerkt es Anzeiger f. dt. altertum I, 77 und will deshalb, wie er das erste Scherersche stuck der Wiener Genesis nochmals in 2 zerlegt, nun auch hier mit 67, 15 ein neues gedicht beginnen. Er sagt: 'wird derselbe dichter den namen seines helden in 2 formen gebrauchen?' Ich antworte darauf: hătte ein fortsetzer, der auf die vorhergehenden sttucke rticksicht nimmt, oder ein sammler die versehiedenen namensformen stehen lassen? Auch beim Nibelungenlied wurde ja mit recht darauf hingewiesen, dass es gerade in der natur eines redigierenden sammlers liegt, kleinigkeiten und äusserliche uneben- 
heiten zu ändern und zu beseitigen. Meiner ansicht nach hat der dichter im verlauf der erzählung mit bewusster absicht Josua und Jesus gleichgesetzt, indem er die taten des ersteren auf das erlösungswerk des letzteren symbolisch ausdeutet. Ein directer hinweis auf diese parallele liegt in den worten:

\section{7, 20: 'er was ein also gut man. \\ so er gote zeineme genannen wole zam.}

Auf den erlöser geht: 'Jesus der gůte hirte' 68,4 . So ist Jesus eingefuhrt, von welchem der dichter mit der prophezeiung seiner geburt auf Maria abergeht. Nachdem er ihr lob mit den tublichen bildern verkundet, spinnt er den faden der reinepischen erzählung im Balaam weiter.

In der orthographie und in den formen ist das 'Marienlob' total mit dem vorhergehenden 'Moses' und dem folgenden Balaam identisch. Wollte man trotzdem und trotz der oben angegebenen grunde nur die reinerzäblenden teile als einheitliches werk gelten lassen und das 'Marienlob' als eingefugt vindicieren, so ist dies eben unmöglich, weil die andre einfugung, der Joseph, in der orthographie nicht normalisiert ist, was dann auch hier der fall sein mulsste.

Wenn Scherer, Quell. u. forsch. VII, 45 zu der ansicht kommt, dass der zweite teil seiner 'Vorauer genesis' an der benutzten stelle des Joseph die lesart der Vorauer, nicht der Wiener hs. voraussetzt, so erklärt sich das bei dieser einheitlichen auffassung des gedichts von selbst, indem eben der dichter seiner ihm vorliegenden und dann aufgenommenen abschrift des Joseph folgte.

Auch Rödigers ansicht, dass alle teile aus Kärnten stammen (Anz. f. dt. altert. I, 68), kann man sich bei einheitlicher auffassung gefallen lassen, obwol seine grunde kaum gentigen.

$\mathrm{Zu}$ widersprechen ist jedoch der meinung Scherers, welcher unter anderm Quell. und forsch. XII, 98 gliederung nach dem bedurfnis der predigt aunimmt: diese ist fernzuhalten, weil in der natur der predigt eine asketische richtung liegt, den 'Buchern Moses' aber eine solche durchaus abgeht. -

Bei der obigen zusammenstellung der schreibungen wurde $\gamma$ ) stillschweigend nur bis 83,27 beigezogen, weil mit dem rest $83,28-85,3$ blatt 96 der hs. beginnt, das letzte der 12. lage, welches wie das erste derselben, bl. 89, von dem jungern 
schreiber erneuert wurde. Der inhalt lässt jedoch keinen zweifel dartiber auf kommen, dass die verse $83,28-85,5 \mathrm{zum}$ 'Balaam', bezüglich nach unsrer auffassung zum ganzen gedicht der 'Bucher Moses' gehören. Die eigentumlichkeiten der schreibung dieser partie finden mit dem tubrigen, was von diesem jungern schreiber berruhrt, besprechung unter:

\section{DIE WAHRHEIT}

(= Diemer, s. 85,4-9,10).

Mullenhoff bemerkte in den Denkmålern ${ }^{2}$ s.438 (1390), nachdem er von der in die Vorauer hs. aufgegangnen 'sammelhs.' der Bücher Moses gesprochen: 'Charakteristisch fur die orthographie dieser hs., mit ausnahme etwa des letzten stücks, der Wahrheit, ist etc.' Factisch ist nun ja diese sonderstellung der Wahrheit richtig, causal aber nicht, und sie musste die falsche vorstellung hervorrufen, der schreiber der hs. sei sehr inconsequent verfahren. Es erklärt sich die sonderstellung aber auf sehr einfache weise, indem eben von 83, 28-90,10 jener jungere schreiber, wir wollen ihn y nennen, das erste wie das letzte blatt der abgegriffenen lage nachtrug, und zwar nicht ohne änderungen. Mullenhotf also fasste das gedicht als zur sammelhs., nach unsrer bezeichnung zum complex B gehörig, auf. Scherer folgte ihm, indem er Quell. u. forsch. VII, 28 bei einem summarischen tiberblick taber die Vor. hs. sagt: 'als solche fruberen sammelhss. sind zu erkennen: 1. die nachfolgenden nummern II-VII', und VII ist bei ihm eben die 'Wahrheit': s. s. 51. Die behauptung beider gelehrten ist jedoch gänzlich unmotiviert. Die ganze 'Wahrheit' ist nămlich, eben auf bl. 96, durch die hand von y gegangen. Will man also uberbaupt ein urteil uber das gedicht fällen, muss man zunäcbst constatieren, welche eigentumlichkeiten $\mathrm{y}$ in den sonst von ibm geschriebenen partien in den text hineingebracht hat; alles diesem entsprechende ist dann abzuziehen, d. b. ausser betracht zu lassen, und bleibt dann noch charakteristisches ubrig, kann vielleicht danach entschieden werden, ob das gedicht als der vorhergehenden oder folgenden vorlage angehörig oder als fitr sich in einer vorlage befindlich anzusehen ist. Auf diesem wege ergeben sich folgende tatsachen: Von y ruhrt her: bl. 1 und 8 der ersten lage = Kaiserchronik 
$1,1-9,9$ und $55,5-62,18$, und blatt 1 und 8 der 12. lage, $=$ bl. 89 und $96=$ Bucher Moses, Diemer 39,12-45, 22 und $83,28-85,3$, und dazu die 'Wahrheit' s. $85,3-90,10$. Ich stelle nun die eigentümlichkeiten der 'Wahrheit' zusammen nach dem gesammtschema und bemerke unter jeder einzelnen rubrik, worin $y$ in der Kaiserchronik ( $K$. Chr.) und in den 'Buchern Moses' (B. M.) auf den genannten seiten von der dort sonst herrschenden schreibung abweicht (vgl. die tabelle). $\mathrm{Zu}$ beachten ist der kleine umfang der Wahrheit, welche in der hs. nur 147 zeilen ausmacht, so dass einzele rubriken unausgefullt bleiben.

1. ei. ei, ai, aei;

y K. Chr. $e i, a i, a i$;

y B. M. $e i, a i, a i$.

2. ou. $o^{v}, \stackrel{\circ}{v}$, ov

y B. M. $o^{v}$.

3. iu. iv, iu, ev, $u$;

у B. M. $i u$, $i v$.

4. ie. ie, $i$

y B. M. ie.

5. a. Gewöhnlich $e$; einige $i(8) ; 2$ uer-, 1 vir-, 3 v'; 3 er-;

y K. Chr. einige $i$;

y B. M. er-, ver-, $v^{5}$ (abbreviatur).

6. Umlaut von $a$ immer als $a, e$. -trehtin 86,16 .

y B. M. von $\hat{a}$ : $\boldsymbol{a}$, e; -eht-.

9. Synkope: ewgen 88,17 ; alrslaht 88,22 ;

y B. M. lebte 41,23 ; menske 42,7 .

10. Abschwächung der nebenvocale: part. sw. v. -ot- niemens 89, 9.

11. Svarabhakti: durich 86,$11 ; 87,25$;

y B. M. durich 84,11 .

12. Accente. 4 circumflexe in lât 86,18 ; grôz 86,27 ; spête 87,$11 ; \hat{e} 88,12$.

13. Dentale. a) Im anlaut fur $t$ - 2 mal $d$ - in dievel 86,16 ; dumben 87, 3 (vgl. nhd.). Umgekehrt $d$ - als $t$ - nach $-z$ in daz, tunchet 90,6 .

c) $-n t$ - wechselt mit $-n d$ -

d) -lt- bleibt. 
14. Labiale. a) $b-: 14 b$-, $1 p$-. Im auslaut therwiegt $-b$.

y B. M. $b$ - entschieden uberwiegend.

b) $u=f<p$ : nicht.

c) $w u$ - orscheint als $w$ -

y K. Chr. $w$ - bevorzugt.

y B. M. wnschen 85,3 ; soren $43,26$.

d) $s w$ - etc. swederes 86,7 ; swer 87,3 .

y B. M. bedwnge 84,5 .

15. Gutturale. a) $k$ : wechsel zwischen $k$-, ch-.

b) $g$ im auslaut -ch.

c) $q u$ - verschmolzen in chollen 87, 24; (c)humt 89; 27.

16. Assimil. in ummere 86,18 .

20. wellen. welt 87,12 ; wolt ir 86,19.

21. mugen. muget $86,12.87,7$; muge wir 88,11 .

23. wurken. y B. M. warehten 43,15 .

26. Flexion. b) Die erste plur. zeigt apokope: hab wir; sul wir; ker wir; dench wir; wolt wir; У B. M. sul wir 43, 19; var wir 43, 22.

27. Zahlwörter. fivnf 86,4 .

y K. Chr. suben 3,10. 3,12. 4, 11 .

y B. M. funf 41,8 ; finf 42,1 .

28. Sonstige einzelne wörter: a), b), c), d) fehlen.

29. Varia. $\mathrm{Zu}$ erwähnen ist: a) ine 85,25 , anlehnungsproduct aus ich ne.

b) Die schreibungen immer $85,23.88,11.88,23$; nimmer $86,10.88,9$.

c) Einmal $e i<$ altem $\hat{\imath}$ : liebe (l. lîbe) : leiden 90,4, wozu kommt:

y K. Chr. weistům 1,8; bei 2, 21; leibe 4,34; cilte 5, 20; reiche 56,10 .

y B. M. troehtein $41,22$.

d) $o v<$ altem $a$ in $o v z 87,20$.

y K. Chr. (ausser dem dort immer ublichen $o^{\circ} f$ und bo wen vgl. A $29 \mathrm{~g}$ und schluss von L) $o^{\circ} z 5,22.7,19 ; h o^{\circ} s$ 6,$3 ; 0^{\vee} z z e r 7,31$.

y B. M. $o^{\circ} f 44,24$.

e) $c=z$ in churcen citen 87,7 .

y B. M. hochcite 42,11 ; cimberunge 84,11 . 
f) Bei y sei hier erwähnt fransmi̊te 84, 8 gegen franspưte Joseph 122, als chronologisch interessant: es hätte sich demnach die umdeutung dieses wortes von der mitte bis zum ende des 12. jh. vollzogen (vgl. Lexer, Mhd. wb.: 'framspuot verderbt in fransmuot').

So schmilnt dasjenige, was in der schreibung der 'Wahrheit' eigentumlich sein konnte, nicht musste, bevor sie durch die bände von y gieng, auf weniges zusammen. Es sind etwa die nummern 12.13 a. 13 c. 14 a. 15 b. 20. 26.b. 29 a.b. Nur mit diesen darf gerechnet werden, und es frägt sich nun, ob man durch sie berechtigt ist, die 'Wahrheit' fur die vorhergehende (B) oder für die folgende vorlage (D) in anspruch zu nehmen. Um auf einzelnes einzugehen, kann 12 nichts entscheiden, weil in $\mathrm{B}$ wie in $\mathrm{D}$ (s. u.) circumflexe vorkommen. In $13 \mathrm{c}$ stimmt $\mathrm{y}$ mit dem sonst in der Kaiserchronik und den 'Blichern Moses' herrschenden brauch uberein; es ist also sehr möglich, dass der wechsel $n t-n d$ ihm adäquat war, und nichts daraus für $\mathrm{C} z u$ schliessen. Was $15 \mathrm{~b}$ und $15 \mathrm{c},-g>-c h$ und verschmelzung von $q u$ - betrifft, liegt dasselbe in B und D vor. Die form wolt in 20 bietet weder in $B$ noch in D anknlupfung.

Die synkopierten formen hab wir, var wir etc. 26,6, sind deshalb nicht schwerwiegend, weil sie unter 9, synkope, gestellt werden können, zu der ja y hinneigt. Dagegen kann $13 \mathrm{a}$, ein anlaut. $t$ - als $d-; 14 \mathrm{a}$, das uberwiegen von auslaut. $-b ; 29 \mathrm{~b}$, die schreibung immer, nimmer als hinweis auf $\mathrm{D}$ (s. dort) gefasst werden. Ich glaube jedoch nicht, dass diese momente genügen, die 'Wahrheit' der vorlage D zuzusprechen, obwol sie auch inhaltlich derselben nahe steht. Das jedoch ist sicher, dass absolut kein grund vorliegt, das gedicht mit Scherer und Mullenhoff der vorlage B zuzuschreiben: sie wurden dazu nur gefuibrt, indem sie den jungeren schreiber $y$ nicht beachteten, durch den eine äusserliche anknupfung vorliegt, indem der schlussteil von $B$ eben auch durch die hand von y gegangen ist.

So ist man gezwungen, die 'Wahrheit' allein zu stellen, indem auch 20, wolt ir, und 29 a, ine < ich ne fur eine sonder: stellung zu sprechen scheinen. 
Nun sieht es vielleicht befremdend aus, fur ein so kleines gedicht eine besondre vorlage anzunehmen, aber es ist noch gar nicht ausgemacht, ob dies gedicht uberhaupt ursprtinglich so klein war. Es schliesst mit dem letzten blatt der 12. lage, auf dessen rückseite nur 42 zeilen entgegen den sonstigen 46 stehen; das ist auffallend, macht aber nicht notwendig, dass dies auch auf dem ursprünglichen blatt der hs. so war, da die von dem jüngern schreiber y erneuerten blätter widerholt lücken zeigen (Diemer, Einl. V), was sich aus unleserlichkeit der ursprünglichen blätter in folge der abnlitzung erklärt; am meisten konnte davon natürlicherweise der untere rand des deckblatts der lage, der als handgriff diente, betroffen werden. Nun beginnt aber mit der folgenden lage ein neues gedicht, und es ist möglich, den ausfall einer oder mehrerer ligen anzunehmen, weil dieselben entgegen dem latein. teil der hs. nicht nummeriert sind (Diemer, Einl. III), und der inhalt es nicht ausschliesst. Nach Scherer zwar ist die 'Wahrheit' abgeschlossen; mir jedoch scheint Diemer entschieden richtig gefüblt zu haben, wenn er sagt (Einl. s. XL): 'Nach dem vielversprechenden eingang: No wil ich bitten den got. der von den iuden wart gemarterot. daz mir uerlihe den sin. daz ich mizze chundin. den armen und den richen. di chunft fraisliche. den iungen ioch den alten. was uns ist behalten. wa wir sulen enden ... sollte man eine ausfuhrliche schilderung des jungsten gerichtes erwarten, die hier jedoch nicht folgt'. Der dichter weist nach diesen worten auf die allgemeine verderbtheit hin (s. Scherers paraphrase). Dann folgt Diemer s. 90, 7: 'des rates wil ich abegan. vil michel iamer miz mich han. daz also maneger miter barn. in die helle sol varn.' Der rât, die rede ins gewissen, ist fertig, und nun hätten eben die ausmalung der hölle, die annoncierte chunft fraisliche folgen sollen. Zwingend ist diese beweisführung nicht, wie jedwede ästhetischer natur, aber den ausfall einer lage anzunehmen, hindern die verhältnisse der hs. keinesfalls.

\section{SUMMA THEOLOGIAE. SALOMO. NABUCHODONOSOR}

(= Diemer, Dt. ged. s. 93-123 = MS D. XXXIV-XXXVII).

Warum ich diese benennung der vorlage $D$ wählte, und dass ich sie wählen musste nach meiner überzeugung, wird 
sich später zeigen. Bei der zunächst folgenden zusammenstellung der schreibungen und formen ist unter $\alpha$ ) 'Summa theol.', unter $\beta$ ) 'Salomo', unter $\gamma$ ) 'Nabuchodonosor' zu verstehen. Nach den Denkmälern zerfällt das letzte stuck, welchem Diemer den gesammtnamen 'Aeltre Judith' gab, in 'Drei juinglinge im feuerofen' und 'Judith', welche nōtigenfalls als $\gamma_{1}$ und $\gamma_{2}$ bezeichnet werden.

1. ei. a) $49 e i, 3 e, 1 a .-6 e i=e$. - Von diesen $3 e$ erscheinen 2 in nebentonigen silben: urtheli 102,16; urthel 102, 20, nur eines in hochton. silbe: bisuech 96,15, im reim: giweich. Warum in MSD, Summa theol., str. 11, bisuêch stehen bleibt, ist bei der sonstigen uniformierung nicht $\mathrm{zu}$ begreifen: in beiden fällen handelt es sich um $e i$ vor $c h<$ urgerm. $k$, wo nach der allgemeinen regel im gegensatz $\mathrm{zu} e i+h<$ urg. $h$, das $e i$ im hd. erhalten bleibt. - Die fälle $e i=e$ sind: eingili 94, 7. 95, 25; eingil 94,11. 94, 20. 96, 25; meinnischeit 97, 9.

B) $29 e i, 3$ e. $-2 e i=e$. e bietet enim 109,13; gistenis 111,2 ; nihenis 112,1. $-e i=e$ in meiri 112,26; eingili 113,8 .

r) $18 e i, 3 e .-3 e i=e$; und zwar:

$\left.\gamma_{1}\right) 7 e i, 2 e .-1 e i=e$.

$\left.\gamma_{2}\right) 11 e i, 1 e .-2 e i=e$.

Im einzelnen zeigt e: eni 117,13; eddin 118,13; hezzit 120,11; $e i=e:$ deim 118,18; eingil 122, 28; geinc (imperat.) 123, 4. Mit dem obigen zusammengeslellt, ergibt sich, dass $e i$ für $e$ uberwiegend vor nasal + cons. erscheint. Ueber den nachklang von $e$ und $i$ nach verschiedenen vocalen, was besonders rheinfränkisch ist, vgl. Weinhold, Mhd. gr. § 105 ff.; Paul, Mhd. gr. $\$ 101^{2}$.

2. ou. In $\alpha$ ), $\beta$ ), $\gamma$ ) immer ou (nie ov), mit ausnahme von iro"gin 94, 2. Ebenso durchgehend ist die gruppe -owi. Also bis auf diese einzelheiten erstreckt sich die consequenz.

3. $i u$ ist vertreten durch: $\alpha) 27 u v, 12 u, 3 i u, 3 e v, 1 u i$ (luiti 102, 14).

B) $22 u v, 9 u, 3 u i, 1$ iu, 1 eu (leuth 107, 17); $1 u i=u o$ in snuir (hs. suuir) 109, 23.

$\left.\gamma_{1}\right) 13 u v, 1 u, 1 u i$ (luithin 117, 19). In 3 fällen lässt Diemer in der schwebe, ob ui oder iu zu lesen ist $(117,16$. 118, 19. 118, 25). 
$\left.\gamma_{2}\right) 19 u v, 10 u, 1 i u, 1 u i=\hat{u}$ (thuisint 120,9). - Vgl. Weinhold, Mhd. gr. § 120: 'Fur oberdt. iu hat das mitteldt. im 12. 13. ff. jh. die vereinfachung $\hat{u}$ durchgefuhrt.'

4. ie erscheint nur als $i$ in $\alpha$ ), $\beta$ ), $\gamma$ ); ausgenommen ist natürlich 'Jerusalem', hierl'm 108, 22. 112, 15, worin man einen beweis sehen mag, dass auch damals kein diphthong, sondern je-gesprochen wurde. - Unetymologisch steht ie in uffriecht $96,6=$ aufrecht, wobei vielleicht der schreiber ufrihtic und ufreht momentan vermischt hat.

5. a verschwindet fast ganz gegen das herrschende $i$. Beispiele fur a sind in $\alpha$ ) vater 93,1 ; minne 96,15 ; armen 101,12; $\beta)$ unde 107, $2 ; \gamma$ ) irchomen 120,17. Der artikel hat gewöhnlich $e ; i$ nur in $\alpha) \operatorname{dim} 93,13 ; \operatorname{din} 103,7 ; \beta) \operatorname{dim} 111,18$; r) din; dir 122, 17. - Die partikel dar, der, welche explicativ zum relativpronomen tritt, lautet immer dir; z. b. der dir 94, 29. - Ueber $\min =$ men, abgeschwächte form von man s. unter 10.

6) Im umlaut von $\hat{a}$ besteht wechsel zwischen $a$ und $e$ : a) $3 e$; 3$\left.\left.) 3 e, 2 a ; \gamma_{1}\right) 4 e, 1 a ; \gamma_{2}\right) 2 e, 2 a$. - Allein zu belegen ist -alt-in umlautsfähiger stellung; in $\alpha) 3$-acht-, 1 -echt(almechtig 95,1); in $\beta$ ) ein -acht- in slachti 108, 15.

7. Contraction mit production eines diphthongen ist nicht eingetreten. Der form mancraft 93, $4<$ magencraft vergleicht sich im 'Joseph' B 7 gesan $<$ gesagen. - Ueber heit $=$ hat 108,19, das uberhaupt nicht hierherzustellen ist, s. unten.

8. Die gruppe -or- ist erhalten.

9. Synkope ist gewöhnlich nicht eingetreten, vgl. $a$ ) bilidi 94,$13 ; \beta$ ) dinisti 112,$21 ; \gamma_{1}$ ) menigi 119,$\left.5 ; \gamma_{2}\right)$ 121,18. -

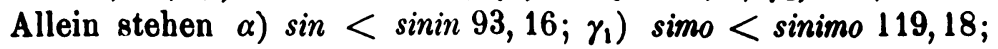
$\left.\gamma_{2}\right)$ ein $<$ einin 122, 28.

10. Abschwächung der nebenvocale. Gewöhnlich ist im swv. -oti, -ot. Die endung des dt. sg. m. n. der pronom. u. st. adj. flex. ist -mo. Auf gleicher stufe steht herro, durch welches nämlich in $\mathrm{D}$ das wort trehtin vertreten wird. Auf diese verschiedenen formeln als trennungskriterien weisen hin $\mathrm{MSD}^{2} 381$.

11. Svarabhakti ist selten; zu nennen ist: gérini 102,24; heliwin (spreu) 102, 25; zesiwin 103, 2; werihi 117, 2 (MSD XXXVI, 1, 2 ăndert in werldi). 
12. Accente. Circumflexe fehlen mit ausnahme von a) $\hat{e}$ 97, 4 und $\beta$ ) wîth 108,5.

13. In der scheidung der dentalen herrscht keine vollständige consequenz, jedoch ist fur $\alpha$ ), $\beta), \gamma$ ) deutlich als urspribnglicher zustand zu erkennen:

a) Urgerm. $d$ : im anlaut $=d-$, inlaut $=-t$-, auslaut $=-t$. Dieser lautstand liegt bekanntlich bei Otfrid vor und fluhrt zur abtrennung des südfränk. dialects (vgl. Braune, Beitr. I). Im widerspruch scheinen die formen mid und midi zu stehen, welche fast allein vorkommen. Jedoch ist für dieses wort grammatischer wechsel anzunehmen; ebenso steht es mit adim 93,16 (vgl. Kluge, Etym. wb. unter 'mit' und 'atem'). Nach der obigen übereinstimmung mit Otfrids schreibung könnte man erwarten, dass auch th- als vertreter von urgerm. $b$ - fungiere: es ist jedoch immer durch $d$ - vertreten, und th erscheint wol $23 \mathrm{mal}$, aber immer $=$ urgerm. $d$, so dass es gleichsteht mit dem hier in- und auslautend sonst eingetretnen $t$; denn es erscheint nie im anlaut, ausser in thusint 111,21 und thuisint 120,9 , welches wort überhaupt in seiner entwicklung von got. pusundi zu mhd. tûsent schwierigkeiten bietet. - Geminiertes - $d d$ - ist erhalten in eddilichin 107, 4; eddin (heitzen) : leiddin 118,13 ; meddewaz (wofur Diemer und Scherer lesen: in eddewaz) 123,7 .

b) $d w$ - bietet nur giduanc 99,23 .

c) Die gruppe - nt- ist nicht erweicht, ausser in undin und under, $3 \mathrm{mal}$ in $\alpha$ ), $1 \mathrm{mal}$ in $\gamma$ ), und $3 \mathrm{mal}$ sundin in $\alpha$ ). Die partikel und entzieht sich meist in der abbreviatur un der feststellung.

d) Die verbindung -lt- ist nicht orweicht. Einmal liegt woldi 96, 23 vor, welches aber ja anders aufgefasst werden kann.

14. Labiale. a) Im anlaut herrscht durchaus b-, woneben nur 1 poumi 95, 22 tritt. Ebenso durchgängig ist $-b$ im silben-, wie im wortauslaut in $\alpha, \beta, \gamma$.

b) $f<$ urgerm. $p$ ist häufig durch $f f$, hie und da durch $p h$, nie durch $v$ oder $u$ vertreten. - Anlautendes $p$ - ist unverschoben in plagin 110,24 und plichti 113,21.

c) Die gruppe $w u$ - ist immer durch $w$ - widergegeben.

d) Die verbindung $s w-, z w-, d w$ - durch $s u-, z u-, d u-$. 
15. Gutturale. a) $k$ und ch wechselt im gesammtrerhältnis von $3: 1$. Im besondern ist zu erwähnen: gismag 96, 3; qnechti 112,5; gnechtin ( $g$ für $q$ ?) 120,15.

b) $g$ schwankt im auslaut zwischen $-g,-c,-c h$, und zwar: a) $14 g, 3 c, 2 c h$; $\left.\left.\beta) 2 g, 4 c, 2 c h ; \gamma_{1}\right) 2 g, 5 c ; \gamma_{2}\right) 2 g, 6 c$, 2 ch. Nur $\alpha$ ) bietet so eine merkličhe differenz.

c) Die verbindung $q u$ - ist immer verschmolzen (13 fälle; praeter. chom).

16. Als assimilation kann gelten: uorchlichi 94,26 ; sellin 100, 8 (vgl. $\mathrm{MSD}^{2} 410$; dialectisch heute seller), vielleicht jedoch nur verschrieben, weil selbo 94, 29 und selbes 98, 20 etc. daneben steht. Weiter ist zu nennen gammi < gab imi 95, 29 und ammichtis, welche assim. im md. sich fruber vollzogen hat: s. Weinhold, Mhd. gr. $§ 150.170$; Paul, Mhd. gr. $\$ 105^{2}$.

17. Metathesis ist nicht zu belegen.

18. Grammat. wechsel ist erhalten in zi heuini 103,13; larin 117, 5 (aber gilesin 117, 8).

19. Vom verbum sîn sind zu erwähnen drei formen wir birin.

20. Von wellen die 2. sg. wildu; prät. wolti, 1 woldi s. $13 \mathrm{~d}$.

21. Von mugen kommt vor: $\alpha$ ) mugin und mochti; $\beta$ ) mochti; $\gamma_{2}$ ) megin 121, 6 .

22. wizzen bietet nur wissi in $\beta$ ) 112,13 .

23. Von wurchen lautet das prät. und part. worchti und givorcht.

24. Von haben das prät. habiti; einmal hetti 122, 16.

25. Von stân und $g \hat{a} n$ kommen ausserhalb des reimes vor: $\alpha) 2 \hat{e}$-formen; $\beta$ ) 2 - $\hat{a}$-formen; $\left.\gamma_{1}\right) 1 \hat{e}$-form. Als imperativ fungiert genc, bezliglich geinc und stant 123, 2 .

26. Flexion. b) Die 2. sg. lautet auf $-s$ aus: $\alpha$ ) woltis $103,15 ; \beta)$ habis 107,$1 ; \gamma_{2}$ ) irlosis 123, 14 . Anlehnung des pron. zeigt nur hast 108, 2 und hastu 103,16. - Im infinitiv tritt in $\alpha$ ) mehrfach apokope des $-n$ ein, desgleichen in $\beta$ ).

d) suerigin : werigin 101,13 kommt nur in $\alpha$ ) vor.

27. Zahlwörter. Das femin. von 2 lautet zuv 100, 18; das neutr. von 3 immer druv, entsprechend der allgemeinen widergabe von iu (8. 3). Allein steht uimf 95,9; zuelf 111,20. 
28. Sonstige einzelne wörter. a) fur ist vertreten durch $\alpha$ ) uvirin 94,7 ; uuri $95,8.29 ; \beta$ ) fehlt; $\gamma_{1}$ ) fuvr 118, 15; fuir 118, 16. 119,3; uuri 118,18; $\gamma_{2}$ ) uur 120, 2.

b) biscof liegt vor in dieser form 121, 5 ;

c) lichname als lichami 102,3.7;

d) diemüete fehlt.

29. Varia. a) Zunächst ist auffällig, dass in $\alpha$ ), $\beta$ ), $\gamma$ ) sehr häufig ein zusammengehöriges wort getrennt geschrieben wird, was.sich nur eben in D vorfindet, und neben vielem andrem für den peinlich genauen anschluss des schreibers an seine jeweilige vorlage zeugnis ablegt.

b) Auf die schreibung uñ für unde ist bei $13 \mathrm{c}$ hingewiesen.

c) Durchgängig ist die verbindung ht durch cht yyidergegeben, was ebenfalls fur D charakteristisch ist.

d) Widerholt liegt a pok ope von $-t$ vor:

a) nich 100,27. Fälschlich wurden früher so aufgefasst die alten doppelformen wie $\alpha$ ) herschaf 94,14 ;

B) ginozschaf: herschaf 112,9. Die erscheinung entspricht dem fränk. dialect: vgl. Weinhold, Mhd. gr. § 183. MSD, Einl. XXI.

e) Merkwürdige formen sind emid 95, 20 und imidalli $100,10$.

f) Ueber $-t h$ - und $-t h=t$ s. 13 a.

Eine trennung des complexes D unter sich nach den hier zusammengestellten schreibungen und formen vorzunehmen, scheint mir nicht möglich; in betracht kämen zu diesem zweck etwa die nummern 6 (umlaut), $15 \mathrm{~b}(g), 25$ (stân), jedoch sind dieselben, zumal der unterschied nur im verschiedenen verhăltnis von nebeneinander vorkommenden erscheinungen besteht, gegenuber der sonstigen fast gänzlichen ubereinstimmung von verschwindender bedeutung. Scherer in den Denkmälern ${ }^{2} 414$ meint: 'Alle 4 gedichte weist ihre orthographie nach dem mittleren Deutschland; doch deutet eine anzahl von mundartlichen abweichungen auf verschiedene noch nicht näher zu bestimmende gegenden.' Seine argumente sind:

1. 'Drei junglinge zeigen mit Judith keine apokope des -e.' Dagegen ist zu bemerken, dass sie in den andern teilen 
nicht gewöhnlich ist, und dass in den 'Drei jünglingen' s. 119, 12 'dem ouini' steht.

2. 'Summa theol. zeigt kein $u i$ für $\hat{a}$ ': das ist allerdings richtig, aber auch in den andern teilen eine grosse seltenheit: im 'Salomo' snuir (hs. suuir) = snuor 109, 23; luithin 117, 19 in den 'Drei jüglingen' wird besser zu liuten als zu luten gezogen; in der 'Judith' kommt rur in betracht thuisint 120,9: also sehr wenig fälle.

3. 'Salomo allein hat ai für $\hat{a}$, heit für habit, karte für kêrte.' - ai fur $\hat{a}$ beschränkt sich auf urambairi (herrlichkeit) 112,14 , ein seltnes wort, bei dem verwechslung sehr leicht möglich war. Die wörterblicher geben sonst keine belege aus mhd. zeit (Otfrid frambâri). - Die form heit = hat 108, 19 scheint mir bedenklich. Die stelle lautet 108, $17 \mathrm{ff.:}$ 1. Ein herro hiz heronimus. 2. sin scripft zelit uns sus. 3. der heit ein michil wndir. 4. uzzir einim buchi uundin. 5. uzzir archely. 6. daz habint noch di crichi. 7. wi in hier $l^{\mathrm{s}} \mathrm{m}$ giscach ... Der syutaktische zusammenhang ist nun doch offenbar: 1. erzählung, 2. parenthese in präsens, 3. und 4. erzählung, 5. apposition zu buch, 6. parenthese in präsens, 7. erzählende ausfuhbrung von wunder. Es erscheint demnach eher hete uundin zu erwarten; um das anzunehmen, brauchte man heit fur het nur unter die rubrik $e i=e$ zu setzen (1); noch einfacher aber ist, heit als verschrieben aus heti oder aus hett $\mathrm{zu}$ betrachten, mit der so leichten verwechslung von $t$ und $i$, womit sich dann hetti 122, 16 vergleicht. - Mit der form karte endlich lässt sich gar nicht operieren; denn sie steht wol in den Denkmälern XXXV, str. 3. 2, ist aber von Mullenhoff construiert, und in der hs. steht keriti 107,16, was mit kerit er 94,15 in 'Summa theol.' und bicherin 118, 9 in den 'Drei junglinge' vollständig stimmt. Auf die grundlosigkeit der änderung hat schon Bartsch, German. IX, s. 62 aufmerksam gemacht.

4. 'Judith allein (hat) $\hat{a}$ - furr ar-'. Dies $\hat{a}$ erscheint nur in auelli 123,8, an einer uberhaupt sehr dunklen stelle; ardagegen in keinem teil, sondern nur ir-.

5. 'Summa theol. allein (hat) synkope und apokope des $-t$ : vorchlîchi, nich; $\dot{a}$ für $a i$, ei, schwanken zwischen $i$ und $e$, $l l$ für $l b$.' Ueber vorchlichî ist zu vgl. 16; apokope des -t liegt auch in andern stucken vor, s. $29 \mathrm{~d} ; a$ fur $e i$ zeigt nur 
gimanidi $=$ gimeinidi 95, 21 (gegenuberstehend 49 ei: s. 1); als beispiele fur schwanken zwischen $i$ und $e$ sind angegeben gibrist 95,2: es reimt zu ist und ist als wechsel zwischen $\ddot{e}$ und $i$ aufzufassen, der, ursprlinglich mit der flexion zusammenhängend, verschieden ausgeglichen ist: s. Paul, Mhd. gr. ${ }^{2} \S 42$. Dazu uffriecht 96,6, welches doch nur als verschrieben angesehen werden kann: vgl. 4. Jedenfalls sind die beiden fälle heterogen. Ueber $l l=l b$ s. 16 . - So liegen demnach hier ganz sporadische fälle vor, welche ebensowenig zu einer trennung berechtigen als eine nähere localisierung möglich machen.

Für die innere trennung von $\mathrm{D}$ bleiben so nur inhaltliche kriterien tubrig. Diesen und der handschriftlichen uberlieferung, d. h. den initialen und dem beginn mit neuer zeile folgend, hatte Diemer in 'Schöpfung', 'Salomo' und 'Judith' geteilt. Der 'Schöpfung' wurde in MSD der richtigere name 'Summa theol.' gegeben. Während hier das gedicht in 31 strophen von 10 zeilen auftritt, construiert Conrad Hofmann deren 32 unter vielfach anderer auffassung: Sitzungsber. d. Munch. akad. 1870 , bd. II, s. $186-196$.

Im 'Salomo' ist nach Mullenhoff die episode von dem drachen interpoliert; sowol Bartsch, German. IX, 63 als Conrad Hofmann s. 556 halten diese ansicht nicht für unmöglich, jedoch beide gelehrte bezeichnen es als einen widerspruch, das einschiebsel dann wider in strophen zu gliedern, indem die verfasser von zusätzen sich um solche regeln bekanntlich nicht kummerten. Unter der annahme, die stelle sei vom dichter selbst, stellt Conr. Hofmann mit sehr wenigen änderungen 25 strophen von 10 zeilen her. Ueber die quelle der episode hat Scherer, Zs. f. dt. a. XXII gehandelt. In der schreibung bietet sie gar keine differenz, so dass sie, wenn uberhaupt früher selbständig, jedenfalls in der vorlage der Vorauer hs. schon gänzlich verschmolzen war.

Als Diemer das dritte stuck 'Judith' nannte, hatte er wol bemerkt, dass darin 'die geschichte der drei männer im feurigen ofen' behandelt ist, und wies in der Einl. 8. 42 darauf hin. Scherer hat sodann in den Denmälern die stofflich verschiedenen teile auch äusserlich getrennt und als selbstãndige gedichte hingestellt ohne năhere angabe der grüde; nur in der 2. auflage 
s. 447 findet sich die bemerkung, die im grundriss von Koberstein-Bartsch ausgesprochne ansicht, dass beide gedichte ('Drei jlinglinge' und 'Judith') von einem verfasser herrubren, sei unbegrindet.

Sehen wir näher zu. Wer die einheit der beiden gedichte annimmt, hat zunächst die handschriftliche uberlieferung für sich. Aber auch inhaltlich lassen sie sich vereinen, wortber sich Conr. Hofmann in den Sitzungsber. d. phil.-hist. classe der Munch. akad. 1871, s. 557 f. folgendermassen ausgesprochen hat: 'Vor allem ist hier die frage zu stellen, mit welchem rechte die herausgeber (der Denkmäler), das stick, welchem in der editio princeps der titel "ältre Judith" gegeben war, in 2 teile zerlegt haben. Wenn man von dem titel, den Diemer geschöpft hat, ausgeht, so ist eine solche trennung allerdings gerechtfertigt; aber der titel steht ja nicht in der hs., und die beiden teile lassen sich sehr gut unter dem einen gesichtspunkt vereinigen, dass sie zu einer geschichte des Nabuchodonosor gehörten, welche den könig (eben dieses namens) des buches Daniel mit dem des buches Judith identificierte und aus den erzählungen beider ein ganzes machte, welches wider den gegensatz zur dichtung von Salomon bildete, als bild und gegenbild des berthmtesten und des berllchtigtsten königs des alten Testaments.'

Das gesammtthema wäre dann: Nabuchodonosor wird von gott zu schanden gemacht, und als grundidee hätten die verse Diemer, 118, 19-26: wir gi loubin ani den crist. der gi schuf alliz daz dir ist. der dir hiz werdin. den himil ioch di erdin. sin ist al der ert rinc. Kunic nabochodonosor dinev ab got sint ungehuiri ein druyi dinc. zu gelten, die sich in der Judith 120,27-121,3 wörtlich widerholen, nur dass hier ungihuiri fehlt. Um den 'Nabuchodonosor' aus der Judith, wo er unbequem, herauszubekommen, hilft sich Scherer mit der kunstlichen aufstellung: in den 'Drei jungl.' seien die worte: Kunic nabochodonosor interpoliert (MSD ${ }^{2} 426$ ), und die ganze stelle sei mit dieser interpolation 'in verhältnismässig später zeit' in die 'Judith' interpoliert worden (s. 428). Aber Nabuch. ist ganz an seinem platz der bibel entsprechend, und auch in der 'jungern Judith' (s. u.) wird s. 128, 3 diese als besiegerin von Nabuchonosors heer gefeiert. 
Weiter weist C. Hofmann auf den ungewöhnlichen, wider allen gebrauch der geistlichen dichtung gehenden anfang der abgetrennten 'Judith' hin und auf die ungebluhrliche änderung Ein kunic hiz Holoferni aus dem handschriftlichen: ein herzogi hiz holoferni. Steht doch Vulgata, cap. II, 4: '... vocavit Nabuchodonosor rex Holofernem principem militiae suae', welchem eben herzogi ganz genau entspricht. Aber 'herzog' konnte Scherer nicht brauchen, weil bei sonderstellung unerklärt blieb, von wem. Wenig vertrauenerweckend ist auch die bemerkung zu XXXVI, str. 2, 1, s. 425: ein kunic hiz Nab.: mit dieser formel werden nicht selten ganze gedichte, wie 'Judith', 'Solomo und der drache' oder auch einzelne abschnitte eingeleitet, wobei sehr merkwürdig ist, dass die beiden belege für den beginn selbständiger dichtungen eben nur nach der ansicht der herausgeber ein neues gedicht beginnen. Fur verwendung der formel mitten in begonnenem zusammenhang bei einfuhrung einer neuen persōnlichkeit bietet allein die Kaiserchronik zahlreiche beispiele.

Seite $427 \mathrm{MSD}^{2}$ wird behauptet, der dichter der 'Drei jüngl' habe sich auf einer höhern bildungsstufe befunden als der dichter der 'Judith', 'der nicht einmal die biblischen namen unentstellt widerzugeben wusste'. Dagegen ist zu bemerken, dass 1. auch in den 'Drei jungl.' unter 4 eigennamen eine entstellung vorliegt in misahel 118, 7 fur den Misach der Bibel (Daniel 3,12) und dass 2. in der 'Judith' auf 13 eigennamen nur eine vollständige entstellung, der bischof bebilin und dazu $3 \mathrm{mal}$ oloferni neben 2 holoferni kommt, welches letztere bei dem bekannten schwanken in der widergabe von $h$ - in fremden wörtern, wie auch in echt deutschen, nicht schwer wiegt. Selbst das mitgerechnet, liegt das verhăltnis $13: 4$ vor, welches sich mit dem andern $4: 1$ fast deckt, so dass nach diesem gesichtspunkte keine trennung vorgenommen werden darf.

Wenn weiterhin in Quell. u. forsch. XII, 41 'Judith' im gegensatz zu den 'Drei jungl.' zum lustigen schwank gestempelt werden soll, ist das sehr gesucht: das zechgelage ist in der Bibel vorgebildet, und auch in unserm gedicht ist der höhere zweck Judiths deutlich hervorgehoben. In den versen 122, 15 f.: 'der zenti saz uffin der banc. der hetti din win an der hant.' will Scherer MSD ${ }^{2} 430$ einen hinweis auf den spielmann, eine 
fabrikmarke der spielmannspoesie sehen. Er verweist dabei auf Parz. 33,16: 'zende an sînes tisches ort sâzen sine spilman.' An der ersteren stelle steht aber nur, dass der, welcher den wein ausschenkte, den Judith dann kredenzte, am ende sass; an der zweiten nur, dass die spielleute am ende sassen: beides sehr begreiflich, denn man wird keinem von beiden den ehrenplatz eingerăumt haben, und ein weiterer schluss ist bei mangelnder beziehung durchaus unerlaubt. Natürlich ist Quell. und forsch. XII, 41 der erschlossene 'spielmann' nicht vergessen.

Demnach ist die trennung in den Denkmälern unmotiviert, und die ansicht des grundrisses von Koberstein-Bartsch hat wol ihre grunde. Zur einheit stimmt das uberwiegen achtzeiliger strophen in beiden stticken, und als gesammttitel empfiehlt sich am einfachsten 'Nabuchodonosor', wie Conr. Hofmann a. a. o. s. 558 und 561 vorschlăgt.

Der dialect der vorlage $D$ ist nach den nummern 1 (nachklang von $i) ; 3(u v, u=i u) ; 5(i=2) ; 13$ a $(d-=t-;-d d-)$; $14 \mathrm{~b}(p l-) ; 14 \mathrm{a}(-b) ; 16(\mathrm{mb}>\mathrm{mm}) ; 29 \mathrm{~d}$ (apokope von $-t$ ) entschieden mitteldeutsch und zwar nach 13 a speciell rheinfränkisch.

\section{E. DIE SOGENANNTE JÜNGERE JUDTH}

$$
\text { (= Diemer, Dt. ged. s. 127-180). }
$$

Im anschluss an Quell. u. forsch. VII, 56-59 hat uber dies gedicht gehandelt Pirig, Untersuch. ab. d. sog. jüngere Judith. Diss. Bonn. 1881. Er bespricht I. die vorlage des gedichts und zeigt, dass die auffallenden abweichungen von der vulgata sich auf die benutzung von Itala-texten zurlickfuhren lassen; II. das verhăltnis des gedichts zur vorlage; III. textkritisches; IV. vers- und reimkunst, wo er die reime verzeichnet 'auf grund des mhd. vocalismus', ohne sich auf den dialect näher einzulassen. - Es folgt wider nach dem grundschema die zusammenstellung von schreibungen und formen, welche $\mathrm{E}$ sowol gegen $\mathrm{D}$ als gegen $\mathrm{F}$ scharf abgrenzen.

1. $e i$ ist vertreten durch $102 e i, 25 a i, 7 a i, 7 e$. Unter den letzteren ist 4 mal bediv, welches auch in der Kaiserchronik uberwiegt, und fur sich zu stellen ist: vgl. Weinhold, Mhd. gr. $\$ 63$. 


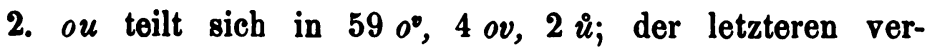
mischung entsprechend stehen umgekehrt $290^{\circ}$ und 4 ov fur uo; wozu widerum die Kaiserchronik entsprechendes bietet.

3. $i u$ ist widergegeben durch $214 i v, 9 e v, 8 u$.

4. ie durch 161 ie, $9 i$; dazu kommt ein falsches $i e=i$ in niedene $144,18$.

5. $a$ erscheint immer als $e$; dagegen uberwiegt $i z$ uber $e z$.

6. Bei umlautsfähigem $a$ wechseln $48 a, 18 e, 18 a$ und 2 ae. Ohne umlaut bleibt die gruppe -aht-, vorhanden ist er in -elt-.

7. Contraction ist nicht consequent: gegen 9 ei und 7 ai stehen 9 age; darunter unverdait 165, 7 und uerzeiten 177,1, welche nach Paul, Mhd. gr. ${ }^{2} § 179$ erst secundär eingetreten sind. Weiter ist $\mathrm{zu}$ nennen lit, git und reite < redete.

8. Die gruppe -or- ist zu -ar- gewandelt in: wart $157,11.164,28.171,28.177,6$ und in warden (geworden) 170, 7.

9. Synkope tritt in viel höherem grad als in D ein: z. b. helde 133,8; emzichlichen 142, 23; chemnaten 170,12; hint (hînaht) 172, 4; dienste 180,6; als specielle fälle sind zu nennen die präter. bette 151, 17 etc.; late < ladote 143, 17; batte < badote 161,6, wobei zu beachten ist, dass der stamm hier immer auf dental endigt (vgl. Kaiserchronik u. Bucher Moses nr. 9). Sodann synkope in der vorsatzpartikel ge- : gwalt 146, 15; gwant 161,5 ; gwonheite 171,9 ; gwis 172,6, neben dem geläufigen gnade $172,15$.

10. Abschwächung der nebenvocale zeigt sich v. a. darin, dass -ote sehr selten ist und der dat. sg. m. $n$. der pron. u. st. adj. fl. nur auf -me oder schon fast häufiger auf -m auslautet; dem entspricht herre 143,16. Beliebt ist iemen und niemen.

11. Svarabhakti zeigt nur phelegent 127, 8.12; chenehte 135, 9. 159,10; zawaincich 135, 3; den ahd. formen entsprechend geruwe : wichgeseruve 175,7 ; begaruwe 179,26 , so dass neigung zu chen', phel'- und 'ruw- vorhanden ist.

12. Accente. Ziemlich häufig ist circumflex, auch auf $\hat{\imath}=i e, \hat{\imath}-u o$. Fälschlich steht er in gôt 138, 27. - Accut steht einmal in ówi 157, 16 (vgl. Kaiserchronik) neben owi $156,19$. 
13. Dentale. a) $d$ - macht keine bemerkung nötig, ausser dass in $d a z$ tu 163,18; daz taz 167, 29; sistu 172,19 etc. assimil. an den auslaut des vorgehenden wortes vorliegt.

b) Die verbindung $d w$ - ist nur vertreten durch dwingen, welches $19 \mathrm{mal}$ mit $d w$-, einmal mit $t w$ - anlautet.

c) Die gruppe -nt- spaltet sich in $43 n d, 5 n t ; n t<n d t$, $n n t$ (sante etc.) in 9 nt und 4 nd (vgl. Kaiserchronik $13 \mathrm{c}$ ).

d) $l t$ ist nicht erweicht.

14. Labiale. a) Im anlaut uberwiegt weitaus $b$-, woneben in dem umfänglichen gedicht nur $8 p$ - treten; im auslaut streiten $22-b$ gegen $38-p$.

b) Urgerm. $p$ ist im inlaut immer durch $-f$ - vertreten.

c) Die gruppe $w u$ - immer durch $w$-.

d) Ueberwiegend ist die schreibung $d w-, s w-, z w-$.

15. Gutturale. a) Für einfaches $k$ herrscht $c h$, neben welches nur $1 c$ in clage 150,16 und $1 \mathrm{gh}$ in erghennent 155,8 tritt.

b) Ebenso entschieden uberwiegt $-c h<-g$ in 70 fällen gegen $4-c$ und $1-g$. Erwähnt sei: daz sach ich (sage ich) $152,11$.

c) Verschmelzung von $q u$ - ist immer eingetreten; präter. chom. Nicht in betracht kommt quaderstein 129,7 als fremdwort.

16. Assimilation ist (abgesehen von 13 a) nur zu erblicken in ureiste 132,16. 138, 14. 148, 24. 178, 10. Der ubergang von -sct- $>$-st- ist nach Paul, Mhd. gr. ${ }^{2} \S 71$, A. 5 alemannisch.

18. Grammatischer wechsel ist orhalten in heuen 164, 12; ausgeglichen nach verschiedener seite in erwerbe 163,11 und in erwive (conj. prä̈t.). Zum letzteren ist die Kaiserchronik zu vergleichen.

19. $\sin$ hat in der 2. pl. ind. birt, und im imper. weset.

20. wellen bietet die 2. sg. $d u$ wil; das prät. wolde, wie solde.

21. mugen hat im pl. präs. nur die formen mugen, im prät. 23 mohte und 4 mahte.

24. haben hat im prät. 28 hab(e)le; 14 hiete; 8 hete; heite 168,18 ist wol nur verschrieben aus hiete. 
25. Bei stân und $g a ̂ n$ stehen die $\hat{d}$-formen zu den $\hat{e}$-formen im gesammtverhältnis von $6: 1$.

26. In der flexion ist a) beim pers. pron. charakteristisch, das der acc. pl. m. der 3. pers. immer siv lautet, woneben 1 se 171,26 steht. Scherer verweist auf Heinzel, H. v. Melk 1,657. In der Vorauer hs. selbst ist zu vergleichen die Kaiserchronik und Arnolds gedicht (K).

b) Die 2. sg. lautet auf -st aus, wozu zwei sistu mit inclination des pers. pron. kommen. Diese zeigt auch mahtu 147, 5.

c) An präteritalformen ist zu nennen bette, batte, late, welche unter 9 besprochen sind.

27. Bemerkenswerte zahlwörter sind 4 mal uunf; 2 mal uivf; 5 mal zwaincich ohne reduction des diphthongen. Ueber cehencich gilt das bei der Kaiserchronik gesagte.

28. Sonstige einzelne wörter. a) fiur kommt nicht vor.

b) biscof aber $4 \mathrm{mal}$ und nur in der form biscolf: 141,8 . 141, 13. 177, 22. 178, 10.

c) lichname fehlt; d) diemüete hat im ersten bestandteil immer die-, nie diu-.

29. Varia. a) Sehr oft steht $c$ fur $z$ im an- und inlaut: so cehenzich 129,18; sicent 132,5 ; besicent 146,28; cierde 161,22 ; ce 166, 22; lucel 170,9; sicen: hicen 173,15; ceswe 179, 2 etc.

b) Bemerkenswert sind die formen ivht, nivh, nivt, neben nieht, nih.

c) Ferner $3 \mathrm{mal}$ older (= oder) 152, 29. 153, 1. 162, 23: nach Weinhold, Mhd. gr. $\$ 314$ eine alemannische form.

d) In bezug auf C 29 e uranspo ${ }^{\circ}$ lige 162, 11 .

Scherer fuhlt sich Quell. u. forsch. VII, 59 durch ou fur uo, $a$ fur $o$ vor $r$, das prät. hiete etc. an die Milstäter hs. erinnert; doch das gute liegt viel näher, indem die Kaiserchronik der Vorauer hs. diese eigentumlichkeiten reichlich bietet.

Es kann nach den obigen zusammenstellungen nicht zweifelhaft sein, dass die vorlage der 'Judith' nach Oberdeutschland gehört; der tubergang ron -sct- $>$-st- (16); ivht, nivt (29 b); older $(29 \mathrm{c})$ weisen auf das alemannische. 


\section{F. LAMPRECHTS ALETANDER}

(= Diemer, Dt. ged. s. 183-226).

Zu dem ubrigen missgeschick, welches uber der uberlieferung des 'Alexander' gewaltet hat, kommt noch, dass die schreibung der vorlage die geringste consequenz unter allen vorlagen der Vorauer hs. zeigt. Denn dass die mischung schon der vorlage und nicht dem Vorauer schreiber zur last zu legen ist, bleibt nach den obigen ergebnissen des fast sclavischen anschlusses keine vermutung (Quell. u. forsch. VII, 60) mehr, sondern ist gewissheit. Scherer empfahl a. a. o. s. 61 eine eingehende untersuchung der sprache, deren kölnischen charakter er durch Pfeiffer, German. III, 494 f. als festgestellt zugab, als dankenswert und lehrreich. Daraufhin machte Rödiger im Anz. f. dt. alt. I, 78-86 einige zusammenstellungen, auf welche öfters verwiesen werden kann. Uebrigens ist eine erschöpfende darstellung der verwirrten schreibung fur unsern zweck nicht erforderlich, indem sich eben der 'Alexander' sowol gegen $E$ als gegen $G$ durch seine inconsequenz gentigend abgrenzt und seine einheit bisher wenigsteps nicht bezweifelt wurde.

1. $e i$ ist vertreten durch $109 e i, 49 a i, 4 e, 4 a e$. In leingisten 208, 4 ist $e i=e$; mit unrecht citiert Rödiger noch gezeim 215, 4, indem dafür mit Diemer gezeme, res. gezemi zu lesen ist (:neme). - Der nachklang von $i$ ist mitteldeutsch, speciell rheinfränkisch, s. Weinhold, Mhd. gr. § 105; Paul. Mhd. gr. ${ }^{2} 101$.

2. ou. Es wechseln $o u, o^{\circ}, o v ; \operatorname{dazu} 40,4 \stackrel{i}{4}, 1 a u, 1 o^{\circ}=$ $u o ; 1 o v=u o$ und $1 o v=\hat{o}$.

3. iu. $54 \mathrm{iv}, 19 \mathrm{iu}, 9 \mathrm{eu}, 5 \mathrm{ev}, 5 \mathrm{u}, 1 \mathrm{i}, 1$ ieu. Zu beachten ist stivphater 198, 21 ohne brechung. Scheinbar $=u$ steht iu in liuzel 224, 23; es ist jedoch dies die ältere form; dazu lvizel 212, 9.

4. ie. $161 i e, 53 i, 5 e i$. Ob man in diesen $e i$ jene furs md. vindicierte wandlung von $i e>e i$ (vgl. Weinhold, Mhd. gr. § 107) oder nur verschreibung sehen will, wird fraglich sein.

5. 2. Es liberwiegt $e ; 25 \mathrm{mal}$ tritt $i$ auf, aber ohne princip. Rödiger s. 85 beschränkt sich auf die $i$ in offener silbe, weil in geschlossener silbe und in vorsatzpartikeln auch sonst in 
der Vor. hs. $i$ verwendet sei. Dieses 'auch sonst' lässt sich aber auf ganz bestimmte teile eindämmen (vgl. die tabelle), so dass unbetontes $i$ keineswegs vom Vorauer schreiber herrubrt. - $e z$ und $i z$ halten sich das gleichgewicht.

6. Umlaut. Es wechseln bei umlautsfähigem $\hat{a}: 39 a$, $4 e, 2$ ae, 1 ea, 1 ai (Kaiben 223, 20). Sonst 4 aht, 2 aeht, 1 eht; 2 alt, 4 elt.

7. In bezug auf contraction stehen sich 7 age und $4 e i$ gegenuber. Merkwurdig ist gesate (sagte) 223, 3.

8. Uebergang von -or->-ar-ist nicht zu belegen.

9. Synkope ist selten; zu nennen ist lemptigen 198, 24; aigeme $217,6<$ aigeneme, analog eime 218,1 .

10. Abschwächung der nebenvocale. Die endung -ote ist reichlich vertreten; der dat. sg. m. n. der pron. und. st. adj. flex. lautet auf -me aus. Altertlimlich ist eror 219, 23; argoren 223, 27.

11. Neigung zu einschubrocal liegt widerholt nur bei $z w$ - vor, welches 10 mal als zew-auftritt. Dazu keneht 220,7 und cheneten 221,1 (= chenehten).

12. Accente. Circumflexe sind nicht häufig; acute stehen auf den ausrufungspartikeln $a ́$, áwie, áwe, $\dot{o} ; 3 \mathrm{mal}$ in $\dot{e}$ und ausserdem in hér 195, 22; gér 208,6; lós 220,8.

13. Die dentalen sind ungemein verwirrt. a) Mhd. $d$ ist durchgedrungen. In 29 fällen steht dafur $t$-, und zwar nach auslaut $-t 6,-s 5,-c h 6,-z 3 \mathrm{mal}$, sonst nur vereinzelt. Man kann darin reste von assim. sehen. Hochdeutsch $t$ hat nach Rödiger folgende vertretung:

$$
\begin{aligned}
& \text { anlaut. gewöhnl. } d-; 17 \text { th-; } \\
& \text { inla ut. }-d-\text {-, }- \text { th-, }- \text { ht-; } \\
& \text { a usla u t. } 2-d, 14-t h, 114-h t
\end{aligned}
$$

(ht und th stehen in demselben bunten wechsel wie hc und $c h, h p$ und $p h)$. - Hdt. $z$ erscheint nie als $t$. Ueber die reime vgl. Rödiger s. 82.

b) $d w-<$ urgerm. $p w$-erscheint 6 mal als $d w$, 1 mal als tw- in twanc 195,4. - tw-< urgerm. $d w$ - kommt nur vor in nenthewalten 205, 22.

c) Es concurriert $n t$ und $n d$. Bei der verwirrung der dentalen ist es zweifelhaft, wie die verbindung aufzufassen ist.

d) $l t$ uberwiegt. 
14. Labiale. a) $b$ im anlaut $94 b$-, $31 p$-, ersteres nach vocal und $-r$, letzteres nach $-s$ und $-z$ therwiegend. 2 mal hat das unbetonte präfix $b e$ - die schreibung $p e$-. - Im auslaut stehen $17-b$ gegen $3-p$.

b) $f<$ urg. $p$ erscheint meist als $f, p h$, seltner als $f f$, als $u$ in gewauen 188,15 .

c) Die gruppe $w u$ - ist ausgeschrieben.

d) Es überwiegt $d w$-, $s w$-, zw- (resp. zew- s. 11).

15. Gutturale. a) Für $k$ uberwiegt weitaus ch. Auf $g$ - in grisp 186, 18; graph (kraft) 204, 9; ebenso auf das verschmolzene uolcquic 215, 24 weist Rödiger 8. 83 hin.

b) $g$ ist im auslaut meist -ch. Verschmelzung mit der vorsatzpartikel ent- ergibt $2 \mathrm{mal} e n k$-. Im anlaut tritt $5 \mathrm{mal}$ $k$ - und $5 \mathrm{mal} c h$ - in betonter silbe, $6 \mathrm{mal}$ die unbetonte partikel $k e$ - auf, und zwar darunter 5 mal nach $-s,-z ; 4$ mal nach - $t$ und 4 mal nach -ch, so dass hierin reste eines kanons stecken könnten.

c) Verschmelzung von qu- liegt immer vor, ausser in qvam 224, 25 und in dem lehnwort quadrestein 202, 28, wozu $\mathbf{E}$ $15 \mathrm{c} \mathrm{zu}$ vgl. ist.

16. Assimilation wirkt in der wandlung der gruppe cons. $+h+$ cons. $>$ cons. + cons., wie in marstat 190,10 ; forten 203, 24. 211, 2; azech (was eine weiterentwicklung der in der Kaiserchronik 303, 18 belegten form ahzec sein kann) 224,28 . - $f$ fällt in gleicher stellung in funzen 192, 23; furmzich 224, 19. Der schwund des $h$ in diesen stellungen ist besonders mitteldeutsch: Weinhold, Mhd. gr. § 226; Paul, Mhd. gr.2 $\S 103$. $3 \mathrm{mal}$ ist die vorsatzpartikel un- an $m$ - zu umm- assimiliert: s. Weinhold, \& $169 \mathrm{f}$.

17. Metathesis. Ausser irchron 184, 16 und vurmeclich 218, 18, was Rödiger s. 84 anfuhrt, erscheint die partikel er$5 \mathrm{mal}$ als re-.

18. Grammatischer wechsel ist ausgeglichen in ge nasen 197, 18; erhalten in heuen 186, 27 und 197, 18; erhalten in heuen 186, 27 und wurte 185, 4 und 29; wurl 190, 19.

20. Im prät. von wellen uberwiegt wolte stark gegen wolde.

21. mugen hat im pl. prăs. nur diese form; im prăt. streiten 11 mahte gegen 10 mohte. 
23. wurken bietet das partic. geworht. 3 hiete.

24. haben die präterita: 18 hete, 10 habete, 4 hate,

25. stân und gân haben $22 \hat{e}$-formen, $17 \hat{a}$-formen, 2 mal $e i$ in umbegeit 183,18 und uersteit 184,2. Dass viele ei-formen aus den reimen zu erschliessen, mit anderen als beweis des niederrhein. ursprungs anzusehen sind, hat Pfeiffer, German. III, 494 gezeigt.

26. Flexion. a) Der artikel n. pl. n. lautet dei (vgl. ub. ursprung Bücher Moses) in dei ovgen 194, 16. Zweifeln kann man, ob die volchwich ... die 226,5 f. ein beleg für die $=d i u$ ist (in dieser zeit namentlich md.: Paul $\$ 148$, A.2), da das wort in seinem geschlecht zwischen m. und n. schwankt. Doch spricht eine andre stelle im Alexander, daz uolcqwic 215, 24 fürs neutrum.

b) Die 2. pl. lautet auf -ent aus: alemannisch-bairisch nach Weinhold, Mhd. gr. § 352.

c) Im präter. ist zu nennen fuhten $209,17.222,15$, secundäre form nach fluhten, wesentlich md.: Weinhold §332. Neben das durch die ganze hs. gehende muose tritt im Alexander muiste 216,18. Sodann fungiert als st. prät. von bringen: gebranc 219,28. Es ist das aus mhd. zeit einer der wenigen reste des bei Otfrid stark flectierten verbums, s. Weinhold $\$ 390$.

d) Einmal ist zu belegen swergen 200,19 mit synkope.

27. Zahlwörter. Zu nennen ist zwa fem. 210,10; funf funzen, funzich, azech, deren stelle unter 16 verzeichnet ist. Dazu einluph 205, 9.

28. Einzelne wörter. a) fiur lautet $4 \mathrm{mal}$ fuur 206,8 . 210, 15. 210, 25. 219,3; einmal fur 211, 5 .

29. Varia. a) $h$ fehlt teils im anlaut, teils tritt es unorganisch vor, was nach Weinhold $\S 225$ besonders md. ist. Im inlaut făllt es häufig: vgl. Rödiger s. 83. Auf den wechsel in der schreibung von $h t$ und $t h, h p$ und $p h, h c$, und $c h$ ist schon unter 13 a hingewiesen.

b) Apokope von auslaut $-t$ in is 214,22; graph (kraft) 204,9 ; scaph 222,12; fälschlich wird hierhergezogen bohtsapf 214, 2. Ueber das md. geprăge dieser formen s. Weinhold, Mhd. gr. \& 347 und MSD $^{2}$ einl. XXI. 
c) Neben der form sol steht $3 \mathrm{mal}$ sal; entsprechend ist wale: vgl. Weinhold $\S 22.394$.

d) Die merkwürdigen formen teht und de̊ht, für welche der reim immer deit erheischt, besprach Pfeiffer, German. III, 495 als beweis der Kölnischen mundart.

Scherer, Quell. u. forsch. VII, 60 ist der ansicht, es sei schwer zu entscheiden, ob der Vorauer schreiber noch die vollständige arbeit Lamprechts vor sich hatte, und glaubt die unvollständige uberlieferung auf mangel an liebe fur den gegenstand zurlickfuhhren zu können. Als beweis dafür darf zunächst nicht gelten, 'dass das gedicht in der gesellschaft, in der es hier auftritt, eine vereinzelte erscheinung bildet': es bildet hier eine vereinzelte erscheinung, wie uberhaupt in der damaligen literatur, indem eben erst allmählich neben die rein-geistliche dichtung producte halbweltlicher natur treten. Es bertihrt sich dieser punkt mit der frage der gesammten anlage der Vor. hs., welche später $\mathrm{zu}$ besprechen sein wird. Wer in der zusammensetzung der Vorauer hs. mit Mullenhoff und Scherer ein system sucht, dem ist allerdings der 'Alexander' hier unbequem; wer aber annimmt, dass in die hs. aufgenommen wurde, was an vorlagen sich darbot, und in der reihenfolge wie es der verkehr mit andern klöstern mit sich brachte, sieht in der zusammensetzung und reihenfolge ein bild des damaligen literarischen lebens nach seinen verschiedenen elementen.

Das verhăltnis der Strassburger bearbeitung (S.) des Alexanderliedes zur Vor. hs. (V.) hat Kinzel, Zs. f. d. ph. $\mathrm{X}, 46 \mathrm{fr} ., 1879$, klargelegt. Er zeigt, dass S. bis vers 2036 (Massmann, sp. 83) mit V. bis 225, 24 im wes. ubereinstimmt. Dann eilt V. zum schluss und knlupft an S. 3247-3251 an, brachte dann den kampf gegen Darius zu ende und liess die entbehrlichen zwischenfälle aus: briefwechel, sendung von mohn und pfeffer, Alexanders heimreise, krankheit. Mit 3220 beginnt die schlacht. V. $225,26-226,5$ stimmt dann ungefähr mit S. $3257-3267$; $226,5-7$ mit $3276-79$, und $226,8-9$ mit $368-69$. Sodann hat $226,12 \mathrm{f}$. in seinen gedanken verwantes mit $3281 \mathrm{f}$. Das andere, 226,9-19 ist selbstăndig hinzugedichteter sctrluss der geschichte, unklar in seinen gedanken: 'Er und das ende des liedes 226,20-21 berechtigen zu der 
annalıme, dass die vorlage, welche der Vor. hs. zu grunde lag, selbständig den faden abgeschnitten hat.' So ist wol entschieden, dass dem Vor. schreiber nicht die ganze arbeit Lamprechts vorlag und er nicht fur die kurzere gestalt verantwortlich ist: man musste ihn denn als 'kürzenden dichter' beanspruchen, welche annahme aber schon durch die auch dem schluss eigne mischorthographie widerlegt wird.

Der Kölnische charakter der sprache ist auch nach Scherer durch Pfeiffer a. a. o. 'kurz, aber entscheidend' nachgewiesen, und er bezweifelt nicht, dass hiermit die heimat des dichters constatiert ist. Auf 8.62 bemerkt er jedoch uber diesen: 'Wir wissen gar nicht, ob er sein werk in der heimat verfasst hat' und verschiedenes scheint ihm für Baiern zu sprechen: 1. sollen der 'pfaff' Lamprecht und der 'pfaff' Konrad zusammengehören, weil sie allein ihren namen nennen: ein solcher schluss wäre aber doch nur möglich, wenn man annimmt, dass die uns erhaltne literatur mit der uberhaupt producierten sich deckt, und das wird doch niemand annehmen. 2. Ferner habe nur Baiern das zu solcher namensnennung nötige selbstgefubl verleihen können: das ist ebensowenig zu widerzulegen, als es nicht $\mathrm{zu}$ beweisen ist. 3. Auf Salomo als typus der herrscherwürde bei Konrad und Lamprecht legt Scherer selbst kein gewicht, mehr 4. auf die bei beiden stattfindende beiziehung der sage von Hilde. Aber bevor das als beweis gelten kann, müssten jene 'umfassenderen beobachtungen uber die landschaftliche gebundenheit von sagen' geliefert und durch andre momente glaubwurdig gemacht sein. Aber abgesehen von der schwäche der argumente: wie soll man sich das vorstellen, wenn ein niederrhein. dichter in Baiern dichtet? Es käme das wider auf einen jener anrtichigen 'mischdialecte' heraus, bei welchen, gibt man einmal diese ungeheuerlichkeit zu, der phantasie ein weites feld geöffnet ist.

Sicher ist nun, dass dem Vorauer schreiber bei der sonst fast sclavischen nachahmung der vorlagen - ich erinnere nur an die getrennte schreibung eines wortes in $\mathrm{D}$ - auch hier das höchste zuzutrauen ist. Wie er in $\mathrm{D}$ die mitteldeutschen eigentlimlichkeiten unangetastet liess, musste es auch hier der fall sein.

Für den mitteldeutschen ursprung des originals zeugen 
die nummern 1 (nachklang von $i$ ); 13 a (dentale); 16 (cons. $+h+$ cons. $>$ cons. + cons.); 25 (geit); 26 a (die $=d i u) ; 26 \mathrm{c}$ (fuhten); 29 a (unorgan. $h$-); $29 \mathrm{~b}$ (apokope von $-t$ ); $29 \mathrm{c}$ (sal, wale); $29 \mathrm{~d}$ (te̊ht = deit). - Das Kölnische original gieng dann durch die hände eines weniger conservativen schreibers aus Oberdeutschland, welcher mit grosser muhe sich dasselbe näher zu bringen suchte. $O b$ dieser act zugleich mit der verkurzung des gedichts vorgieng, oder ob eine weitere mittelstufe anzunehmen ist, wird nicht zu entscheiden sein, indem die verse von V., welche in S. keine entsprechung haben, nämlich 226, 9-21, in ihrer schreibung daruber keinen aufschluss geben. Die form de̊ht und tèht sind sprechende zeugnisse für die muhseligkeit des verfahrens. Diesem oberdeutschen schıtiber fällt die vermischung und verwirrung in den dentalen, die alem. bair. endung -ent 2. pl., der wechsel von $b$ - und $p$ - und die einfuhrung von ai zúr last. Erst in dieser form kam der Alexander vor den Vorauer schreiber, der wie sonst seine vorlage getreu nachahmte.

Die ausgabe des Alexander von Kinzel, Halle 1884 ( $=$ bd. VI der germanist. handbibl.) bietet uber die Vor. hs. im speciellen nichts neues.

\section{G. DIE GEDICHTE DER AVA.}

(= Diemer, Dt. ged. s. 229-292).

Auch an die gedichte der Ava hat Scherer das kritische seciermesser angelegt (Quell. u. forsch. VII, 64-77). Aber wio seine chorizontischen versuche fur die Wiener Genesis von Vogt, Beitr. II zurickgewiesen wurden, ist hier von Adolf Langguth, Untersuchungen uber die gedichte der Ava, Budapest 1880, gezeigt worden, dass die von Scherer vorgebrachten momente zu einer trennung nicht berechtigen. Auf s. $8 \mathrm{ff}$. bespricht er das verhältnis der Vorauer und Görlitzer uberlieferung (Fundgruben I) und erörtert dann, dass im gegenteil das verhăltnis der reime, speciell der rührenden, bei denen sich W. Grimm in seiner 'Geschichte des reims' s. 38 geirrt hatte, ferner der stil und syntactisches, die gleiche behandlung der wunder und andres mehr für die einheit spricht. Dazu stimmen die folgenden orthographischen und formellen zusammenstellungen. Was in der Vorauer hs. nach Scherer andern verfassern angehören 
soll, - 'Jesus' von 2 verfassern und die 'Kirche' - geht von 8. 229 bis 276, 4; dann beginnt nach ihm erst Ava mit den 'Gaben des hl. geistes', 'Antichrist' und dem 'Jungsten gericht'. Scheint also citierung specieller beispiele nötig, um die gleichheit der beiden als unecht und echt getrennten teile zu zeigen, so bildet vers 276, 4 den scheidepunkt. Hervorgehoben sei, dass auf diese weise 47 seiten bei Diemer einem kleineren teil von 16 seiten, also fast nur einem drittel gegenuberstehen, so dass das gesammtverhältnis $3: 1$ ist.

1. $e i$ ist vertreten durch $156 e i, 53 a i, 6 e$; bestehend aus $99 e i, 42 a i, 5 e+57 e i, 11 a i, 1 e$, welches beispiel dem gesammtverhältnis der beiden teile nicht allzufern steht.

2. ou zeigt 24 ou; $22 o^{\circ} ; 3$ ov; $4 \stackrel{u}{0} ; 1$ o. $4 o^{v}, 1$ ou $=u o$.

3. iu. $108 \mathrm{iu} ; 21 \mathrm{eu} ; 16 u ; 5 \mathrm{iv}$. Bemerkenswert ist die form liuf 250, 13. 268, 8 ohne eintritt der brechung: vgl. $26 \mathrm{c}$.

4. ie. $177 i e ; 38 i ; 5 e i$. -5 ie sind $=\hat{\imath}, 2=i$. Die hälfte der $i=i e$ bilden, durch alle teile gehend, iht, niht und nine, was wol mit ihrer proklitischen natur zusammenhängt.

5. Fur unbetontes a erscheint nur $6 \mathrm{mal} i$, ohne dass ein princip zu finden wäre. Durchgehend ist die form $i z$; ez nur 240, 25.

6. Umlautsfähiges $a$ ist vertreten durch $88 a ; 27 a$; $4 e ; 1 e a ; 1$ ae. Die gruppe aht ist nicht umgelautet, womit hier auch trahtin 245, 17. 260,13. 269, 15 stimmt; nur einmal thretin 253,23. Ebenso ist -alt- ohne umlaut, ausser in geweltich 258,27, neben welches gleich 259,10 gewaltich tritt.

7. Contraction von age, ege unterbleibt gewöhnlich. Nur mait und leit sind je 2 mal zu belegen 237, 11. 238, 15. 243, 4. 264, 1 .

8. Der übergang von or $>$ ar liegt vor in warte: harte 256, 22 und wird erheischt durch den reim worte : harte 256,6, wo die Görlitzer hs. Fundgr. I, 171 aber auch worte hat. Vielleicht ist dieses reimschlusses wegen warhten 260,22 und gewarhten 260, 25 hierherzuziehen und nicht als 'andre ablautsstufe zu fassen.

9. Synkope ist in mässiger weise eingetreten; durchgehend ist sie beim präfix ge- in gnade. Ebenso kehrt in allen teilen wider die form mayde. 
10. Abschwächung. Als endung der pron. und st. adj. flex. erscheint im dat. sg. m. n. nie -mo, sondern nur -me und mit apokope $-m$, und zwar auch vor consonant. -ote, -ot ist häufig. Der superlativ endet auf -iste; öfters ist zu belegen niemen. Altertümelnd ist das zahlwort ahtoden 285, 7 .

11. Neigung zu einschubvocal ist vorhanden bei den gruppen $p h l-, z w$ - und $c h n-$, die widerholt phel-, zen-, chengeschrieben sind.

12. Circumflexe kommen etwa 2 auf eine seite bei Diemer, c. 30 verse. Meistens circumflectiert ist $\hat{e}$.

13. Dentale. a) Mhd. $d$ liegt $11 \mathrm{mal}$ im anlaut als $t$ vor: 3 mal nach $s, 2$ nach $t, 3$ nach $t$; die andern fälle zersplittern sich.

b) $d w$-, tw sind nach ihrem verschiedenen ursprung geschieden: duoch (wusch) 244,10; entwalt 249,21; gedwest 252, 16; ungedwagen 257,17; tuwale 289, 23; dwinget 290,3. 291, 17.

c) 89 nd stehen gegen $29 n t$; umgekehrt $11 n t$ gegen $1 n d$, wo ndt, nnt zu grunde liegt (nante, bechante, sante, chunte [kindete], enzunte).

d) It geht durch. bis auf gehalden 244, 24 welches wort uberhaupt auch bei sonstigem lt zur erweichung neigt: s. Paul Mhd. gr. ${ }^{2} \S 71,4$ anm. 2.

14. Labiale. Im anlaut wechseln $48 p$ - und 33 b-; deutliche verhăltnisse prägen sich aus nach auslaut:

$\begin{array}{lrr} & \mathrm{p}- & \mathrm{b}- \\ -\mathrm{ch} & 13 & 2 \\ -\mathrm{z} & 9 & 1 \\ \text { vocal } & 3 & 13\end{array}$

worin man wol mit recht spuren eines kanons sehen wird. Eine ausnahme von der schreibung des unbetonten prăfixes be- macht pechante 267,18. Im auslaut steht 43 mal -p, nur 4 mal $-b$.

b) $f<$ urg. $p$ hat immer diese schreibung ausser in slauende 256, 1.

c) Die gruppe $w u$ - erscheint meist als $w$ -

d) Es tuberwiegt $d w-, t w-, s w-, z w-$ (resp. zew-).

15. Gutturale. a) Bei einfachem $k$ verschwindet $c$ gegen ch. Die gemination < urgerm. $k k$ hat keine besondre schreibung: so diche : bliche 285,3 . 
b) $g$ ist im auslaut durch $-c h$ vertreten, wozu $8-g$ in präter. formen mit inclination des pers. pron. er kommen: z. b. lag er 237, 25; dwog er 252,10. Das wort grim hat 2 mal anlaut. cr- 260,23. 264,16. Erwähnt sei huskenosce 272, 15. Urgerm. $g g$ erscheint in lukken 249,9 ; zerukke 256,23 ; zeruke $267,8$.

c) $q u$ - ist immer verschmolzen (prät. chom). Gleich lauten corter (heerde < quártarium) und chorter (köder) 262, 5.

16. Assimilation zeigt noturft 229,18. 246,12; grascefte 280, 9; merkwürdig sind die schreibungen suas so 280,6 ; wa si (waz, si) 262,15; das tritte 274, 24, welche formen reste eines ausgedehnten assimilationssystems von auslaut an anlaut sind (vgl. Arnolds gedicht $=\mathrm{K}$ ), wovon auch Otfrid spuren aufweist: vgl. II, 1, 16 so was ses (so waz sie es); ebenso 20. 24. 28. 32.

17. Metathesis. Das präfix er- nimmt $4 \mathrm{mal}$ die gestalt $r e$ - an nach vorhergehendem er; ganz verschmolzen ist erestanden 266, 18.

18. Grammatischer wechsel ist erhalten in heuen; genaren 255, 25; wrten 265, 4; ausgeglichen in wrfen $240,6 \mathrm{zu}$ gunsten der wurzelbetonten formen, was besonders bairisch sein soll: vgl. Kaiserchronik. Dieser entsprechend kommt 2 mal flegen vor 236, 7. 280, 22. $292,10$.

19. Von $\sin$ lautet die 2. pl. ind. birt; Imper. wesent

20. wellen hat im prät. 25 wolte, 5 wolde.

21. mugen. 8 megen stehen gegen 1 mugen; 7 mahte gegen 5 mohte.

22. Von wizzen lautet das prät. 4 mal wesse.

23. Von wurken 2 mal warhte, 2 mal worhte, das partic. geworeht 285,22. Vgl. ubrigens 8 .

24. haben bietet 31 hete; 16 habete; 1 hiete.

25. st $\hat{a}_{n}$ und $g \hat{a} n 32 \hat{e}-, 18 \hat{a}$-formen; der imper. lautet gench; das part. prät. gegên 249,20 ; ergen 257,3 ; einmal ergan 231,24 , was wesentlich alemannisch ist.

26. In der flexion a) des pronom. ist zu nennen: Dei buich 242,4. b) Die 2. sg. lautet auf -st aus. Inclinierte formen sind sistu 250,21; pistu 269,16. c) An präteritalformen sind zu nennen: 2 mal liuf neben 2 lief, vgl. unter 3. - 
Neben riefen 265, 6 steht ruofte 261, 23. Seite 256, 26 steht spiren: scriren, wofur die jungere bearbeitung Fundgruben I, 171, 40 spiten: schriten, also schwache formen setzt. Vgl. Diemer, Gen. u. exod. I, 155, 21: schriren, und Weinhold, Mhd. gr. § 337. 408.

27. Zahlwörter fem. von 2: zua 236, 27; 5 immer uinf; 11 einlef $268,20.285,25 ; 20$ zwainzech obne reduction; 80 hazech 237, 3 ist wol verschrieben fur ahzech, vgl. Kaiserchronik 27.

28. Einzelne wörter. a) fiur lautet 8 mal uiur 257,5 . 273, 16. 282, 17. 287, 4 etc.; einmal uir 263, 21.

b) biscof $2 \mathrm{mal}$ biscof 257,8.276, 2 und 2 mal biscolf $248,10.258,26$, also in kreuzstellung, alle fälle vor der kritischen ecke: $276,4$.

c) lichname nur in dieser form z. b. 230,10. 272,6.

d) diemüete hat die gestalt dieumuit 233,11. 276,17.

29. Varia. a) Aphärese von anlaut. $j$-findet in allen in betracht kommenden fällen statt: ennen 234, 26; amer 267,6. 273, 3; amere 270, 18. Diese erscheinung weist aufs alemannische.

b) Neben niht, nieht tritt in allen teilen niuht: 241, 20. 250, 14. 255, 5. 264, 9. - 285, 10. Auch diese form ist alemannisch, entsprechend dem heutigen nüt in der Schweiz.

c) Unorgan. $h$ - tritt auf im anlaut in heste (äste) 250, 21; habe 263,12 - hif 283,17 , also in beiden teilen.

d) Analog der Kaiserchronik erscheint die bair. form stram im reim: man 283, 24.

e) Die form uernunst ist 5 mal $\mathrm{zu}$ belegen; im reim: anedunst 273, 19; sie ist gherdeutsch nach Weinhold, Mhd. gr. $\S 142$.

f) sunne ist in allen teilen immer masc.: der sunne 237, 18 . 284, 19. 290, 27. In der Görlitzer hs. begegnet auch das femininum.

g) Statt der reimpunkte erscheint in diesem teil der hs. bis auf sehr wenig ausnahmen durchgehends ausrufungszeichen: !, worauf Diemer s. 229 anm. hinweist. Also bis auf diese kleinigkeiten erstreckt sich die treue des Vorauer schreibers. 
h) Erwăhnt sei die form daz fiehe 280,4, was keine verschreibung zu sein braucht, indem formen derart bei Notker vorkommen.

i) Die formel eines nahtes 238,4 (das heutige 'eines nachts') ist interessant als ubergangsstufe. Bei Otfrid schon ist zu belegen: dages inti nahtes Widmung an Hartmuat 168, wobei nahtes als alter genetiv der cons. flex. zu fassen ist. Die nhd. form 'des nachts' erklärt man nun gewöhnlich als uniformierung des verschiedengeschlechtigen artikels in jener verbindung; es kann aber auch eines nahtes mitgewirkt haben, wobei eines ursprunglich zeitadverb (einst) ist, dann aber als artikel gefasst wurde, wonach man auch des nahtes bildete.

Sind wir nun auch bei Avas gedichten nicht in der gunstigen lage, durch die tibereinstimmung in schreibung und form wie bei den 'Buchern Moses' auf grund einer abweichenden einschiebung die einheit $\mathrm{zu}$ beweisen, so ist doch durch die obigen zusammenstellungen dem auf anderm wege von Langguth gewonnenen urteil eine stutze geboten, mindestens ein stein aus dem wege gerăumt; denn mit einer merklichen differenz in der orthographie einzelner teile hätte man wol zu rechnen.

Ist somit die einheit von Avas dichtung ausser zweifel gesetzt, so wird damit nicht geleugnet, dass sie sachlich in einzelne abschnitte zerfällt. Wie aber bei den 'Büchern Moses' gliederung nach dem bedurfnis der predigt zurluckzuweisen war, so auch hier, wie Langguth s. $113 \mathrm{ff}$. auseinandersetzt: 'Das leben Jesu ist durchaus nicht im predigtstil geschrieben, ebenso wenig steht der verfasser seinem publicum wie ein prediger gegenuber.' Die gedichte der Ava sind vielmehr mit Diemer in das gebiet frommer andachtsuibungen $\mathrm{zu}$ verlegen, und die abschnitte erklären sich aus der einzig zulässigen annahme, dass sie zum lesen oder vorlesen bestimmt waren. -

Die uberlieferung trägt jedenfalls oberdeutschen character; aufs bairische scheint 3. liuf; 8. or >ar; 18. wurfen; $29 \mathrm{~d}$. stram; aufs alemannische 25. part. ergan; 29 a. aphärese von $j$-; $29 \mathrm{~b}$. niuht $\mathrm{zu}$ weisen. Genaue bestimmung ist nach den vorhandenen hilfsmitteln nicht möglich, aber auch der angenommenen ansicht, dass die dichterin Ava mit der Ava des Annales Mel- 
licenses identisch sei, kein hindernis in den weg zu legen. Kommt man doch immer mehr zur einsicht, dass eine abgrenzung z. b. des Bairischen vom Oesterreichischen in jener zeit nicht möglich ist, weil eben die dialecte erst in der differenzierung begriffen waren (vgl. Paul, Gab es eine mhd. schriftsprache?).

\section{H. SÜNDENKRAGE}

(= Diemer, Dt. ged. 8. 295-316).

Die Vorauer Sündenklage, welche Diemer nach einer weniger wichtigen seite des inbalts, 'Loblied auf Maria' genannt hat, und welcher in der Milstäter hs. der sog. 'Verlorene sohn', Karajan, Dt. sprachdenkmale s. 47-67 entspricht, grenzt sich trotz ihres geringen umfanges scharf gegen $\mathbf{G}$ und $\mathbf{J}$ ab.

1. $e i$ hat fast die alleinherrschaft, indem zu 36 ei nur 3 ai kommen.

2. $o u$, in seinem vorkommen uberhaupt viel seltner als $e i$, was die bisherige zusammenstellung unter anderm gezeigt haben wird, bietet 7 ou, $4 o^{\circ}, 1 o$.

3. iu erscheint $40 \mathrm{mal}$ als $i u$; daneben $7 i v, 4 e u, 2 \dot{u}$, $2 v$. Darunter ist $4 \mathrm{mal}$ tiuvel ohne eintritt der brechung.

4. ie zeigt $63 i e$; dazu 5 niht und 3 nine, wol mit ihrer unbetontheit zusammenhängend. Sonst liegt $i$ nur vor in liht 296, 23, vgl. G. 4.

5. Herrschend ist $\partial$; neigung zu $i$ haben die vorsilben $i r-$, int-; uberwiegend sind die formen $i z$.

6. Bei umlautsfähigem $a$ concurrieren $16 a, 11 e, 11 a$. Die gruppe -aht- ist nicht umgelautet, wol aber das oft alleinstehende drehtin $308,20.313,3$.

7. Contraction findet nicht statt bei age, dagegen in weiz < was iz 297, 18. 306, 26; ebenso in deiz < daz iz 308,16. theiz < thaz $i z$ ist auch bei Otfrid häufig; nach der auffassung von Paul (Beitr. IV, 467) geht es auf altes pa iz zurtick, indem entsprechend dem got. $h v a$ fruher ein $p a$ bestehen musste, wo kein deiktisches element angetreten und folglich das $-t$ unter das auslautsgesetz gefallen war. $\mathrm{Da}$ jedoch in unserm text weiz $<$ was iz 2 mal belegt ist, wo eine ähnliche erklärung unmogglich ist, kann man auch direct thaz $i z>$ theiz ansetzen. Dem weiz entspricht als vorstufe wes $i z$ z. b. Otfrid II, 1, 8, 
indem der umlaut ursprunglich nicht nur von der endung auf die wurzel, sondern im engem syntactischem zusammenhang auch von einem inklinierten wort aus auf ein höher betontes wort wirkte, welche ergebnisse wider durch ausgleichung schwanden.

8. Die gruppe -or-ist erhalten.

9. Synkope ist im inlaut mässig $\mathrm{zu}$ belegen: urende 299,16 ; menske 303,19; gnoz 311, 22; gebildet 316,4 dienen als beispiele.

10. Abschwächung der nebenvocale. Neben die endung -ot tritt schon -et. Der dat. der pron. u. st. adj. flex. endet auf -me. Eine archaische form ist sterchorre 316,1.

11. Einschubvocal tritt nie auf: also auch hierin consequenz.

12. Circumflectiert ist $6 \mathrm{mal}$ die partikel $\hat{e} ; i \hat{e}$ $305,24$.

13. Dentale. a) Mhd. $t$ erscheint $20 \mathrm{mal}$ als $d$ und zwar sowol anlautend als inlautend. Daneben in beiden stellungen und auslautend $-t$. $-31 n d$ stehen gegen $2 n t$; bei dem obigen zustand ist man berechtigt, die vorliegenden $n d$ als unverschoben und nicht secundär aus nt erweicht aufzufassen. Zweifelhaft, wie immer, ist solde, wolde; da jedoch in den überhaupt in betracht kommenden 16 fällen nie solte, wolte auftritt, kann man sie hieherziehen. ld liegt sonst vor in behalden 311,11; chuldestu (kuhlen) 311,26; $l t$ in doltest 309, 20. - Speciell $\mathrm{zu}$ nennen ist brehdest 297, 7 und sande (= sancte, heilig) 302,14; ebenso widerholtes drut 295, 18; gedrwe 296,1; drut 300,6 mit erweichung von ursprungl. $t$, welche erscheinung in himelisgin (s. 15 a) ihre parallele bat und hauptsächlich fränkischen quellen eigentumlich ist. Vgl. Paul, Beitr. VII, 129; $\mathrm{MSD}^{2}$ einl. XIV. XXII.

b) Die verbindung $d w-, t w$ - bietet nur twale 313,20 (urgerm. $d w-$ ).

c) nt und $l t$ s. unter a.

14. Labiale. a) Im anlaut steht nur $b$-; im auslaut meist $-p$, nur 2 mal $-b$.

b) $f<$ urgerm. $p$ erscheint $10 \mathrm{mal}$ als $u$; das haupt. contingent liefert dabei heluen; dazu uerworuener 310, 25. 
buluer < lat. pulverem darf jedoch nicht hierhergezogen werden, wie Scherer s. 78 tut. ff in geweffene 313, 28; tieffe 305, 4.

c) Die gruppe wu- ist ausgeschrieben: z. b. wurde 297, 2 .

d) Die verbindung $t w-, s w-, z w$ - hat nur diese schreibung; z. b. twale 312,20 ; zwei 313,10 .

15. Gutturale. a) $26 \mathrm{ch}$ stehen gegen $4 \mathrm{k}$; auf ureislic 313, 18 macht Scherer aufmerksam. Erwăhnt sei cheinerslahte 299, 3. Es hat den anschein, als ob die form chein am fruhsten in Mitteldeutschland auftauchte; nähere angaben daruber fehlen.

b) Im auslaut ist $-g$ durch -ch vertreten; durch $-c$ nur in phlac 307,22. Gemination bietet luggeme 312,10. Auf die erweichung himelisgiu 296, 2 ist unter 13 a hingewiesen.

c) Verschmelzung von $q u$ - ist immer eingetreten; als product daraus tritt beim präter. von kommen neben 1 chom 308,62 mal cham 296, 6. 297, 3, welche form sonst nie in der hs. vorkommt.

17. Metathesis liegt vor in einbron 295, 15 (md. nach Weinhold, Mhd. gr. § 146); dazu mir rezeiget 304, 14 .

18. Grammatischen wechsel haben bewahrt die interessanten formen irneren : geleren 311,11.

19. sîn. Auf weiz < was iz ist unter 7 hingewiesen.

20. wellen. 2. sg. du wil 299,7; prät. wolde und solde siehe $13 \mathrm{a}$.

21. Bei mugen stehen sich merkwürdiger weise 2 mege und 5 mohte gegenuber, die ja in der stammform nicht correspondieren.

22. wizzen hat das prät. wesse 315,26 .

23. wurken bietet worhte 297,11 und uerworht 305, 25. $311,13$.

24. haben im prät. nur 11 mal hete.

25. st $\hat{a} n$ und $g \hat{a} n 4 \hat{a}$ - und $1 \hat{e}$-form, alle im reim. Der imper. lautet stant 300,7 .

26. In der flexion a) des pron. ist zu nennen dei gebénde n. pl. neutr. 309, 20; sodann dire: mire 316,4, was neubildung nach den doppelformen ir und ire sein kann.

b) Die 2. sg. endet auf -st. Eine angelehnte form ist z. b. sandestu 311, 28.

c) Die formen unergagen 296,14 und beuagen 312,5 können 
wie das ahd. intfieg neubildung nach den präsentischen formen sein, wo der nasal vor $h$ schwinden musste.

d) Zweimal ist wergen zu belegen 312, 25. 313,1.

27. An zahlwörtern kommen vor: niun 298, 21; nůn 299, 28; uinf 300, 25.

28. Einzelne wörter. d) diemüete als demůl 313,28.

29. Varia. Ueber a) abfall von $-n$;

b) chnet fur chneht;

c) sogenannte attractionen;

d) relativ gebrauchtes pers. pron. vgl. Scherer, s. $79 \mathrm{ff}$. Weiter ist hervorzuheben:

e) halt (= eben) 307, 25; vgl. Weinhold, Mbd. gr. § 309.

f) ine < ich ne 306, 18 .

g) $z \ddot{u}=z e$, d. h. als präposition in 8 fällen: $295,9$. 295, 23. 297, 1. 298, 17.21. 299, 22. 301, 19. 315, 4, was im allgemeinen schon seit dem 10. jh. vorkommt (Weinhold § 317), sonst aber in der Vor. hs. nicht auftritt und vor allem md. ist.

Scherer äussert 8. 79: 'Die nähere erforschung der mundart überlasse ich anderen, es wird sich dann zeigen, ob man nicht schon dem verfasser eine mischung oder ausgleichung verschiedener dialecte zutrauen muss.' Dazu sind keine gründe vorhanden, aber ebenso sicher ist, dass der Vorauer schreiber, der $\mathrm{ja}$ in $\mathrm{D}$ getreulich das anlautende $d$ - (fur mhd. $t$ )- seiner vorlage uberliefert, hier fur die verwirrung in den dentalen nicht verantwortlich gemacht werden kann. Sondern der weg ist der, dass das mitteldeutsche, und zwar fränkische original von einem oberdeutschen schreiber abgeschrieben wurde, dessen arbeit dann die vorlage des Vorauer schreibers wurde.

Die frankische beimat des originals ist nach den obigen zusammenstellungen (13 a: brehdest, sande; $14 \mathrm{~b}: u<f ; 15 \mathrm{a}$ cheiner; $15 \mathrm{~b}$ : himelisgiu; 17: einbron; $29 \mathrm{~g}:$ zu $=z e$ ) sicher; wie denn auch Scherer, Quell. u. forsch. XII, 61 von der 'fränkischen Sundenklage' redet. Speciell fur Mittelfranken wird sprechen, dass auch inlaut. $-d$ - unverschoben auftritt (s. 13 a); sodann ist noch sit $<$ si it 312,13, wenn man diese auffassung Scherers gelten lässt, dafür anzufuhren, indem ja im mfr. $t$ zu $z$ verschoben wurde mit ausnahme der pronom. 
formen dat, wat, dit, it, allet: Weinhold § 180; Paul 2 \$2. Allerdings steht daneben $i z$ 296, 14; ez 305, 6 etc.

\section{EZZOS GESANG}

(= Diemer, Dt. ged. 8. 319-330 = MSD. XXXI).

Eine klare ubersicht und beurteilung der versuche, welche uber autorschaft und reconstruction von Ezzos gesang bis dahin vorhanden waren, lieferte Conrad Hofmann, Munch. sitz. ber. 1871, s. $293 \mathrm{ff}$. Daran schloss er unter ausscheidung der ersten, vierten und siebenten strophe eine widerherstellung, welche durch die auffindung des Strassburger textes (Barack, Zs. f. d. a. XXIII, 209-216) glänzend bestätigt wurde, während Mullenhoffs kritik sich als wenig stichbaltig erwies (vgl. Bartsch, Lit. bl. f. g. u. r. phil. I, sp. 13). Mit Diemer, Sitzungsber. d. phil. hist. classe d. Wiener akad. bd. 55, 1867, s. 271 ff. stimmt Hofmann darin uberein, dass das tiberlieferte gedicht die 'cantilena Ezzos' sein könne, dass aber fur die notwendigkeit ein zwingender beweis unmöglich sei. - Wie beim 'Alexander' die verworrenheit der tuberlieferung zu beklagen war, zeigt nun auch die jüngere bearbeitung von Ezzos gedicht, welche dem Vorauer schreiber vorlag, wenig consequenz in der schreibung.

1. ei. $15 e i, 3 e$.

2. ou. ov, $o^{v}$, ou nebeneinander.

3. $i u .8 i u, 7 i v, 1 u$.

4. $39 i e, 11 i$.

5. a hie und da als $i$; durchgehend ist das prätix $i r$ $e z$ und $i z$ wechseln.

6. Umlautsfähiges $\hat{a}$ erscheint als $10 \hat{e}, 1 a e, 1 a, 1 \hat{a}$. Die behauptung Mullenhoffs Denkm. ${ }^{1} 335$, zu str. 1. 9, dass mehrere reime gegen den umlaut zu sprechen scheinen, weist Bartsch, German. IX, 60 mit recht zurick. - Ungelautet sind 2 elt; nicht ergriffen aht, dagegen wider 3 mal trehtin 320, 22. $329,2.329,14$.

7. Contraction der gruppen aye, ege . ist nicht eingetreten.

8. Ebensowenig ist or $>$ ar gewandelt.

9. Synkope tritt auf ohne consequenz: gnade steht neben genade; mangen neben menige und andres mehr. 
10. Von der abschwächung der nebenvocale siud nicht ergriffen die suffixe -ote, -ot. Archaische formen sind langore 323,2 ; sterchore 327,5 . Der dat. sg. m. n. der pron. u. st. adj. flex. endet auf $-m o,-m e$ und $-m$; ein beispiel fur diese mischung ist: imo 327,7 ; ime 327,5 ; im 327,6 , alle nahe bei einander, alle vor folgendem cons. anlaut.

11. Svarabhakti ist nicht vorhanden.

12. Circumflex hat nur êe 327,$8 ; \hat{e} 327,9$.

13. Dentale. a) Im anlaut erscheint mhd. $d$ - als $t$ - in $d a z$ ter ist 321, 2: assimil.

c) 27 nt stehen einem nd gegenüber: sunde 323, 24 .

d) $l t$ ist nicht erweicht; z. b. gewelte 322, 7 .

14. Labiale. a) Im anlaut wechseln $13 p$ - und $3 b$; nach $-z$ und $-s$ steht nur $p$-; sonst sind zu wenig fälle da, um auf spuren eines kanons schliessen zu können. - Im a usla ut stehen $12-b$ und $8-p$ ohne regel.

b) $f<$ urg. $p$ in helfene 330,27; hilfet 329,17.

c) Die gruppe $w u$ - ist meist, aber nicht immer durch $w$ vertreten: wrte vir 324, 16.

d) Die verbindung $z w-(d w-, t w-$ kommt nicht vor) schwankt zwischen $z w$-, zv- und zuv-: zwein 321,19; zuvo 324,5 ; zven 325, 25; also auch hier keine consequenz.

15. Gutturale. a) ch uberwiegt; daneben tritt $c$.

b) $g$ wird im auslaut $>-c h$, bleibt nur in lag in 328, 2.

c) Die verbindung $q u$ - ist verschmolzen, mit ausnahme von bequam 319,20 , jedoch in einer strophe, die durch die Strassb. hs., wo bechom steht $(2,4)$, als echt erwiesen ist.

16. Assimilation zeigt nur allenfalls daz ter ist s. 13 a. Bemerkt sei ubrigens, dass auch in der Strassb. hs. 4, 1 daz ter ist steht, wonach diese erscheinung wol ursprünglich ist.

18. Grammatischer wechsel ist erhalten in wrte wir $324,16$.

19. sîn bietet pir wir $325,24$.

20. wellen das prät. wolte; ebenso solte 320,3. 329, 25.

21. mugen ein mohte 321,6 .

22. wizzen ein wessest 321,9 .

23. wurken ein worhte 320,8 .

24. haben 2 habete, 1 habte, 1 hiete, 1 hete. Auf die un- 
berechtigte änderung des handschriftlichen hiete in hate in MS D, str. 18, 6 macht Bartsch, German. IX, 60 aufmerksam.

25. stân und $g \hat{a} n$ bieten nur $1 \hat{e}-$ und $3 \hat{a}$-formen.

26. In der flexion a) des pronom. ist zu nennen: $d i$ bvich $=$ diu pl. n. 319,6 ; dine wort 329,8 . Die ausgleichung findet am fruhsten im md. statt, was zum Bambergischen ursprung stimmen würde. Weiter se ac. pl. m. 327, 19, wozu die 'jungre Judith' (E) zu vgl. ist.

b) Die 2. sg. endet auf -st; eine inclinierte form ist bistu $320,22$.

27. An zahlwörtern ist zu belegen: fem. von 2: zuvo 324, 5; uinf und zwelf.

28. Einzelne wörter. a) fiur ist nicht belegt, indem auch Diemer seine vermutung, das handschriftliche uieren 320,25 sei $=$ uiurin in den Wien. sitz.-ber. 1866, s. 434 zurtickgezogen hat.

b) biscof nur einmal als biscoph 319, 1 .

d) diemüete als diemot $325,10$.

29. Varia. a) -ch ist widerholt als - $h c$; analog $-h t$ als -th geschrieben, und als folge dieses schwankens tritt auch zu $t$ bald vorher, bald nachher ein unetymol. $h$ hinzu.

b) 4 mal steht fur inlautendes $-z$ - ein -c-: becechenit 320,11; wrcen 320,13; lucel 326, 12; herce 329, 9.

c) sunne schwankt im geschlecht: uon der sunnen f. 320,17, in einer durch die Strassb. hs. als unecht erwiesenen strophe; warer sunno m. 322, 8 in einer echten; sodann, wo die fragmentarische Strassb. hs. uns verlässt, der sunne m. 323, 2. 326,4, so dass man man daraus gewissermassen auf die echtheit dieser beiden betreffenden strophen schliessen könnte.

Man erwartet nun vielleicht, es liesse sich nach der schreibung uber die nur in dér Vìi. ho. Uberlieferten strophen ein urteil in bezug auf ihre echtheit fällen: dies ist jedoch nicht möglich bei der herrschenden inconsequenz, indem sich auch nicht nach dem wechsel der verschiedenen eigentumlichkeiten zusammenfallende einschnittspunkte finden lassen. 


\section{K. ARHOLDS GEDICHT}

(= Diemer, Dt. ged. s. 333-357. Daraus 354, 8-355, $23=$ MSD XLV).

Es ist nach Scherer, Quell. u. forsch. VII, 82 'eins der schrecklichsten gedichte unserer ganzen literatur'. Mullenhoff in $\mathrm{MSD}^{2} 458$ nannte das gedicht: 'von der siebenzahl zum lobe des hl. geistes' und bemerkte: 'uberhaupt scheint das ganze eine rohe zusammenstellung oder schlecht verbundene, ungeordnete masse von urspringlich z. t. selbständigen stucken ... und bruchstlicken verschiedner gedichte zu sein.' Er scheidet dann das oben genannte stuck - auf 'den schönen hymnus auf den hl. geist' hatte ubrigens schon Diemer, Einl. s. $L$ und in den anm. zu 354,10 und 354, 20 hingewiesen als selbständiges, von Arnold aufgenommenes gedicht aus unter dem titel: 'Laudate dominum'. Scherer hegt a. a. o. gegen den hymnus verschiedene bedenken und kommt s. 83 zur ansicht: 'Ich glaube nicht, dass seine (Arnolds) arbeit interpoliert ist; was wir haben, entspricht der vagen angabe des themas bei ihm selbst; er hat also vermutlich diese verschiedenartigen bestandteile zusammengeflickt.' Er gliedert dann in etwa acht stucke, zu deren erstem vielleicht der 'hymnus' als 'schluss' gehört habe. In Quell. u. forsch. XII citiert er dann die einzelnen teile: s. 64 'liturgische betrachtungen'; 'fragmente einer poetischen predigt'; s. 68 'der hl. geist'; s. 78 'der siebenformige gott' und characterisiert das ganze s. 68 mit den worten: 'das ärgste leistet ein priester Arnold, der auf grundlage eines bairischen gedichts vom siebenbildigen gotte alle möglichen siebenzahlen und manches andre zu ehren des hl. geistes in einen ungeniessbaren brei zusammenruhrt.' Der hymnus 'Laudate dominum' ist nicht besonders erwähnt. Auch auf grund der schreibung und formen ist eine abtrennung desselben nicht möglich. Was die form betrifft, stimmt Conrad Hofmann, Munch. sitz.-ber. 1871, s. 561 der ansicht Mullenhoffs, welcher ungleiche strophen mit verlängerter schlusszeile annimmt, bei, will jedoch dies princip in dem ganzen gedicht Arnolds erkennen und auf dasselbe anwenden. Die schreibung ist im einzelnen:

1. $e i$ ist vertreten durch $30 e i, 4 a i, 2 e$;

2. ou durch $26 a u$, was allein in diesem complex öfters 
auftritt; $4 o^{\circ} ; 2$ ou. Dabei sind nicht mitgerechnet 7 iouhc, $6 i 0^{\circ} \mathrm{hc}$, welche nur in dieser form erscheinen. Ferner stehen $18 o^{v}=u o$, ebenso $4 o v ; 1 \omega v=\hat{u} ; 1 o^{v}=i u ; 1 o^{v}=o$; $10^{\circ}=\hat{o}$.

3. iu als $46 i u, 5 u, 3$ eu (nie iv oder ev).

4. ie als 56 ie, $13 i$.

5. Unbetontes $a$ hat $i$ neben sich, jedoch ohne princip. Durchgehend ist $i z$.

6. Umlautsfähiges $\hat{a}$ weist auf $14 a, 6 e, 1 e a$; die gruppe aht 4 aht, $1 e$; dazu 8 mal trehtin, wobei also wider sonderstellung dieses wortes zu constatieren ist.

7. age ist in 3 fällen nicht contrahiert, wol aber in treit $341,13$.

8. Bei der gruppe or stehen 2 wart gegen 1 worten $336,22$. 356,18 . 340,16. Wider ist fraglich, ob warhte und uerwarht hierherzuziehen ist: s. 23.

9. Synk ope ist ziemlich stark eingetreten: pilde 333,3 ; sinme 347,18 . 352,1 ; lemtigis 355,4 .

10. Abschwächung der nebenvocale. Erhalten ist -ote; neben -ot tritt schon -et. herro steht $345,10.355,3$ etc. Die endung des dat. sg. m. n. pron. und st. adj. flex. ist -me.

11. Svarabhakti findet hie und da statt; vor allem wird chr'- > cher', z. b. cherefte 338,1 ; cherum $(p) 341,21$; charaft 343,2 ; zw' > zen': zewischen 337,26 ; zewire 344,21 ; den altdeutschen einschiebungen entsprechend: - - rch $>$ 'rech : werich 335,16 ; durech 337,28 ; wrichen 350,9 ; stariche 357,1 .

12. Circumflectiert ist $12 \mathrm{mal} \hat{e}$, welches $3 \mathrm{mal}$ auch als $\dot{e}$, mit acut erscheint, welche zeichen, wie vorher in der Kaiserchronik, dem kleinen wort- und schriftkörper zur stutze dienen sollen.

13. Dentale. a) Mlid. $d$ - arscheint $12 \mathrm{mal}$ als $t$, und zwar nach $-s$ und $-z$, nur einmal nach $-e$, was spur eines kanons oder assimil. sein kann.

b) Beispiele fur $d w$-, $t n$ - fehlen.

c) Die gruppe $n t$ ist unerweicht in 94 fällen, erweicht in 16.

d) $l t$ ist nie erweicht.

14. Labiale. a) Im anlaut wechseln $104 p-, 13 b$ 9 von diesen stehen nach auslaut. vocal, die andern fälle zer- 
splittern sich. Dazu kommt, was in keinem andern complex

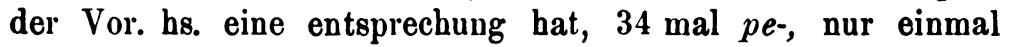
be-, während sonst das unbetonte präfix mit der media anlautet, zusammenhängend mit der schwächeren exspirationskraft der vorsilbe. - Im a uslaut steht immer $-p$.

b) $f<$ urgerm. $p$ hat die schreibung $f, f f ;$ nur in slauen 356,10 ; schon öfters war zu bemerken, dass diese erweichung ohue durchfuhrung sporadisch nach langem vocal erscheint.

c) Die gruppe $w u$ - ist meist durch $w$ - angedeutet; gewunne $353,7$.

d) Die verbindung $s w$-, $z w$ - ist vertreten durch $s u-, z u-$, woneben zew- tritt: s. 11 .

15. Gutturale. a) fur einfaches $k$ herrscht in allen stellungen $c h$.

b) $g$ wird im auslaut uberwiegend zu ch, seltner zu $-c$. Anlautend $k$ - in got kan (gönnt) 347, 17; mach kelirnen 347, 21. - Urgerm. gg liegt vor in manslech : ecke 349, 2; liken 356, 12.

c) qu- ist immer verschmolzen, unter anderm auch in dem lehnwort cherine < quadragena (40 tägiges fasten) 348, 12. Das product von quam ist chom; erwähnt sei an dieser stelle die präs. form chumpt 353,19, wo also secundär eine entwicklung vorliegt, welche fur kunft schon in urgerm. anzusetzen ist und die heute in vielen dialecten herrscht.

16. Assimil. zeigt suas so 334,4 . 336, 2, wozu Avas gedichte $\mathrm{zu}$ vgl. sind. - Vielleicht ist 13 a hierher zu ziehen.

17. Metathesis erscheint beim präfix er-: 5 mal re-, und zwar nach auslaut $-r 2$; nach $-t 2$; nach vocal 1.

18. Grammatischer wechsel ist erhalten in heuen 357,12 ; uunten $343,28.345,27$ (nt ist meist nicht erweicht); wrte wir 352, 24.

20. wellen im prät. wolte wie scolte; wolde nur 338, 26.

21. mugen. 8 mugen; 1 mage wir; 1 mege wir; 3 mahten; 1 mehte, also das umgekehrte verhältnis von $\mathrm{H}$.

23. wurken. 2 worhte; 2 warhte.

24. haben. 2 hete.

25. st $\hat{a} n$ und $g \hat{a} n$. $10 \hat{a}-, 6 \hat{e}$-formen. Im besondern ist $\mathrm{zu}$ erwähnen die form wir stanten 1. pl. präs.: hanten 356,13; uerstanten infin.: enplanten 348,28, welche sonst in keinem 
complex vorkommen. Weinhold, Mhd. gr. § 336, der ubrigens die erste form. auch als infin. citiert, kennt weiter keine belege. Ferner kommt vor stuten 336, 20: vgl. 'Bücher Moses' (B) $26 \mathrm{c}$.

26. Flexion. a) pronom.: $5 \mathrm{mal}$ siu $=$ acc. pl. m., wozu die 'jungre Judith' (E) etc. zu vgl. ist. - uns 5 mal als accus. (daneben 6 unsihc); dei vazzer 341,13; dei alter 346,16; dei po ${ }^{\natural}$ ch 348, 19. 352,11: vgl. 'Bücher Moses'. Ob sich die form $d e i=d i u$ local begrenzen lässt? Zusammenstellungen dartiber fehlen bis jetzt.

b) Die 2. sg. endet auf -st.

27. An zahlwörtern sind zu nennen: 2. fem. zua 338, 1. 343,27 ; uiunf und uunf; gewöhnlich siben (in diesem gedicht von der siebenzahl sehr bäufig), aber seben 334,26. 345,10; einleuen 343,22; zuelf.

28. Einzelne wörter. a) fiur $4 \mathrm{mal}$ als uiur; c) lichname 3 mal als lichename.

29. Varia. a) $h t$ erscheint oft als $t h$; sodann $-t$ als $-t h$ und auch als -ht; entsprechend -ch meist als -hc.

b) $c$ steht für $z$ - und -z- sehr oft in ceichen 342,4 etc. (10 mal); tagecit 354,15 ; ceigte 338,20 ; peceichenote 351,27 ; cite 352, 25.

c) Inlautendes und anlautendes $z$ ist sehr oft durch $h$ vertreten, wie die anm. Diemers unterm text zu 340,1. 340,23. 342,4 . 342,23 . 342 , 27. 344,4 . 352,26 . 353, 28. 357,16 belegen, wobei die doppelte möglichkeit geboten ist, dass entweder der schreiber der Vor. hs. diese vermischung schon vorfand oder nur undeutliche schreibung, so dass er die 2 buchstaben nicht unterscheiden konnte. In beiden fällen ist ein zeugnis für das sclavische nachahmungsbestreben des Vorauer schreibers enthalten. Ueber die ähnliche gestalt von $h$ und $z$ in hss. sind ubrigens zu vgl. die 'Fundgruben' II, 139.

d) Die form prutegaum 335,14 , deren auffassung jedoch zweifelhaft ist; lässt sie sich mit stram $=$ straum $=$ strom vergleichen?

e) Neben nieht, bezüglich nieth (vgl. a) treten formen wio niuth 33॰, 24; niuuet 337, 24.

f) Erwähnt sei mit talle 348,5 ; metalle 348,13 . 
g) Die form dester 339, 23 für das ältere deste, indem das wort bei comparativem begriff comparative form nach sich zog.

h) Neben scol steht $4 \mathrm{mal}$ die form scal. Sie ist fur unsere zeit nicht ausschliesslich md.: vgl. Weinhold, Mhd. gr. $\S 394$.

i) Sehr häufig kehrt wider auer sâ und auer sus, und zwar als ein beispiel für 'versus tyrannus', immer wechselnd, je nachdem ein lat. wort auf - $a$ oder auf -us darauf reimen soll. Uebrigens kommt diese formel sowol im 'hymnus' Mullenhoffs als auch in den sonstigen abschnitten von Arnolds gedicht widerholt vor, was neben anderem für einheitliche composition spricht.

Bei dieser zusammenstellung sind stillschweigend die verse $349,15-350,20$ ubergangen worden, weil sie von einem andern schreiber herrühren: vgl. Diemer, Einl. IV, und anm. s. 349. Die eigentümlichkeiten dieses schreibers werden unter $\mathrm{L}$ ('himml. Jerusalem') besprechung finden, indem auch dort eine spalte von ihm herrührt. - Der charakter der überlieferung ist bairisch nach 2 (au =ou: Weinhold $\S 96) ; 8$ (or $>a r) ; 14$ ( $p e^{\prime}$ ); 15 (chumpt: nach den heutigen mundarten zu schliessen oberdeutsch); 26 a (siu acc. pl. m.); $29 \mathrm{~d}$ (prutegaum).

Erwähnt sei, dass nnser priester Arnold nach der ansicht von Schönbach identisch ist mit einem Arnold, welcher als verf. einer ' $h$ l. Juliana' taberliefert wird, wie er in seiner ausgabe: 'priester Arnolds gedicht von Juliana' $1882 \mathrm{zu}$ beweisen versucht. Vgl. Bartsch, German. XXVIII, 257-265.

Auf benutzung von Arnolds gedicht weist hin Mullenhoff, MSD $^{2} 458$.

\section{BESCHREIBUTG DES HMMML. JERUSALEM}

(= Diemer, Dt. ged. s. $361-372$ ).

Das gedicht, dessen anfang auch in der Milstäter hs. steht - vgl. Diemer, Dt. ged. einl. L; Karajan, Dt. sprachdenkmale - wird von Scherer, Quell. u. forsch. XII, 68 kurz und treffend bezeichnet als 'ein stück theologischer mineralogie, das sich der theolog. zoologie des Physiologus wurdig anschliesst.' Nach Conrad Hofmann, Münch. sitz.-ber. 1871, s. 561 
besteht das gedicht, wie Arnolds werk, aus strophen mit wechselnder verszahl, deren schlusszeile eine oder 2 hebungen mehr hat. Die einzelheiten der schreibung sind:

1. $e i$ ist vertreten durch $72 a i, 23 e i, 6 e$. Das hauptcontingent stellt stain und gehaizen, welche wörter, entsprechend dem inhalt des gedichts, ungemein häufig widerkehren.

2. ou. 9 ou, $6 o, 3 o^{\circ}, 3$ ov. $2 o^{\circ}$ sind $=u o$.

3. iu. $25 \mathrm{iu}, 13 \mathrm{u}, 2 \mathrm{eu}$. In geriuste 364,13 steht iu für $u$; in griune 364,20 für $u o$, vielleicht zur andeutung des umlauts. Unter den iu fungiert tiuuel.

4. ie. $22 i, 4 e i, 1$ ie. Auch hier liegt also wider vermischung von ie und $e i$ vor, wo $i$ fur $i e$ das gewöhnliche ist. Naturlich darf ierusalem $=j e^{-}$nicht mitgerechnet werden.

5. a liegt als $i$ vor in inslif 362,4; sodann in dem aus man abgeschwächten men : $\min 365,14$. Nebenbei sei bemerkt als characteristicum für den gewanten stil, dass in dem bei Diemer 12 seiten umfassenden gedichte nie $e z$ oder $i z$ vorkommt.

6. Umla utsfähiges $\hat{a}$ zeigt $7 a, 1 e$. - Vereinzelt steht 1 elt und 1 aht, zu welchem ubrigens trahtin 369,11. 370, 21. 371, 17 stimmt. Inconsequent setzt Diemer 369, 11 fur das handschriftliche trahtin die form trehtin ein.

7. Contraction liegt widerholt in treit, trait vor; ebenso in lit.

9. Synkope findet selten statt; lemtigen 361,4 .

10. Abschwächung des nebenvocals trifft das suffix -ot, neben welches -et tritt. Die endung des dat. sg. m. n. der pron. und st. adj. flex. ist $-m e$ und $-m$.

11. Svarabhakti tritt ein im höchsten grad; so ent. stehen fast nach einem system aus cons. + cons. die gruppen: anlautend: gel-(gelas 365,21); chel- (cheleine 365,20); pel(pelut 368,3); sel-(selahte 370, 28); ber-(berucge 368,12); ger- (gerife 366,15); ter-(terahtines 370,21); uer- (ueraisen 370,28$)$; sem- (semal 372,18$)$; sen- (sene 367,20$)$; sun- (suwarz 367, 18); zun- $(369,18)$;

inlautend: den altdeutschen zwischenvocalen entsprechend:

-leh- (uersuelehen : beuelehen 364, 23); -reg-(burege : sorege $368,10)$; -rew- (uarene 367,21 );

auslautend: -rech (burech 362,8 ); -lem (halem 365,17 ). 
12. Circumflex steht nie; 2 mal steht auf der partikel $\dot{e}$ ein acut $370,9.10$.

13. Dentale. a) Mhd. $d$ - erscheint $13 \mathrm{mal}$ als $t$-, und zwar 7 mal nach ausl. $-t$, 5 mal nach $-c h, 1$ nach $-z$ : spur eines kanons oder assimilation.

b) $d w$ - liegt nur vor in geduange 369,9 .

c) $23 n t$ stehen gegen 7 nd.

d) $l t$ ist nie erweicht.

14. Labiale. a) Im anlaut streiten $17 b$ - und $12 p$-. Ausgeprägt ist das tuberwiegen von $p$ - nach auslaut. $-z$, die andern fälle zersplittern sich. Dazu kommt neben dem präfix be- vereinzelt $6 \mathrm{mal}$ die schreibung $p e$ - vor nach verschiedenem auslaut. Im auslaut herrscht $-p$.

b) $f<$ urgerm. $p$ erscheint nie als $v$.

c) Die gruppe $w u$ - ist als $w$-geschrieben in wnder 361, 23. $368,19$.

d) Die verbindung $s w$-, $z w$ - hat nach 11. die form sun-, zun-, indem sich die natur des einschubvocals nach dem folg. cons. richtet.

15. Gutturale. a) Fur einfaches $k$ herrscht $c h$. Speciell zu erwähnen ist die erweichung in himelisgen 368,13 ; uber die erklärung und das $z$. t. in den nämlichen denkmälern begegnende $c g$ (s. b) ist zu vgl. Paul, Beitr. VII, 129.

b) -g wird im auslaut immer zu $-c h$. Westgerman. gemination liegt vor in den formen legge (leiste) 362,17 ; cerucge : berucge $368,11$.

c) Verschmelzung von $q u$ - findet immer statt.

16. Assimilation zeigt isele 361,18 , so dass der vorgang des as. und ags., wonach $n+s>s$ wird unter dehnung des vorhergehenden vocals, sich hier widerholt hätte; wahrscheinlicher aber liegt ubernahme aus dem romanischen vor, auf dessen gesammtem gebiet dies lautgesetz gleichfalls gilt (vgl. ital. isola, wovon isolieren).

17. Metathesis bietet nur in rethotit 366,5 .

18. Grammat. wechsel ist erhalten in heuen; eruunten 370, 10 (nt unerweicht: vgl. $13 \mathrm{c}$ ); ausgeglichen in erworuen 368,6 .

20. wellen hat das prät. wolte.

21. mugen im präs. 3 mugen, 1 magen. 
23. wurken. beworth 364,18 ; umbeworith 365,18 ; gewerchet 362, 16 ist wol zum swv. wërken (ahd. wërkôn) zu ziehen.

25. stân und gân hat $8 \hat{e}-, 4 \hat{a}$-formen, die ersten 6 mal im reim: ierusalem, also wechsel rein nach dem reimbedurfnis.

26. Flexion. b) Die 2. pl. endigt auf -ent in habent 372,6 ; uuoltent 372,9 , neben -et.

c) Das prät. screb 362,6 . 8. Da die form 2 mal erscheint, ist es zweifelhaft, ob sie einfach unter die rubrik $e=e i$ (s. 1) zu setzen ist, oder ob nicht vermischung mit den auf $r, h, w$ endenden stämmen (vgl. Paul, Mhd. gr. § 46) vorliegt.

27. Zahlwörter fem. von 2 zuwa 369, 18.

28. Einzelne wörter. a) fiur hat die schreibung uiur 368,1 . 370,5; fuer 371, 10.

29. Varia. a) -ch erscheint meist als - $h c$; analog - $h t$ meist als $-t h$; als folge der verwirrung tritt $h$ auch zu beliebigem auslaut. $-t$; zu anlaut. $t$ - nur in tho(u)gen 366, 25; thot 365,1 ; 366,20 ; thut 366,9 .

b) Unorganisches $h$ - steht im wortanlaut 9 mal: hewen 365,11 ; huf 365,16 ; herde 365,17 ; hin 365,19; hiu 367, 18; hobene 367, 20; hiuch 372,19.21; he 372, 23.

c) Für anlautend und inlautend $z$ steht $c$ in den wörtern: geceiret 365,9 ; herce 365,24 ; becaihenet 366,6 ; lucel. 367,10 ; ufiverce 367,$24 ;$ cu 369,14 ; ce 369,14 ; gecinnet 369,26 ; cit $371,25$.

Scherer bemerkt nun Quell. u. forsch. VII, 89 zum 'himml. Jerusalem': 'die orthographie stimmt trotz individueller eigentumlichkeiten im ganzen doch sehr nahe zu dem werke des priesters Arnold', und entsprechend stellt er $\mathrm{s}$. 28 bei einem summarischen uberblick über den inhalt der hs. XX (= Arnold bei ihm) und XXI (= Jerusalem) als eine fruhere sammelhandschrift zusammen, allerdings mit einem fragezeichen. Seine gründe dafür, welche ich der ubersicht halber nummeriere, gibt er s. 89 an: 1. 'Beide (Arnold und Jerusalem) haben, wie Ezzo, noch auf althochdeutsche weise unte, sunten, funten, wente, ente, wante u. dgl.' Das ist im wesentlichen richtig, indem ich nur auf $13 \mathrm{c}$ zu verweisen brauche, wo sich zeigt, 
dass Ezzo nur $n t$ hat, und dass bei Arnold das verhăltnis von $n t: n d=6: 1$, im Jerusalem $=3: 1$ ist.

2. 'Beide haben au und ai (ersteres bei Arnold, letzteres im Jerusalem häufiger), sogar haus 365, 13.' Das ist schon weniger richtig. Zunächst ai. Nummer 1 ergiebt, dass Arnold $30 e i, 4 a i, 2 e$; Jerusalem $72 a i, 23 e i, 6 e$ hat, also verhältnisse, die sich absolut nicht vergleichen lassen. Sodann au. Nummer 2 ergibt für Arnold $26 a u, 10 o^{\circ}, 9 o u$; für Jerusalem aber $9 o u, 6 o, 3 o^{v}, 1$ ov und kein einziges au, sondern nur jenes haus, wo $a u=\hat{u}$ steht, was bei Arnold keine parallele hat und deshalb als beweis nicht in betracht kommt.

3. 'Dem gepuet für gepiutet bei Arnold 354,14 vergleicht sich fluet 365, 26 für fliuhet.' Ob diese formen sich vergleichen lassen, ist denn doch die frage. gepuet muss jedenfalls verschrieben sein, entweder für geputet oder für geput mit synkope, indem, gegen $u=i u$ nichts einzuwenden ist: vgl. 3. Andrerseits bemerkt auch Scherer, s. 82, dass die stelle uberhaupt zweifelhaft sei. fluet sodann im Jerusalem steht einfach = fuhet mit vernachlässigung des $h$, bei dem in diesem stück uberhaupt verwirrung herrscht, was die ganz in der nähe stehende form fluhet $364,15.364,27$ beweist.

4. 'Beide auch unorganisch $h$ - im anlaut statt spiritus lenis'. Fur Jerusalem kann ich auf 29 b verweisen, wo sich ergibt, dass 9 mal unorgan. $h$-im wortanlaut steht. Bei Arnold ist jedoch nur dass eine hatem 356, 26 zu belegen, so dass wider kein vergleich möglich ist, zumal Arnold bei Diemer 25 seiten, Jerusalem nur 12 einnimmt, wodurch das eine $h$-im Arnold noch mehr verschwindet.

5. 'Das charakteristische euphonische $e$ in verbindungen mit der liquida ist bei Arnold lange nicht 80 häufig, aber so z. b. 341, 21 cherup fur chrump oder 334, 3 chesiene, wo durch conjectur cheleine herzustellen ist.' Scherer legt also selbst bierauf nicht viel gewicht; ubrigens zeigt ein blick auf nr. 11, dass im Arnold sich nur die erweiterung cher- und -rech widerholt, während in dem kleinen Jerusalem fast ein vollständiges system aller möglichen fălle vorliegt. Dazu kommt der weitere unterschied, dass bei Arnold $z w->z e n-$, im Jerusalem dagegen $>$ zun- gewandelt wird.

6. 'Beide haben ein paarmal $e i$ für $\hat{\imath}$.' Die fälle, welche 
Scherer im besondern nicht auffuhrt, sind: Arnold: liebe : weibe (lies lîbe : wîbe) 350,16; Jerusalem: leip 363,7. Hier ist nun der ort zu besprechen, was schon oben beruhrt wurde, dass nämlich die verse 349,15-350,20 (auf bl. 132 c) bei Arnold und $362,22-364,11$ (auf bl. 134 a) von einem andern schreiber geschrieben sind, worauf Diemer ausdrucklich in der Einl. s. IV und in den anmerkungen unter dem text zu s. 349 und 362 aufmerksam macht. Das characteristische dieses schreibers besteht im wesentlichen darin, dass er die synkope und die schreibung $n d$ gegen $n t$ bevorzugt; dass er im Jerusalem ie für $i$ und die form trehtin einsetzt (welche beide im gesammttext des Arnold schon vorhanden sind); und endlich eben, dass er 2 mal für $\hat{\imath}$ ein $e i$ setzt an den genannten stellen. Dass darin, wie Scherer wollte, kein beweis dafur liegt, dass Arnold und Jerusalem in einer sammelhandschrift standen, ist wol klar.

Da ubrigens für die im südosten Deutschlands anhebende wandlung von $\hat{\imath}>e i$ und $\hat{u}>o u$ meist auf die Vorauer hs. zurückgegriffen wird, z. b. MSD, Einl. XXVII, so sei hier zusammengefasst, dass in derselben altes $\hat{\imath}$ beim urschreiber nie als $e i$ erscheint, sondern nur bei jenem jungern schreiber $\mathrm{y}$, der bl. 1 und 8 und bl. 89 und 96 (correspondierende deckblätter der 1. und 12. lage) erneuert hat, und zwar $7 \mathrm{mal}$ (8. bei der 'Wahrheit' = C); ebenso bei dem oben genannten dritten schreiber, wir nennen ihn $x$, der eben auf bl. $132 \mathrm{c}$ eine halbe und auf bl. 134 a eine ganze spalte geschrieben hat (Arnold und Jerusalem), $2 \mathrm{mal}$.

Altes $a$ erscheint bei urschreiber als ov nur in ovf 357,12 (Arnold); als au nur in haus 365, 13 (Jerusalem); sodann geht durch die ganze Kaiserchronik $b 0^{\circ}$ wen und $0^{\circ} f$. Aber die auffassung von $b 0^{\vee}$ wen ist sehr fraglich, indem vielleicht fur das präsens stammabstufung mit altem au anzusetzen ist. Unregelmässig ist das verbum ja auch durch sein st. part. gebuwen. Bei $o^{\circ} f$ könnte man auf den.gedanken kommen, die diphthongierung von $\hat{u}>$ ou habe sich im wortanlaut fruher vollzogen. Dazu wurde stimmen, dass bei dem jungern schreiber y $0^{\circ} z$ und $o^{v} z z e r$ zu $o^{v} f$ hinzukommt; ferner hat er einmal $h o^{v} s$ Kaiserchron. 6, 3. So sind der belege fur diese lautubergänge sehr wenig. Der schreiber $\mathbf{x}$ wird von Diemer, Einl. VI mit 
dem urschreiber gleichzeitig, in die mitte des XII. jh. gesetzt, $y$ aber an das ende desselben, was wegen der chronologie des lautwandels wichtig ist.

Die argumente Scherers von 2-6 sind somit hinfällig, und auf 1 allein $(n t)$ durfte kein grosses gewicht zu legen sein. Dazu behauptet er: 7. 'Beide (Arnold und Jerusalem) haben unorganisch th für $t$, besonders im auslaut.' Das ist richtig (s. nr. 29a), aber es ist zu bemerken, dass dieselbe erscheinung sowol in dem beiden vorausgehenden 'Ezzo' (s. 29a) als in dem beiden folgenden 'Gebet' (s. u.) vorliegt. Und so komme ich zu meiner ansicht: Scherer behauptet mit unrecht, dass Arnold und Jerusalem fur sich in einer sammelhs. standen, wol aber kann wahrscheinlich gemacht werden, dass Ezzo, Arnold, Jerusalem, Gebet zusammen in einer vorlage waren; und zwar aus folgenden grtunden:

1. in allen 4 gedichten wechselt $h t$ mit $t h$, und $h$ tritt unorganisch $\mathrm{zu}$ auslaut. $-t$;

2. in allen 4 gedichten wechselt $-c h$ mit $-h c$;

3. in allen 4 gedichten steht $c=z$ (s. unter 29). Nur diese behauptung kann aufgestellt werden: aber sie ist nur haltbar unter der annahme, dass ein solcher schreiber jene 4 gedichte zu einer vorlage vereinigte, welcher im allgemeinen ebenso sorgfältig und passiv wie der Vorauer schreiber war, und der nur die eigentumlichkeit gehabt hätte, für $h t$ ein $t h$; fur -ch ein $-h c$; fur $z$ ein $c$ zu setzen. Denn in andern erscheinungen herrschte ja grosse differenz; ich hebe nur hervor: Ezzo $e i$, Arnold $e i$, Jerusalem $a i$, Gebet $e i \overline{;}$ Ezzo ov, $o^{\circ}$, Arnold $a u$, Jerusalem ou, Gebet $o^{v}$, ou; Ezzo ie, $i$, Arnold ie, $i$, Jerusalem $i$, Gebet $i e$; Ezzo ez, Arnold $i z$; Ezzo trehtin, Arnold Irehtin, Jerusalem trahtin, Gebet trehtin; Ezzo kein e inschubvocal, Arnold wenig, Jerusalem sehr viel, Gebet wenig; Ezzo $p$-, $b$-, Arnold $p-, p e^{-}$, Jerusalem $b-, p-$, Gebet $b-, p-;$ nur Jerusalem suw-, zuw-; Ezzo zwo, Arnold zua, Jerusalem zuwa; Ezzo worhte, Arnold warhte, Jerusalem geworth.

Unter der obigen annahme kann nach jenen 3 momenten die zusammengehörigkeit der 4 gedichte zu einer vorlage behauptet werden; zwingend ist jedoch der beweis nicht, und praktisch hat man jedenfalls mit 4 vorlagen zu rechnen, wes- 
halb auch bei der gesammtdarstellung und nummerierung die 4 gedichte getrennt aufgeführt wurden. -

Die uberlieferung des 'himml. Jerusalen' trägt die characteristica des oberdeutschen; aufs bairische weist 1 (ai). Auf $c g$ und $s g$ (s. 15 a und b) wird nach Paul, Beitr. VII, 129 kein gewicht zu legen sein.

\section{GEBET EINER FRAU}

(= Diemer, Dt. ged. s. $375-378$ ).

Das gedicht ist nur fragmentarisch uberliefert, indem es mitten im satz mit dem ende des letzten blatts der 17. lage abbricht (vgl. Diemer, Einl. s. I). Die von Diemer, s. XVII aufgestellte vermutung, es ruhre von der Ava her, ist aufgegeben. $\mathrm{Zu} \mathrm{vgl.} \mathrm{ist} \mathrm{hieriiber} \mathrm{Langguth,} \mathrm{welcher} \mathrm{in} \mathrm{seinen}$ mehrfach citierten 'Untersuchungen ub. d. ged. der Ava' 1880, s. 6 bemerkt, dass sprachlich nichts für die identität der verfasserin mit Ava anzufuhren ist, die situation eher dagegen spricht. - Bei der kürze des bruchstücks kommen bei der folgenden darstellung manche erscheinungen resp. nummern wegen mangel an beispielen ganz in wegfall.

1. $e i$ ist vertreten durch $9 e i$;

2. ou durch $2 o^{v}, 1$ ou. Sodann stehen $23 o^{v}=u o ; 5 o^{v}=$ $\hat{o}$, auf welch letztere erscheinung Scherer s. 90 hinweist unter bezug auf MSD LXXXIV, 2. Dort ist ${ }^{2}$ s. 582 bei der schreibung $i r l 0^{v} s e=$ irlôse Weinhold, Bair. gr. s. 103 citiert, welcher an diesem ort die vertretung von $\hat{o}$ durch ou bespricht und auch aus unserm gedicht belege bringt. Lautliche bedeutung ist jedoch kaum anzunehmen, indem in 10 fällen, also doppelt so viel, $\hat{o}$ durch einfaches $o$ widergegeben ist.

3. iu liegt vor in $4 \mathrm{iv}, 4 \mathrm{iu}, 1 \mathrm{u}$.

4. ie. 7 ie, $3 i$; unter diesen 2 nine, deren $i$ aus der proklise zu erklären sein wird.

5. a hat nur diese vertretung.

6. Umlautsfähiges $\hat{a}$ schwankt zwischen $9 a$ und $2 e$. Die gruppe aht liegt nur vor in trehtin 376,14. 378, 4.

9. Synkope findet nicht statt. dieme 376,5 ist wol für dineme verschrieben.

10. Abschwächung der endung zeigt herre. Der dat. sg. m. n. der st. adj. und pron. flex. endet auf -me. 
11. Svarabhakti bietet nur zevein 375,9 und 3 mal die alte form durech.

12. Circumflex steht 2 mal in der partikel $\hat{e}$.

13. Dentale a) mhd. $d$ - erfordert keine bemerkung;

c) 14 nd stehen gegen $2 n t$;

d) $l t$ ist nicht erweicht.

14. Labiale. a) $4 b$ - wechseln mit $2 p$-, die ersteren 3 mal nach auslaut. vocal, 1 nach $-c$; die letzteren wach $-c h$.

b) $f<$ urgerm. $p$ erscheint als $f$.

c) Die gruppe $w u$ - liegt vor in wundern 376,20 .

d) Die verbindung $s w$ - in gesuichen 375,$14 ; z w$ - in $z e$ wein 375,9 .

15. Gutturale. a) Fur einfaches $k$ herrscht $c h$.

b) $-g$ als $-c$ in lac 377,13 ; manecfalt 378,1 . - Verschmelzung von $g$ - in enkelten $376,13$.

c) $q u$ - ist verschmolzen in bechome 377,22 ; chum mir 377, 27.

21. mugen bietet 2 muge.

25. stân uersten 375,4 ; stât 376,2 .

26. Flexion a) des pronom. Einmal begegnet mire 375,15 , welche form auch in der Sundenklage vorkam (siehe dort 26 a).

b) Die 2. sg. vertritt mov zest 375, 14; du welles 377, 19.

27. Das einzige zahlwort ist zevein 375,9 .

29. Varia. a) -ch ist durch $-h c$ widergegeben in uerlihc 375,2 ; dihc 375, 6 und $9 \mathrm{mal}$ in ihc. Unorgan. -th zeigt boseith $377,1$.

b) $z$ - ist durch $c$ - vertreten in ce neren 377,7 .

Ueber die eventuelle möglichkeit einer sammelhs., worin I, K, L, M gestanden hätten, ist unter $\mathrm{L}$ gehandelt.

So wären wir am ende unsrer zusammenstellung angelangt. Ich brauche wol nicht hervorzuheben, mit welcher mlihe sie gewonnen wurde; wie mancher zweifel aufstieg, bis sich eine klare ubersicht ergab über die möglichkeit einer trennung von eigentümlichkeiten, die sich auf einzelne complexe beschränken liessen, und solchen, die als durchgehend unberticksichtigt 
bleiben mussten; dass auch diese vollständige aufzeichnung erheischten und viel zeit raubten. Dafür ergaben sich aber auch mannigfache resultate, deren wesentlichste ich mit übergehung grammatischer kleinigkeiten zusammenfasse:

1. Der schreiber der Vorauer hs. XI hat im wesentlichen seine vorlagen mit sclavischer treue nachgeahmt.

2. In folge dessen liessen sich als einzelne vorlagen abgrenzen: A Kaiserchronik; B Bucher Moses; C die Wahrheit; D Summa theologiae, Solomo, Nabuchodonosor; E (jungere) Judith; F Alexander; G Avas gedichte; H Sundenklage; I Ezzos gesang; K Arnolds gedicht; L das himml. Jerusalem; M Gebet einer frau. Als möglich, aber nicht absolut beweisbar, musste hingestellt werden, dass $I, K, L, M$ fruher fur sich in einer sammelhs. standen.

3. Aus verschiedenen sprachlichen argumenten wurde bewiesen, dass in der vorlage der Kaiserchronik die verse $526,22-530,6$ erst später hinzugefügt wurden, wodurch die schon früher geäusserte ansicht, die ålteste form der Kaiserchronik habe nit dem tode Lothars, mit dem jahre 1137 geschlossen, ausser zweifel gesetzt wird.

4. Das von Diemer als 'Bucher Moses' bezeichnete stuck ist abweichend von Scherer als einheitlich gewolltes gedicht aufzufassen. Ebensowenig darf das 'Marienlob' abgetrennt werden.

5. Es ist wahrscheinlich, dass die 'Wahrheit'-vorlage C ein fragment ist.

6. Zur trennung der einheitlich uberlieferten gedichte '3 junglinge im feuerofen' und 'Judith', wie sie in MSD vorgenommen ist, sind keine sprachlichen grunde vorhanden; im gegenteil beweisen andre momente, dass sie mit Conrad Hofmann unter dem titel 'Nabuchodonosor' zusammenzufassen sind.

7. Das von Pfeiffer erwiesene Kölnische original von Lamprechts Alexander ist zunächst durch die hände eines oberdeutschen gegangen; erst dessen werk war die vorlage des Vorauer schreibers.

8. Der ron Langguth wahrscheinlich gemachten einheit der gedichte der Ava ist durch die gleichheit der sprachlichen uberlieferung eine stütze geboten. 
9. Das original der 'Sundenklage' war mittelfränkisch; auch sie gieng durch die hände eines oberdeutschen schreibers, bevor sie der Vorauer schreiber bekam.

10. $\mathrm{Zu}$ der trennung von Arnolds gedicht, wie sie Mullenhoff vornahm, Scherer wider aufgab, sind in der uberlieferung und sprache keine gründe vorhanden.

Dazu gesellt sich: 11. Die Vorauer hs. XI bietet in ihrer zusammensetzung weder das princip einer weltchronik noch irgend ein anderes, sondern ihre anordnung ist als unabsichtlich, wie es gerade der verkehr mit den umliegenden klöstern bedingte, entstanden aufzufassen.

In den Denkmälern ${ }^{2} 371 \mathrm{f}$. bemerkte Müllenhoff mit herbeiziehung des lateinischen teiles der hs., dieselbe ergebe eine art weltchronik, wenn man die Kaiserchronik ans ende der Dt. ged. vor die 'Gesta Friderici imperatoris, von Otto v. Freising stelle. Schon dieses 'wenn' ist nicht sehr vertrauenerweckend. Sodann darf aber der lateinische teil uberhaupt nicht in betracht gezogen werden, weil er ursprünglich selbständig war und mit neuer zählung der quaternionen beginnt, während der $d t$. teil überhaupt keine lagenbezeichnung hat (vgl. Diemer, Einl. s. III). Weiter ist es überhaupt verfehlt, ein princip aufstellen zu wollen, weil das letzte gedicht, 'das Gebet', mit dem ende der letzten lage mitten im satze abbricht, so dass also noch eine lage ursprunglich darauf folgen musste, mehrere folgen konnten. Dabei sehe ich ganz davon ab, dass auch die 'Wahrheit', welche jetzt mit dem ende einer lage abbricht, höchst wahrscheinlich eine fortsetzung hatte, so dass auch zwischen der 12. und 13. lage eine oder mehrere in wegfall kommen konnten. Jedenfalls ist es unberechtigt, für die nicht vollständig uberlieferte hs. ein system ihrer zusammensetzung und anordnung aufzustellen.

Anders verfährt schon Scherer. Er errichtet Quell. und forsch. VII, 30 ein mystisches gebäude von glaube, beichte, himmel und hölle, welche in der anordnung vorhanden sein sollen; aber der schlauberechnende priester verrät sich, wenn er sagt: 'Mit andern worten, auf die predigt, auf den populären, deutschgeübten gottesdienst des 11. jahrhunderts geht alles zuräck, er enthält im keime die ganze geistliche poesie des 12. jahrhunderts'. Das ist wol die ansicht Scherer's, aber 
sie war sowol für die Bücher Moses als für Ava zurllckzuweisen, weil beiden gedichten jeder asketische zug fern liegt. Und hier, für die anordnung der Vorauer hs.? Bei dem princip: glaube, d. b. gott vater der schöpfer (= Bucher Moses); Gott sohn der erlöser (= Avas gedichte); beichte (= Sundenklage); himmel und hölle (= himml. Jerusalem) wird, abgesehen von der sonstigen schiefheit der vergleichungen, die Kaiserchronik am anfang, ebenso Lamprechts Alexander in der mitte gänzlich ignoriert. Unḍ wider ist vergessen, dass die Vorauer hs. nicht ganz uberliefert ist.

Vollständig hinkt der vergleich mit der Milstäter hs. Gleich ist nur, dass in der Vorauer hs. die 'Bticher Moses', in der Milstäter hs. 'Genesis und exodus' stehen, aber nicht an der gleichen stelle, indem eben in der Vorauer hs. die Kaiserchronik vorausgeht. Mit den vergleichungen der folgenden gedichte weiss selbst Scherer s. 30 nichts anzufangen. Falsch ist aber, von dem 'himml. Jerusalem' als beiderseitigem schluss zu reden: denn in der Vorauer hs. folgt noch das 'Gebet' etc., und die Milstäter hs. bricht nach den ersten versen des 'Jerusalem' ab, so dass niemand sagen kann, was noch folgte.

So ist es unmöglich, für die anordnung ein princip aufzustellen, und sowol das von Mullenhoff als das von Scherer postulierte hat keine beweiskraft. Was ist aber auch wahrscheinlicher, als dass kein princip vorlag? Der eine Vorauer schreiber schrieb sicher lange zeit an seinem peinlich genauen werk, und kaum hat er während dem gesammten zeitraum seiner schreibertätigkeit alle vorlagen beisammen gehabt, so dass er gerade wählen konnte. Das ist durchaus nicht wahrscheinlich bei dem damaligen regen interesse für neue erzeugnisse auf dem literarischen markt. Ein directer beweis fur die rasche verbreitung und den vielfachen wechsel von novitäten liegt darin, dass gerade blatt 1 und 8 der ersten wie der 12. lage von einem jungern schreiber erneuert werden mussten, d. h., dass jene deckblätter abgentitzt und schwer lesbar waren, woraus hervorgeht, dass die ersten vollendeten lagen sich längst in den händen der leser befanden, während an den letzten noch geschrieben wurde, vgl. Diener, Einl. s. V. 
Die beigegebene tabelle, welche eine summarische ubersicht uber die verschiedenen schreibungen und formen der einzelnen vorlagen oder complexe ermöglicht, erheischt folgende bemerkungen: 1. Die 'Wahrheit' $=\mathrm{C}$ ist weggelassen, weil sie wie oben ausgefuhrt, in ihrem ganzen umfang von einem jüngern schreiber herruhrt, dessen zutaten nicht genau festzustellen waren, und weil die mischung sich nicht in kurze darstellen lässt.

2. Steht in der tabelle eine schreibung, z. b. ei. allein, so bedeutet das, dass sie ausschliesslich vorkommt oder in der gesammtsumme der fälle, wo der betreffende laut vorliegt, unter den verschiedenen, wechselnden schreibungen mindestens $3 / 4$ einnimmt. Steht dagegen ei, ai nebeneinander, so heisst das, dass ihr verhältnis zwischen $1: 1$ und 2:1 schwankt. Steht endlich $e i$ uber $a i$, so wird angezeigt, dass $e i$ : $a i$ zwischen 2: 1 und $3: 1$ steht.

Nur die wichtigsten rubriken sind in die tabelle aufgenommen worden, zumal von einigen schon anfänglich zugegeben wurde, dass sie nur wegen der vollständigen darstellung der einzelnen denkmäler behandelt sind. - Die ergebnisse von nr. 24 und 25 sind eine bestätigung dafür, dass weder für das prät. von haben, noch für stân und gân sich ein bestimmter wechsel nach dialecten feststellen lässt.

FREIBURG i. B., februar 1885.

ALBERT WAAG. 


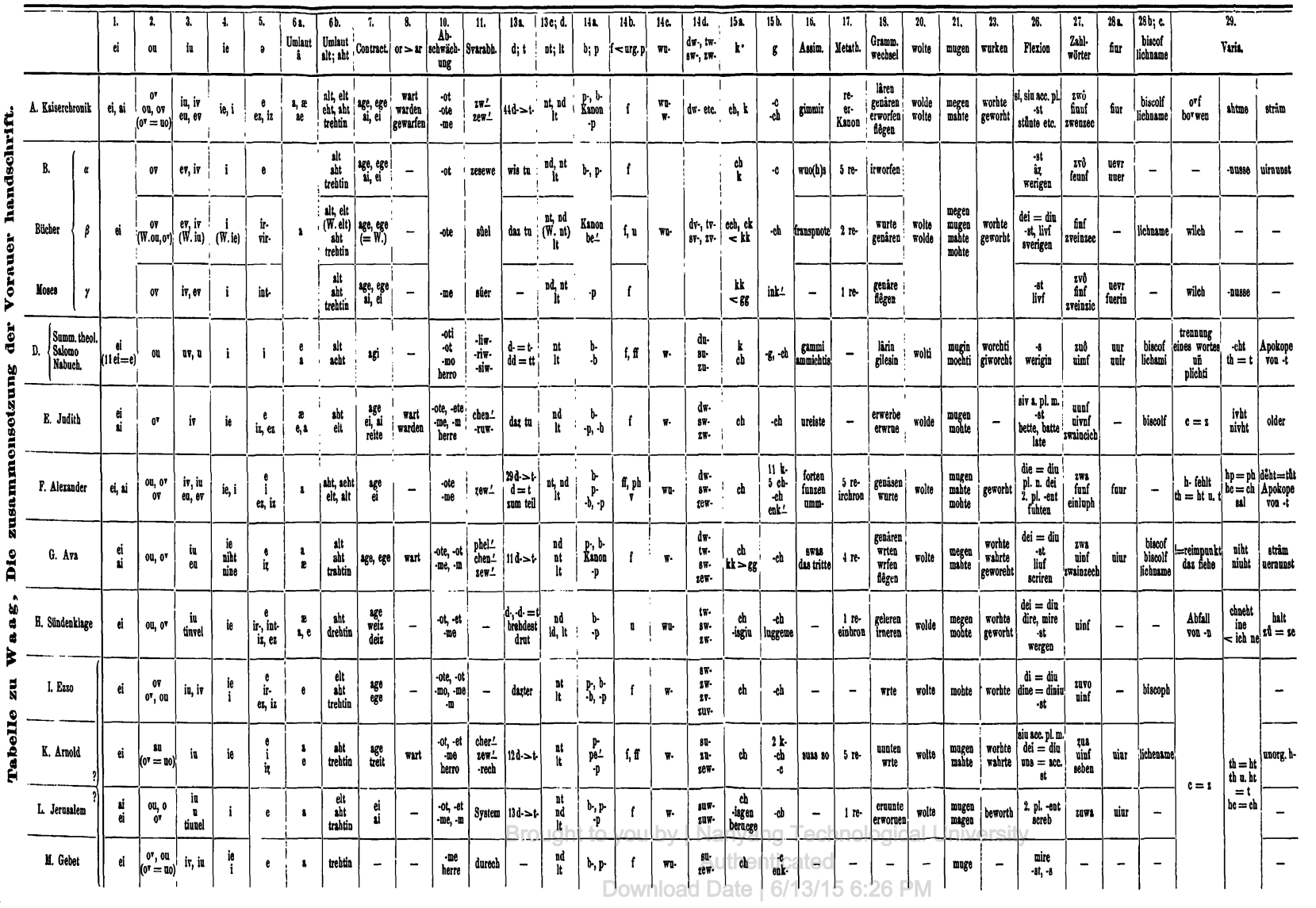


Brought to you by | Nanyang Technologil Authenticated

Download Date | 6/13/15 6:26 